\title{
COMPARAÇÃO DE MODELOS MATEMÁTICOS APLICADOS A ENSAIOS DE CALAGEM COM A CULTURA DA SOJA (Olycine max [L.] Merrill)
}

MARIA CRISTINA NEVES DE OLIVEIRA

Orientador: Prof. Dr. ROBERTO SIMIONATO MORAES

Dissertação apresentada à Escola
Superior de Agricultura "Luiz de
Queiroz", da Universidade de São
Paulo, para obtenção do título de
Mestre em Agronomia, Área de
Concentração: Estatística e Expe-
rimentação Agronômica.

PIRACICABA

Estado de São Paulo - Brasil

Junho - 1986 
Ao Dr. Roberto Simionato Moraes, nelos ensinamentos, orienração, encorajamento e amizade.

A Empresa Brasileira de Pesquisa Agropecuária, pela oportú nidade dada para a finalização deste trabalho.

A todos os funcionários do Centro Nacional de Pesquisa de Soja que me acolheram, incentivaram e deram apoio, para que esta dissertação se realizasse.

Aos pesquisadores da Ārea de Nutrição de Plantas, do Centro Nacional de Pesquisa de Soja, pelo fornecimento dos dados experimentais utilizados neste trabalho.

Ao Dr. Gedi Jorge Sfredo, pela compreensão, amizade e ensinamentos.

Aos pesquisadores do Departamento de Técnicas Experimentais, do Instituto Agronōmico de Camoinas, em esoecial a Drạ Violeta Nagai, pelo carinho, amizade e surestões.

Ao Dr. Renato César Dittrich pelas sugestões, amizade e ensinamentos transmitidos.

Ao Dr. Norberto Antonio Lavorenti, pelo apoio, amizade e pe Io processamento das anälises estatisticas desta dissertação. 
Aos colegas do curso de oós-graduação, pela união, incentivo, carinho, amizade, em especial aos colegas: Antonio Carlos Gomes, César Pereira, Édio Vizoni, Eliana Schammas, Inês Fumiko Ubukata, Maria Elizabeth Vasconcellos, Maria Imacu lada de Lima, Maria Luiza Meneqhetti, Norberto Antonio La vorenti e Tiemi Matsuo.

A Srta. Rosa Maria Alves, pela versão do resumo deste traba lho para o inglès.

Aos mestres do Departamento de Matemática e Estatística da Es cola Superior de Agricultura "Luiz de Queiroz", pelos ensinamentos transmitidos durante o curso de poós-graduação.

Ao Dr. Humberto de Campos, pelo auxilio prestado na obtenção de bolsas de estudos, através do CNPa e CAPES.

Ao CNPq e CAPES, pelo apoio à pesquisa.

A todos os funcionários do Departamento de Matemática e Estatística da ESALQ̣, em especial ao Sr. Octávio Frassetto.

As Srtas. Maria Izalina Ferreira Alves e Luciane Brajão, nelo excelente trabalıo datilográfico.

As Sras Marisa Santos Eumann e Nilza Brito Goulart, pela colaboração nas análises estatísticas e datilografia preliminares.

A todos que direta ou indiretamente colaboraram. 
Agradeço especialmente a meus pais, irmãos, cu nhados, cunhadas, sobrinhos, minha companheira Ivonice, ao Tia go, e ao meu filho Rodrigo, que me tem dado força, amor, cari nho, dedicação, confiança, fatores estes que muito me auxilia ram para valorizar minha vida e o meu trabalho. 
Pág.

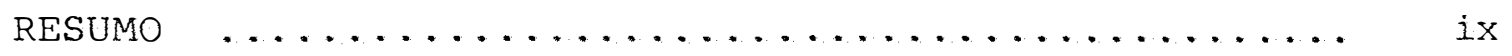

SUMMARY $\quad \ldots \ldots \ldots \ldots \ldots \ldots \ldots \ldots \ldots \ldots \ldots \ldots \ldots \ldots \ldots \ldots \ldots \ldots \ldots \ldots$

1. INTRODUÇÃO $\quad \ldots \ldots \ldots \ldots \ldots \ldots \ldots \ldots \ldots \ldots \ldots \ldots \ldots \ldots \ldots \ldots \ldots \ldots$

2. REVISÃo de LiteraturA $\ldots \ldots \ldots \ldots \ldots \ldots \ldots \ldots$

2.1 - Ajustamento de Modelos Matemáticos a Dados de Produção $\ldots \ldots \ldots \ldots \ldots \ldots \ldots \ldots \ldots \ldots$

2.2 - Determinação da Dose Econômica ......... 20

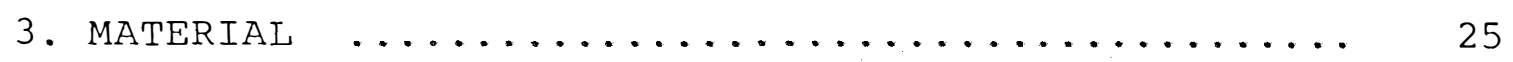

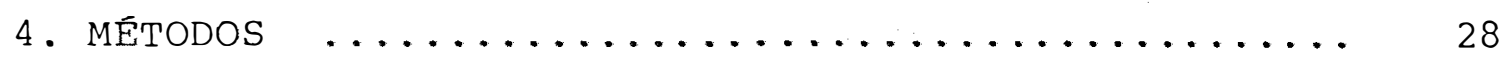

4.1 - Modelos $\ldots \ldots \ldots \ldots \ldots \ldots \ldots \ldots \ldots \ldots \ldots$

4.2 - Estimativa dos Parâmetros ............. 29

4.2.1 - Método para ajuste dos modelos quadrático e raiz quadrada .......... 29

4.2.2 - Método para ajuste da equação de Mitscherlich 2 à aproximação $\quad . . \ldots \ldots .31$

4.2 .2 .1 - Método do gradiente .... 31

4.2.2.2 - Processo iterativo .... 32

4.2 .2 .3 - Aceitabilidade $\ldots \ldots \ldots .33$

4.2.2.4 - Finalização do processoite rativo $\ldots \ldots \ldots \ldots \ldots \ldots .36$

4.2.2.5 - Método de Marquardt para as estimativas dos parāmetros 38 
vii.

Pág.

4.3 - Cálculo do Máximo da Função ............ 44

4.3 .1 - Modelo quadrático $\ldots \ldots \ldots \ldots \ldots \ldots$. 44

4.3 .2 - Modelo raiz quadrada ........... 45

4.3 .3 - 2ạ aproximação de Mitscherlich .... 46

4.3.3.1 - Método de Newton Raphson .. 47

4.3.3.2 - Método direto através do teo rema de Rolle .......... 47

4.4 - Dose Econômica do Calcário ............ 48

4.5 - Análise de Variância ................... 50

4.6 - Critérios para Avaliar o Ajuste dos Mocielos Estudados $\ldots \ldots \ldots \ldots \ldots \ldots \ldots \ldots \ldots \ldots \ldots . \ldots \ldots$

4.6 .1 - Critério de informação de Akaike ... 54

4.6 .2 - Critério do total de nostos ...... 55

4.7 - Programação da Metodologia ............ 57

5. RESUltados E DiscussÃo $\ldots \ldots \ldots \ldots \ldots \ldots \ldots \ldots \ldots \ldots \ldots$

5.1 - Valores Iniciais das Estimativas dos Parâmetros da 2a Equação de Mitscherlich ....... 59

5.2 - Ajuste dos Modelos ................ 60

5.2.1 - Ajustamento dos modelos aos dados experimentais de Campo Mourão ....... 60

5.2.1.1 - Modelo quadrático e modelo raiz quadrada $\ldots \ldots \ldots \ldots$..... 60

5.2.1.2 - Modelo da 2a aproximação de Mitscherlich $\ldots . . . . .$. 
viii.

Páq.

5.2.2 - Ajustamento dos Modelos aos Dados Expe rimentais de Guarapuava ..........

5.2.2.1 - Modelo quadrático e raiz qua drada $\quad \ldots \ldots \ldots \ldots \ldots \ldots \ldots$

5.2.2.2 - Modelo da 2ạ ap̣roximação de Mitscherlich $\ldots \ldots \ldots \ldots 69$

5.3 - Cálculo do Ponto de Máximo .............. 73

5.3.1 - Cálculo do ponto de máximo para os modelos quadrático, raiz quadrada e 2 a aproximação de Mitscherlich com os dados experimentais de Campo Mourão ...

5.3.2 - Cálculo do ponto de máximo para os modelos quadrático, raiz quadrada e 2 a ap̣roximação de Mitscherlich com os dados experimentais de Guarapuava ....

5.4 - Determinação da Dose Econômica ..........

5.4.1 - Determinação da dose econômica aconselhável para os experimentos de Campo

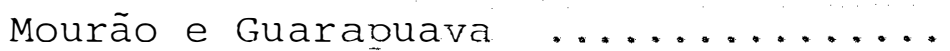

5.4.1.1 - Modelo quadrático ....... 89

5.4.1.2 - Modelo raiz quadrada .... 89

5.4.1.3 - 2ạ aoroximação de Mitscherlich $\ldots \ldots \ldots \ldots . \ldots . \ldots 90$

6. CONCLUSÕES $\ldots \ldots \ldots \ldots \ldots \ldots \ldots \ldots \ldots \ldots \ldots \ldots \ldots \ldots \ldots . \ldots \ldots$

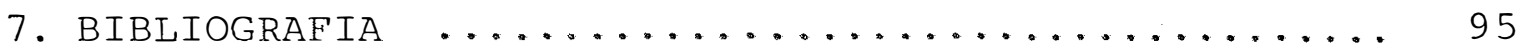

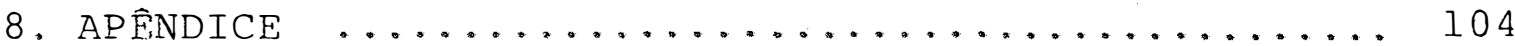


COMPARAS̆̃̃O DE MODELOS MATEMÁticos APLICADOS A ENSAIOS DE

CALAGEM COM A CULTURA DA SOJA (Glyeine max [L.] Merrill)

Candidata: Maria Cristina Neves de Oliveira

Orientador: Prof. Dr. Roberto Simionato Moraes

R E S U U M O

As funções de produção desemrenham importante papel nos estudos de ensaios de adubação e correção dos solos. O emorego destes corretivos, em doses tecnicamente determinadas, é considerado o meio mais viável e mais rápido oara o aumento da produção agrícola.

O presente trabalho teve como objetivo princi pal, o estudo de modelos matemáticos que melhor se ajustam aos dados de aplicacão de calcário na cultura da soja, e tam bém o estudo de uma dose de calcário que possibilite obter a produção máxima econômica. Estes dacos toram obticos tor resonisa dores do Centro Nacional ze Pescuisisa de Soja, nos locais de Campo Mourão. e Guaranuava, (em Latossolos Roxo disträ́ico e Bruno Aistrócico), à partir do ano agrícola 1978/79 até 1983/84, no Estado do Paraná, Brasil. 
Aos dados de produção de soja, com aplicação de diferentes doses de calcário, foram empregados os modeIos: Quadrático, Raiz Quadrada e 2ạ Ap̣roximação de Mitscherlich, os quais são expressos por:

$$
\begin{aligned}
& Y=A+B X+C X^{2}+e \\
& Y=A+B \sqrt{X}+C X+e \\
& Y=A\left[1-10^{-C(X+b)}\right] 10^{-k(X+b)^{2}}+e
\end{aligned}
$$

Para as estimativas dos parâmetros dos modelos quadrático e raiz quadrada, foi utilizado o método dos quadrados mínimos.

Sendo o modelo da 2ạ aproximação de Mitscherlich não linear nos parâmetros, o método empregado para esti mar os parâmetros do mesmo foi o método de Marquardt.

Inicialmente foram realizadas as análises de variância para cada ano agrícola nos dois locais. Em seguida fez-se o desdobramento dos graus de liberdade do calcário,le vando em conta a regressão.

Através das análises de regressão, pōde-se com parar os três modelos, com o objetivo de selecionar o melhor deles. Para isto foram utilizados os critérios usuais, do teste F, coeficientes de determinação, ouadrado Médio do Des vio de Regressão Mínimo (QMDRM), bem como o Critério de In- 
formação de Akaike (AIC), e o Total de Postos (estatistica de ordem) .

Estes dois últimos foram consistentes quando comparados com os critérios convencionais.

Determinaram-se também as doses máximas econô micas para os três modelos.

A partir destes resultados oôde-se concluir que:

- para os experimentos de Campo Mourão, o modelo que me Ihor se ajustou foi o quadrático e, em sequida, a 2 ạ aproximação de Mitscherlich;

- para os experimentos de Guarapuava, obteve-se como o melhor modelo a 2 ạ aproximação de Mitscherlich e, em seguida, o modelo raiz quadrada;

- na determinação da dose econômica, utilizando os mode los quadrático e 2 ạ ap̣oximação de Mitscherlich, obtí veram-se as doses econōmicas próximas às recomendadas pelo método de saturação de bases (70\%). 
COMPARISON AMONG MATHEMATICAL MODELS APPLIED IN EXPERIMENTS USING LIMIRU WITH SOYBEAN CULTURE (Glycine max'[I.] MLRRILL),

Candidate: Maria Cristina Neves de Oliveira

Adviser: Prof. Dr. Roberto Simionato Moraes

The yield response functions represent an important part in the fertilizer experiment studies and soil correction. The employement of this correctives, in technically determined levels, is considered the most practical and the fastest for the increasing of the agricultural production.

The present dissertation has as a princinal objective the study of mathematical models that best fit 1 ime data in soybean culture and also the finding of economical level of the corrective. These data were colected bv researches by the Centro Nacional de Pesquisa de Soja (CNPSo), both soils Earlustox, from Cañpo Tourão and Guarapuava locals, in State of Paraná, Drazil, in the aqronomic vears of $1978 / 79$ to $1983 / 84$. 
The models employed as response functions to soybean yield data were Quadratic, Square Root and Mitscherlich II Model, expressed by

$\begin{aligned} \text { [I] } & Y=A+B X+C X^{2}+e \\ \text { [II] } & Y=A+B \sqrt{X}+C X+e \\ \text { [III] } & Y=A\left[I-10^{-C(X+b)}\right] 10^{-k(X+b)^{2}}+e\end{aligned}$

For the parameter estimation of the square root and quadratic models, the least square method was used. Because of the non-linearity of the parameter of Mitscherlich II model, the Marquardt method of parameter estimation was used.

Initially the variance analysis were calculated for each agronomic year. Afterwards the degrees of freedom for lime was partioned, take in care of the non li near regression.

Through the regression analysis the three models could be compared and the best selected. For this purpose the usual criteria commonly used like $\mathrm{F}$ test, determina tion coefficient, lack of fit mean square, the information criteria of Akaike (AIC) and rank total (statistical order). The last two above should consistence when compared with the conventional criteria. The economical level was also determined for each model. From this results we 
xiv.

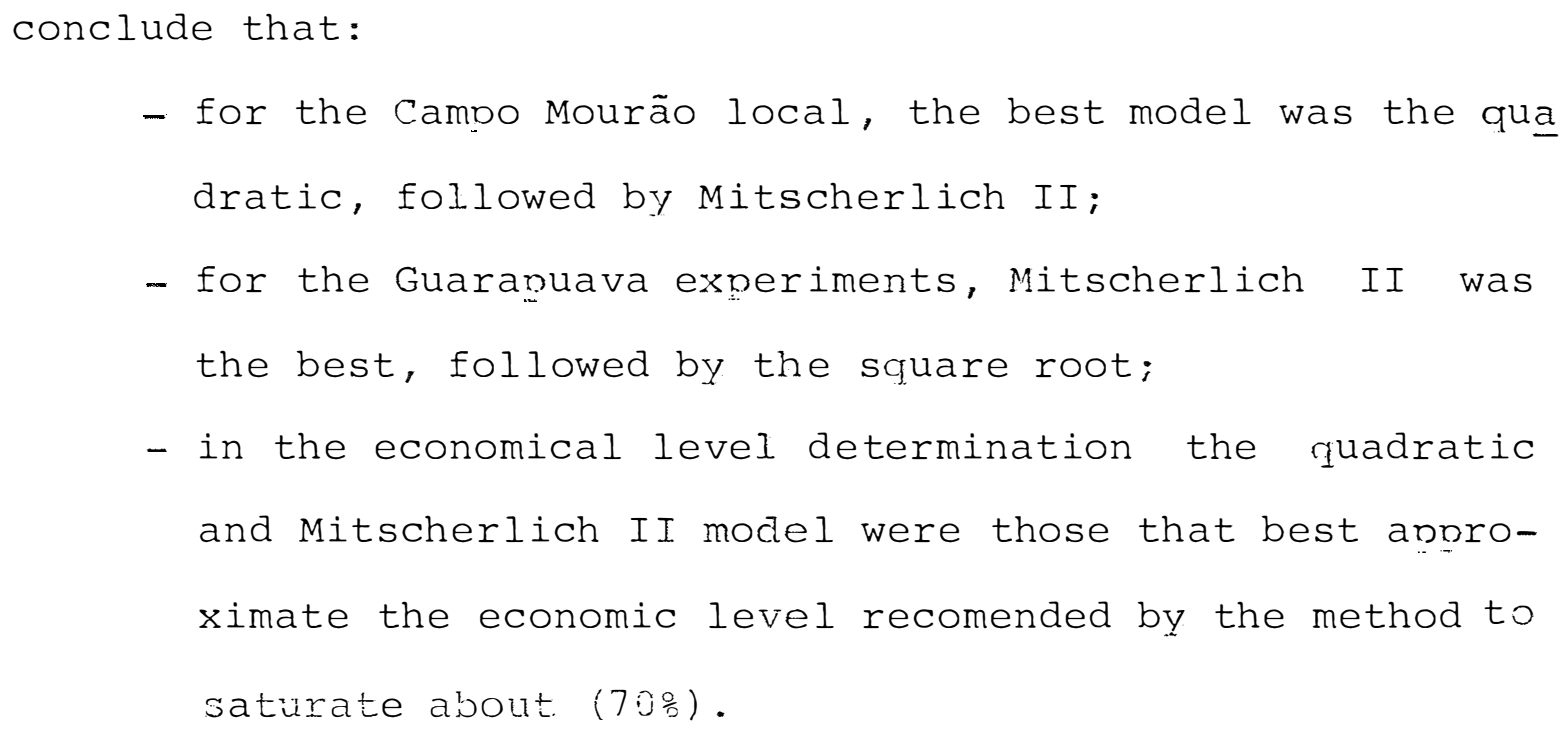


1 .

1. INTRODUÇÃO

A soja vem sendo cultivada em grande escala devido a sua utilização como alimento protéico e comóleo de soja comestivel. Devido a boa qualidade de proteina veqe tal nela encontrada, a soja vem auxiliando no desenvolvimen to de rebanhos de pequenos animais. Além disso, outros fato res vieram contribuir para sua exnansão, tais como: as elevações de cotações internacionais e alterações na politica cambial, propiciando desta maneira um maior retorno econômi co.

Na safra 85/86, O Brasil produziu 13,3 milhões de toneladas de grãos de soja, contribuindo com uma parcela representativa em nossa economia e poderá contribuir ainda mais se estender o plantio a solos devidamente 
apropriados para essa cultura. A quantidade produzida seria teoricamente suficiente para suprir as necessidades anuais em proteina de mais de 2 vezes a nonulação brasileira.

Essa expansão da cultura da soja fez com que ela fosse levada para solos de acidez elevada, nois a gran de maioria dos solos nacionais possuem essa caracteristica.

Sendo a acidez do solo um dos principais prọ blemas limitantes no desenvolvimento das olantas, a prática da calagem deve ser utilizada, para obtenção de maior rendi mento das culturas nesses tipos de solos. Frequentemente, nos solos com esta caracteristica, detectam-se concentrações muito elevadas de alumínio e manganês trocáveis. Através de pesquisas, tenta-se verificar a eficiência do calcário, com o intuito de anular o efeito da acidez dos solos brasileiros. Determinada essa eficiência, é fundamental fazer-se um estudo econômico dessa aolicação.

o principal objetivo deste trabalho é obter uma função matemática de resp̣osta à calageme, com isso, nro piciar estudos de aumento de orodução e obtenção de doses econômicas de calcário.

Para esse fim foram testadas as funções:qua drática, raiz quadrada e 2 ạ aproximação de Mitscherlich, aos dados experimentais de ensaios je calagem. 
No ajuste dessas funções foram utilizados os métodos:

- minimos quadrados para as funções polinomiais quadrāticas;

- método iterativo de Marquardt para uma função não linear nos parāmetros, a 2a aproximação da equação de Mitscherlich.

A comoaração dessas funções foi baseada no valor do coeficiente de determinação $\left(R^{2}\right)$, do coeficiente de determinação ajustaảo $\left(\bar{R}_{A}^{2}\right)$, do nuadrado séảo do Desvio de Regressão rinimo (OMOR!) , do critério de informação de Akai ke (AIC) e do total dos postos de classificacão lou orảem de classificação), onde cbteve-se o maiox múmero de quảracios mêủios residuais mínimos, intermediários e máximos. 
2.1 - Ajustamento de Modelos Matemáticos a Dados de Produção

Neste capítulo será feita uma revisão de tra balhos referentes ao ajuste de modelos matemáticos a dados de produção, e à determinação de doses econômicas de nutrientes.

Um dos primeiros trabalhos onde se estudou o ajuste de funções de produção, foì o de MITSCHERIICH(1909), onde o autor utilizou a função:

$$
Y=A\left[1-10^{-C(x+b)}\right] \quad[2 \cdot I \cdot a]
$$

para representar a produção vegetal, onde o parâmetro $\mathbb{A}$ é a produção máxima teórica, c é o coeficiente de eficācia, b é a cuantidade de corretivo contido no solc e $x$ é a riantidade de corre 
tivo adicionada aó solo, medidos en torelałas por hectare.

Esta função não se adantou bem aos dados de produção, quando dosagens muito altas de nutrientes eram aplicadas, pois à medida em que se aumentavam as doses de nu trientes, a produção tambēm aimentava, até um certo ronto, para dai comegar a decrescer.

Assim, foi proposto pelo mesmo autor, em 1928, uma modificação da lạ equação, na qual foi acrescido um novo parâmetro quadrático, passando a ser denominada de segunda aproximação de Mitscherlich, expressa por:

$$
\begin{aligned}
& Y=A\left[1-10^{-C(x+b)}\right] 10^{-k(x+b)^{2}} \cdot[2.1 . b] \\
& \quad \text { valor de } k \text { foi denominado de fator prejuí }
\end{aligned}
$$

zo. Esta modificação, proposta por MITSCHERLICH, partiu da seguinte equação diferencial:

$$
\frac{1}{Y} \cdot \frac{d y}{d x}=C_{1} \frac{10^{-C X}}{1-10^{-C X}}-2 k \cdot x, \quad[2.1 . c]
$$

obtendo-se, então, a 2ạ aproximação de Mitscherlich.

o autor afirmou que esta função se adaptava melhor aos dados, tendo apenas o inconveniente de ser uma função mais complicada.

PIMENTEL GOMES A MALAVOLTA (1949 a e b) fizeram estudos teóricos da $1^{a}$ e e 2. anroximacão de Mitscherlich. Os autorres neste estudo mostraram corno a emacão [2.1.a] poae ser anlicada a cados experimentais e, discutiram tarbēn o mroblema da deteiminação 
da dose de nutrientes econômica. Comentam sobre a não arbitrariedade desta equação quando aplicadas a ensaios de adubaŗão.

Os autores discuten a equação expressa [2.1.b] e mostram como chegar nesta, a knartir da equação diferencial [2.1.c]. Confimam os resultados de MITSCHERI ICH (1928), de que à equação [2.1.b] se adaptava melhor aos dados exnerimentais de adu bação, tendo o inconveriente ciesta equação, ser mais complicada e coñ um parâmetro a mais. Segundo os autores é preferível ultilizar-se da e quação [2.1.a] quiuando houver adubações excessivas. Os autores tambēin cesenvolveram estudos para determinar os parâmetros da la aproximação , pelo método dos quadrados ininimos. Este método leva a un sistema de 3 equações e uria incógnita, resolvido pelo teorema de Rouché-cappeli. BOX e WILSON (1951), em seu trabalho, difun diram a metodologia de superficies de resposta ajustando a regressão polinomial. Discutiram os delineamentos experimen tais com o objetivo de se determinar, com um reduzido número de observações, o ponto de resposta máxima. Introduziram também os delineamentos compostos, os quais muito tem contribuido na pesquisa agrícola.

Mujtas tentativas foram feitas no sentido de ajustar novos modelos matemáticos a ensaios de adubação. HEA DY e PESEK (1954) estudaram cinco funções: três do tino cobb-Douglas, uma função raiz quadrada e uma quadrática. Estas funções foram aplicadas a um ensaio " fatorial incomoleto 
de adubação cm Is e $P$, cada um cain cinco nutrientes, com a cultura do

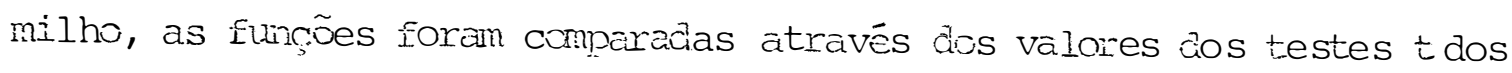
parâmetros e seus respectivos coeficierites de correlação.

Os autores concluiram que o modelo que melhor se ajustou aos dados foi o modelo raiz quadrada.

Neste mesmo ano, MITSCHERLICH (1954) deu con tinuidade aos estudos da 2 ạ aproximação, reafirmando que es ta equação deve ser empregada, pois através dela é possível determinar quando o efeito do adubo é prejudicial à planta. Concluiu seu trabalho mostrando que esta função reflete melhor a queda de produção, a qual se dá de maneira lenta e mais próxima da realidade.

FRENCH (1956) estudou os modelos: quadrático, raiz quadrada, Spillman, Gompertz e Cobb-Douglas, aplicados a dados de produção de milho obtidos de um ensaio de adubação nitrogenada. O autor verificou que, através do modelo raiz quadrada obtiveram-se as produções máximas com os níveis mais altos de nitrogēnio do que no modelo quadrático, e que para a obtenção de estimativas econômicas, os modelos raiz quadrada e exponencial foram os que se comoortaram meIhor.

HEADY e DILLON (1964), estudando o ajuste de funções, empregaram também os modelos quadrático e raiz qua drada, a dados de produção de trēs ensaios de adubação, com 
as culturas de: milho, trevo vermelho e alfafa. Os autores verificaram que o modelo raiz quadrada se adaptou melhor aos dados, em decorrência do menor desvio de regressão e ao maior coeficiente de determinação $R^{2}$. Continuaram enfatizan do que este modelo é aprop̣riado ao estudo de funções de pro dução com fertilizantes, que incluam os elementos do solo e os que são aplicados aos mesmos.

NELDER (1966) propôs um modelo muito interessante, o polinomial quadrātico inverso, dado pelo mode10:

$$
\begin{aligned}
& Y=\frac{X}{\beta_{0}+\beta_{1} X+\beta_{2} X^{2}} \quad[2.1 . d] \\
& \text { o autor inicialmente fez um estudo teórico }
\end{aligned}
$$
do modelo quadrático inverso comparando-o com o modelo quadrático comum, enumerando as seguintes vantagens do modelo em estudo:

- o modelo polinomial inverso geralmente não é negati$\mathrm{VO}$;

- é Iimitado;

- tem forma quadrática assimétrica;

- além disso não conduz a absurdos como valores de y negativos. 
Estas vantagens do modelo quadrático inverso refletem melhor a queda da produção, que deve ser sempre assimétrica, o que não ocorre no quadrático.

INEIDER (1966) concluiu gue o modelo polinomial qua drático inverso é o moảelo mais aderuado para estudos de sü perficie de resposta, e çue o mesmo é de fácil ultilização em relação ao đuadrático comum.

MORAES (1969) estudou a regressão dolinomial ajustada a dados de um ensaio fatorial $3^{3}$ com a cultura de milho. O autor ajustou o modelo quadrático a um ensaio fatorial com doses não igualmente espaçadas, determinandoos intervalos de confiança para os parāmetros, as estimativas das produções e os seus respectivos intervalos de confiança. Concluiu ainda, que o modelo de regressão polinomial levou a intervalos muito amplos para os parāmetros. Discute também a necessidade do uso do computador quando não se utiliza a variável transformada, no caso das doses de nutrientes não equidistantes. Foram também determinadas as rendas líquidas para o modelo em estudo.

VIEIRA (1970) estudou os modelos: quadrático, raiz quadrada, potência $3 / 2$ e Mitscherlich lạ aproximação. Estes modelos foram ajustados aos dados de exnerimentos fatoriais $3^{3}$ em adubação. Também foram estudados os niveis ótimos em cada modelo. 
Resumindo, a autora comentou que:

a) Os parâmetros das quatro funções ajustadas obtiveram intervalos de confiança bastante amolos, mas foi possivel obter estimativas razoáveis para os rendimentos, pois a precisão das mesmas depende da grandeza relativa das variâncias e covariâncias das estimativas dos varâmetros.

b) Os modelos quadrático e o de potência 3/2 obtiveram ajustes semelhantes, sendo que o modelo potência $3 / 2$ apresentou maiores dificuldades nos cálculos da ren da liquida.

c) Dos três modelos polinomiais, o raiz quadrada apresentou maior coeficiente de determinação, consequen temente, obteve o melhor ajuste.

d) para a determinação da dose económica foi indicado o uso da lei de Mitscherlich, para o caso onde se tem três níveis, facilitando os cálculos matemáticos. Caso existam interações significativas, a dose econōmica deve ser calculada através da regressão oo linomial, dando preferência ao modelo raiz quadrada. 
STEFANELO (1975), com o objetivo de ajustar modelos matemāticos, estimando a sup̣erfície de produção em função da quantidade de nutriente aplicado, estudou os mode los: Cobb-Douglas, raiz quadrada, quadrático e potência 3/2, ajustando-os a dados experimentais de produção de triqo. o autor obteve uma resposta diferente da encontrada por VIEIRA (1970), pois o modelo que melhor se ajustou foi o quadrá tico.

Os modelos matemáticos possuem caracteristi cas pröprias e pode-se notar que, em trabalhos com dados de produção com um mesmo modelo, os mesmos conduzem a resultados muito divergentes. Estas divergências devem ser conside radas segundo diversos aspectos: a qualidade do material utilizado, as condições climáticas onde estão sendo conduzidos os experimentos, o planejamento do experimento, e a pers picácia do experimentador em detectar as ocorrências anormais observadas, impedindo que o resultado da pesquisa seja comprometido com estes fatores.

Dentre os modelos mais utilizados, o modelo Cobb-Douglas foi o que pior se comportou. Alqumas vezes este modelo foi eliminado e, em outras, não obteve um bom ajuste sob o ponto de vista econômico. Este modelo foi novamente utilizado por RAMIREZ DÁVILA e BENITEZ (1975), que em pregaram também os modelos: quadrático, raiz quadrada e Mi- 
tscherlich em sua lạ aproximação, com os dados de resposta a fertilizantes.

Os autores concluiram que, com o modelo qua drático, pode-se obter bons resultados quando se usam altas doses de nutrientes, permitindo mostrar possiveis quedas na produção. Comentam ainda que a curva que representa este mo delo é descrita através de uma parábola com simetria em relação ao ponto de máximo, o que não ocorre na prática com as curvas de respostas a nutrientes, as quais são assimétri cas.

A equação de Mitscherlich (lạ aproximação), apresentou algumas limitações, não indicando quedas de produção quand• se aplicam altas doses de um nutriente.

MENEGHELLI (1976), estudando o ajuste das funções: raiz quadrada, quadrática, linear, e a Eunção de Mitscherlich lạ aproximação, aplicadas a dados de ensaios de adubação com a cultura do milho, concluiu que a função raiz quadrada foi a que melhor se ajustou. Para isto foi utiliza da a técnica de simulação, gerando dados experimentais. Com os dados gerados estimaram-se os parâmetros dos modelos tes tados, e a partir delesas rendas liquidas mais próximas da real foram as escolhidas. 
RIBOLDI (1978) fez um estudo sobre superficie de resposta em ensaios de adubação NPK, e calcário com a cultura do milho. Os dois modelos de superficie de respos ta utilizados pelo autor foram ajustados pelo método de poIinômios ortogonais. Foram também determinadas as variâncias das estimativas dos parâmetros, intervalos de confiança e estimativas dos parâmetros, intervalos de confiança e estimativas das produções.

O autor pôde concluir que o método dos poli nômios ortogonais utilizado para ajustar as duas superficies de resposta é satisfatório, e é muito útil nos estudos de modelos com expoente fracionário, onde os niveis de nutrien tes não são equidistantes.

Finalizando, o autor comenta sobre a extrapolação com as equações de regressão, obtidas pelo método dos polinômios ortogonais para os dois modelos. Comenta também sobre a concordância entre as produções médias dos tratamentos ajustados e as observadas.

Neste mesmo ano, SILVA (1978) estudou o aju te de três modelos: o quadrático, a função Mitscherlich lạ aproximação e a 2 ạ aproximação em experimentos de adubação na cultura de trigo. Após estudos detalhados para cada mode 10, a autora concluiu que o melhor ajuste se deu com o mode lo quadrático, mas a viabilidade da utilização da função de 
Mitscherlich (2ạ aproximação) foi sugerida, pelo fato de re presentar melhor a queda brusca que se dá logo após o ponto de máximo, quando se utiliza o modelo quadrático.

SPARROW (1979), utilizando dados de 84 expe rimentos de adubação nitrogenada em gramíneas, estudou o ajuste dos seguintes modelos: o quadrático, o modelo de Mits cherlich modificado, o polinomial quadrático inverso, o inverso linear e o de duas linhas retas. O autor utilizou o valor do quadrado médio residual mínimo (QMRM), dos viéses dos resíduos após o ajuste do modelo, e os valores de $\mathrm{R}^{2}$, co mo ponto de referência para selecionar o melhor modelo.

Finalizando, fez alguns comentários sobre os modelos:

- Afirmou que, para o caso em estudo, da relação da oro dução de gramíneas com adubação nitrog̣enada, não sōde dizer que exista um determinado modelo que se ajuste totalmente a esses dados, devido à falta de base teórica na descrição do fenômeno.

- Sugeriu, para o ajuste de modelos, a utilização de ou tros critérios de àvaliação além do $R^{2}$ e do QMRM, pois estes são insuficientes para a seleção de um modelo, já que todo modelo possui caracteristicas próprias.

Finalizando, o autor achou o modelo polinomial quadrático inverso como o mais adequado, pois ajustou 
bem na maioria dos experimentos. Considerou este modelo mui to poderoso, pois obteve os valores dos quadrados médios re siduais mínimos (QMRM) para 52 experimentos, confirmando os resultados de NELDER (1966).

Neste mesmo ano SPARROW (1979), dando conti nuidade ao estudo de ajuste de funções, empregou os modelos: linear, quadrático, cúbico, exponencial modificado, inverso linear modificado, quadrático inverso e duas linhas retas in terceptadas, aplicados aos dados de 85 experimentos com adu bação com a cultura de cevada. Os modelos foram juigados pe los métodos dos quadrados médios residuais mínimos (QMRM), pelo total da classificação de ordem quando obteve o QMRM, pelo Critério de Informação de Akaike (AIC) e pela análise dos resíduos após o ajuste.

O autor concluiu que o modelo duas linhas retas interceptadas ajustou-se bem quando foram utilizados os critérios dos OMRM, do AIC, mas quando foi avaliado pelo total da classificação de ordem, o modelo quadrático inverso ajustou-se melhor.

$$
\text { SILVA (1980) fez um estudo sobre o ajusta- }
$$

mento da 2ạ aproximação de Mitscherlich a dados de maturação de cana-de-açúcar. A autora utilizou três métodos para as estimativas dos parāmetros da equação mencionada acima. 
Estes métodos estudados poor ela são iterativos, e necessitam de valores iniciais arbitrários com o objetivo de se ob ter a convergēncia. O método que obtivesse um menor número de iterações, e a menor soma de quadrados de desvios, seria o mais eficiente.

A autora pôde concluir o seu trabalho da se guinte forma:

a) Quando o comportamento da maturação para todas as variedades eram idênticas, os três métodos de estimativas apresentavam os mesmos resultados.

b) Para o método de Newton sempre foi exigido um maior nûmero de iterações, para que houvesse a convergência, exigindo ainda a matriz das derivadas segundas (matriz Hessiana).

c) O método de Gauss-Newton não exige a matriz Hessiana. Este método proporcionou bons resultados e não necessita a proximidade dos valores iniciais ao pon to de mínimo para convergência.

d) Onde o comportaménto da maturação da cana-de-açúcar foi anormal, obtiveram-se resultados diferentes para os três modelos.

e) As estimativas dos parâmetros não foram adequadas quan do empregados os métodos de Newton e Gauss Newton, onde as variedades apresentaram pontos intermediários de decréscimo. 
Finalizando, a autora afirma que o método de Marquardt apresentou bons resultados. Onde os dados não foram discrepantes necessitou um número reduzido de iterações para convergir.

NICOLLELA (1981) empregou a superficie de res posta a dados de cinco ensaios de adubação NPK com a cultura do cacau. O modelo utilizado pelo autor foi o polinomial quadrático, com o objetivo de se determinar as estimativas dos parâmetros dos rendimentos e seus intervalos de confian ça, as doses econômicas e a recomendação de adubação na região cacaueira no Estado da Bahia. O autor fez cortes na su perfície polinomial quadrática, com e sem interação, determinando também os pontos de máximo. Quando considerou o modelo com as interações, os pontos de máximo se localizaram fora dos intervalos estudados.

O autor pôde concluir que o modelo de regressão polinomial quadrático, com e sem interação, não se ajustou bem aos dados de produção de cacau, quando se consí derou individualmente cada local e ano. Concluiu também que os intervalos de confiança foram amplos, comprometendo a pre cisão das estimativas dos rendimentos.

UDO (1983), dando continuidade aos estudos de SILVA (1978), empregou os modelos: Mitscherlich (2ạ apro 
ximação), quadrático e raiz quadrada, aos dados experimentais de maturação de cana-de-açúcar.

Concluiu que o modelo quadrático tem algumas desvantagens em relação à 2ạ aproximação de Mitscherlich, mas foi o que melhor se ajustou a estes dados, contrariando o resultado do trabalho de SILVA (1978). O modelo raiz quadrada não foi adequado para o estudo do fenômeno da maturação da cana-de-açúcar, pois obteve-se sempre o ponto de máximo deslocado para a direita.

MENEGHETTI (1983) estudou os modelos quadrá tico e a equação de Mitscherlich lạ aproximação, aplicados a um ensaio de adubação NPK com a cultura da cana-de-açúcar. A autora determinou as estimativas dos parâmetros e seus in tervalos de confiança e a melhor dose econômica dos nutrien tes em estudo. Fez também o ajustamento de superficiede res posta para o modelo polinomial quadrático e concluiu que,pa ra se obter resultados confiáveis para as doses econômicase intervalos pouco amolos, deve-se sempre utilizar doses altas de nutrientes.

Concluiu também que utilizando os dois mode los para o ajuste aos dados de adubação, não se obteve interpretação racional dos ensaios.

BIANCHINI SOBRINHO (1984) empregou 11 modelos matemáticos para estudar o período de lactação de vacas 
da raça Gir. O autor estudou os modelos: linear, linear com 2 e 3 etapas, o quadrático, o cúbico mais duas retas, o linear logaritmico, o quadrático logarîtmico, a função Gama Wood, o linear hiperbólico e o polinomial quadrático inverso. Segundo o autor, houve a tentativa de se prever a produção leiteira total a partir dos resultados parciais e em cada es tágio de lactação através de um modelo que se adequasse bem aos dados.

As estimativas dos parāmetros para a maioria dos modelos propostos foram feitas através do método dos quadrados minimos, por serem lineares nos parâmetros.

A função Gama wood foi linearizada para que se pudesse aplicar o método acima.

o modelo polinomial quadrático inverso teve suas estimativas dos parãmetros obtidas pelo método dos quadrados mínimos ponderados.

Dentre os modelos estudados, o autor selecionou, na ordem, os modelos: quadrático logarítmico, linear hiperbólico, a equação Gama wood e o polinomial quadrático in verso. Esta seleção baseou-se na menor soma de quadrados de desvios de regressão, no coeficiente de determinação ajustado ao no de parâmetros e na distribuição de exreçuência dos coeficientes de determinação ajustado para cada curva. 
Um estudo mais recente utilizando o modelo quadrātico e a 2ạ aproximação de Mitscherlich foi feito por MAGNANI (1985). O autor comenta sobre a dificuldade do ajustamento de modelos, quando estes, por serem complexos, neces sitam do uso do computador para o seu estudo. Para isso, foram realizados programas em linguagem Basic, facilitando o ajustamento, principalmente da 2ạ aproximação de Mitscherlich, a qual é não linear nos parâmetros. Foram utilizados os dados de 27 grupos de experimentos com a maturação da cana-de-açúcar, expressos em polo da cana. Para as estimativas dos parâmetros da 2 ạ aproximação de Mitscherlich, foram apli cados os métodos de Newton, Gauss e Marquardt, e para o mode lo quadrático o método dos quadrados mínimos usual.

MAGNANI afirma que o método de Marquardt foi o mais eficiente, concordando com os resultados obtidos por SILVA (1980) .

2.2 - Determinação da Dose Econōmica

Com o aumento do custo de fertilizantes, mui tos trabalhos com adubação e correção dos solos vem sendo con duzidos, com o objetivo de aumentar a produtividade agricola minimizando seus custos. Para isso é necessário determinarmos doses econômicas de fertilizantes ou corretivos na obten 
ção das produções agrícolas.

Assim, PESEK e HEADY (1956) fizeram um estu do para determinar o nível ótimo econômico de dois nutrientes em ensaios de adubação com a cultura da alfafa. Utilizaram os modelos: logarítmico, quadrático e raiz quadrada. o experimento foi conduzido sob o esquema fatorial fracionado repetido e os nutrientes utilizados foram o fósforo e o potássio.

Os autores concluiram que o modelo que permitiu obter o nível ótimo de aplicação dos nutrientes combinados, com preços mínimos, foi o modelo raiz quadrada,o qual obteve um coeficiente de correlação $r=0,8793$, a um nivel de significāncia de l\% de probabilidade.

ZAGATTO e PIMENTEL GOMES (1960), com o objetivo de fazer um estudo econômico da adubação, utilizaram os modelos: quadrático, raiz quadrada, Mitscherlich lạ aproximação, e Cobb-Douglas. Os autores comentaram as vantagens e desvanta gens de cada modelo, e afirmaram que nenhum dos modelos foi plenamente satisfatório.

PIMENTEL GOMES e ABREU (1963) fizeram um es tudo teórico da dose econômica aconselhável para a lạ aproxi mação de Mitscherlich e obtiveram a seguinte expressão

$$
x^{*}=\frac{1}{c} \log \frac{c x_{u} L 10}{1-10^{-c x_{u}}}+\frac{1}{c} \log \frac{w \cdot u}{x_{u} t}[2.2 . a]
$$


c é o coeficiente de eficácia, u u ẻ o aumento de produção do produto agrỉcola, $x_{u}$ é a dose do nutriente, w o preço unitário do produto agrícola e $t$ é o preço unitário do nutriente.

Os autores afirmam que a fórmula citada an teriormente pode ser substituida nor :

$$
x^{*}=\frac{1}{2} x_{u}+\frac{1}{c} \log \frac{w \cdot u}{x_{u} t} .
$$

quando se tem numerosos ensaios é possivel obter es timativas razoáveis para os valores de $\underline{c}$, isto então permite o uso da ûltima equação.

PIRINTEL GOMES'E CAMPOS (1966) utilizaram värios ex perimentos de adubação com a cultura do milho, para um estudo econônico. Enpregaram a $1^{a}$. aproximaŗão de Mitscherlich e confrontaram os resultados com os obtidos com a regressão polinomial de 2\% Grau. Os autores concluíram que a regressão polinomial de 20 Grau possui algumas vantagens, mas é desaconselhāvel em ensaios de adubação, não permitindo extrapolação e testes de significância adeñuados no caso de grupos de experimentos.

ZAGATTO E PIMENTIEL GOMES (1967) estudaram, sob o aspecto econânico, muitas funções de produção, com uma, duas e três variāveis independentes.

Resumindo os autores reconendaram :

- O uso de gruoos de ensaios numerosos, ou ensaios isolados com um grande nưmero de repetições. 
- Não confiar em doses ótimas obtidas através de polinô mios de coeficientes de termos de 2 9 grau que não sejam significativamente diferente de zero.

- Detectar a veracidade dos valores obtidos corresnon dem a um máximo.

- Determinar os intervalos de confiança para as doses econōmicas.

LANZER (1970), seguindo exemplos de autores anteriores, preocupou-se também com o estudo econômico de dạ dos de grupo de experimentos de adubação e correção na cultu ra do trigo. O autor empregou os modelos: quadrático, raiz quadrada, potência $3 / 2$ e Cobb-Douglas.

O autor concluiu que, dos modelos estudados, a potência $3 / 2$ prejudicou o estudo econômico, sendo desta ma neira desaconselhável o uso do mesmo.

COSTA (1977) comparou os modelos polinomiais: quadrático, raiz quadrada e potência 3/2, a dados experi mentais de 27 ensaios fatoriais $3^{3}$ com a cultura do arroz.Es ta comparação foi feita com o objetivo de se recomendar doses econômicas para a adubação, mas isto não foi possível, pois em algumas vezes as doses econômicas obtidas apresentaram-se além dos intervalos estudados, confirmando desta forma resultados de outros trabalhos. 
PALHANO et alii (1984) fizeram estudos com dados experimentais com a cultura da soja, com o objetivo de comparar os melhores métodos de recomendação de calcário. Pạ ra isso os autores testaram o ajuste de modelos aos dados de produção, com o fim de determinar doses econōmicas de calcário. Foram testados os modelos: quadrático e a função de Mitscherlich em sua lạ aproximação, concluindo que o modelo que possibilitou recomendar a melhor dose econōmica foi o modelo de Mitscherlich, confirmando os resultados obtidos através do método de saturação de base (70\%). Verificaram que doses maiores que a dose econōmica não conduziram a acréscimos sig̣ nificativos na produção. 
3. MATERIAL

Os dados utilizados neste trabalho foram obtidos de ensaios de calagem em soja, instalados nor pesquisadores da EMBRAPA, da ārea de Nutrição Vergetal do Centro Ma cional de Pesquisa de Soja. Eles podem ser encontrados nas Ta belas de números 22 a 33 do Apêndice. O primeiro experimento foi instalado na região de Campo Mourão, em Latossolo Roxodis trófico, nas doses $0,2,4,6,8$ e 10 toneladas de calcário por hectare. O segunảo na região de Guarapuava, em Latossolo Bruno distrófico, nás doses 0, 3, 6, 9, 12 e 18 toneladas de calcário por hectare.

Os experimentos foram conduzidos por seis anos consecutivos. 
o delineamento utilizado nara o experimento de Campo Mourão foi o de bloco casualizados, sendo o número de blocos iqual a quatro, com seis tratamentos representados pelas doses de calcário. Cada parcelá foi constituída por 14 linhas de soja, con 12 m de comuri mento cada e espaçamento entre linhas de 0,50 metros.

A ârea útil colhida foi de oito linhas centrais de 10 metros cada, serido o restante da parcela tomado como bordadura.

$$
\text { O delineamento utilizado para o experimento de }
$$
Guarapuava foi o de blocos casualizados, con quatro blocos e seis tratamentos representados pelas doses de calcário. Cada parcela foi constituĩda por 12 linhas de soja com espaçamento entre linhas de 0,50 metros.

A área útil colhida foi de oito linhas centrais de 8 metros, sendo as demais tomadas cano bordadura.

Os solos apresentaram as características çuímicas mostradas na Tabela 1.

Tabela 1 - Análise química inicial.

\begin{tabular}{|c|c|c|c|c|c|c|c|c|c|}
\hline \multirow[b]{2}{*}{ IOCAL } & \multirow[b]{2}{*}{$\begin{array}{r}\mathrm{pH} \\
\mathrm{H}_{2} \mathrm{O} \\
\end{array}$} & \multicolumn{5}{|c|}{$\mathrm{meg} / 100 \mathrm{ml}$ de solo } & \multirow{2}{*}{$\begin{array}{l}C \\
\frac{\circ}{0}\end{array}$} & \multirow{2}{*}{$R C^{*}$} & \multirow{2}{*}{$\begin{array}{c}\mathrm{P} \\
\mathrm{p} P \mathrm{~m}\end{array}$} \\
\hline & & $\mathrm{AI}^{3+}$ & $\mathrm{Ca}^{2+}$ & $\mathrm{Mq}^{2+}$ & $\mathrm{K}^{+}$ & $\mathrm{H}^{+}+\mathrm{Al}^{3+}$ & & & \\
\hline Campoo Mourão & 4,5 & 0,8 & 1,49 & 0,61 & 0,22 & 10,32 & 1,75 & 6,5 & 8,2 \\
\hline Guarapuava & 4,5 & 1,7 & 0,27 & 0,13 & 0,14 & 16,24 & 2,42 & 11,2 & 0,09 \\
\hline
\end{tabular}


A cultivar de soja utilizada nos experimen tos para os dois solos foi a Paraná, (Glyeine max [L.] Merrill).

A adubação de correção foi de $200 \mathrm{~kg}$ de $\mathrm{P}_{2} \mathrm{O}_{5}$ como super fosfato trinlo incorporado à lanço no inicio do experimento. De acordo com a tabela de recomendação de adubação para soja no Estado do Paraná, foram aplicados anualmente $100 \mathrm{~kg}$ de $\mathrm{P}_{2} \mathrm{O}_{5} / \mathrm{ha}$ e $60 \mathrm{~kg}$ de $\mathrm{k}_{2} \mathrm{O} / \mathrm{ha}$, no sul co de plantio.

O método da análise química do solo utilizado foi o de Mehlich (Carolina do Norte). 
28.

4. MÉTODOS

4.1 - ModeIos

Os modelos a serem estudados neste trabalho são os descritos abaixo:

$$
Y_{i}=A+B X_{i}+C X_{i}^{2}+e_{i} \quad[4 \cdot 1 \cdot a]
$$

onde,

$y_{i}$ é a produção de soja, em kg/ha:

$x_{i}$ é a dose de calcário em ton/ha;

A, B e c são os parâmetros da função;

$e_{i}$ são os erros aleatórios $\cdots N\left(0, \sigma^{2}\right)$. 


$$
Y_{i}=A+B \sqrt{X_{i}}+C X_{i}+e_{i}
$$

onde,

$Y_{i}$ é a produção de soja, em kg/ha;

$x_{i}$ é a dose de calcário, em ton/ha;

A, B e C são os parâmetros da função;

$e_{i}$ são os erros aleatórios $\sim N\left(0, \sigma^{2}\right)$.

$$
\mathrm{y}_{i}=\mathrm{A}\left[1-10^{-\mathrm{C}\left(\mathrm{x}_{i}+\mathrm{b}\right)}\right] 10^{-\mathrm{k}\left(\mathrm{x}_{i}+\mathrm{b}\right)^{2}}+e_{i} \text { [4.].c] }
$$

onde,

$Y_{i}$ é a produção de soja, em kg/ha;

$x_{i}$ é a dose de calcário, em ton/ha;

A, b, c e k são os p̣arâmetros da função;

$e_{i}$ são os erros aleatórios $\sim N\left(0, \sigma^{2}\right)$.

4.2 - Estimativas dos Parâmetros

4.2.1 - Método para ajuste dos modelos quadrático e raiz quadrada

o critério utilizado para estimar os parâme tros dos modelos [4.1.a] e [4.1.b] foi através do método dos quadrados minimos.

Dado $\mathbb{i}$ pares de valores $\left(\mathrm{X}_{i}, \mathrm{Y}_{i}\right), i=1,2, \ldots$ $\ldots, N$ 
A solução do sistema de equações normais é dada pela equação matricial:

$$
\widehat{B}=\left(X^{\prime} X\right)^{-1} X^{\prime} Y
$$

onde,

$\bar{\beta}$ é o vetor das estimativas dos parâmetros, dado por:

$$
\underset{\sim}{\widehat{B}}=\left[\begin{array}{c}
\widehat{A} \\
\bar{B} \\
\mathrm{C}
\end{array}\right]
$$

y é o vetor das produções, ou seja,

$$
\underset{\sim}{Y}=\left[\begin{array}{c}
\mathrm{Y}_{1} \\
\mathrm{Y}_{2} \\
\vdots \\
\mathrm{Y}_{\mathrm{N}}
\end{array}\right]
$$

A matriz X para o modelo quadrático será da-

da por:

$$
X=\left[\begin{array}{ccc}
1 & x_{1} & x_{1}^{2} \\
1 & x_{2} & x_{2}^{2} \\
1 & x_{3} & x_{3}^{2} \\
\vdots & \vdots & \vdots \\
1 & x_{N} & x_{N}^{2}
\end{array}\right]
$$


e a matriz para o modelo raiz quadrada será:

$$
\mathrm{X}=\left[\begin{array}{ccc}
1 & \sqrt{\mathrm{X}_{1}} & \mathrm{x}_{1} \\
1 & \sqrt{\mathrm{x}_{2}} & \mathrm{x}_{2} \\
1 & \sqrt{\mathrm{X}_{3}} & \mathrm{x}_{3} \\
\vdots & \vdots & \vdots \\
1 & \sqrt{\mathrm{X}_{N}} & \mathrm{X}_{\mathrm{N}}
\end{array}\right]
$$

4.2.2 - Método para ajuste da equação de Mitscherlich 2ạ aproximação

4.2 .2 .1 - Mëtodo do gradiente

Dados os valores $\mathrm{Y}_{i} ; \mathrm{X}_{1 i} \mathrm{X}_{2 i}, \ldots, \mathrm{X}_{\mathrm{ki}}$, $i=1,2, \ldots, n$, a Eunção de regressão é dada por:

$$
\mathrm{Y}_{i}=\mathrm{f}_{\sim}\left(\underset{\sim}{\mathrm{X}_{i}}, \underset{\sim}{\theta}\right)+\mathrm{E}_{i} \quad[4.2 \cdot 2.1 . \mathrm{a}]
$$

onde,

$$
\begin{aligned}
& x_{i} \text { é o vetor }\left(x_{1 i}, x_{2 i}, \ldots, x_{k i}\right) ; \\
& \underset{\sim}{\theta} \text { é o vetor }\left(\theta_{1}, \theta_{2}, \ldots, \theta_{m}\right) ; \\
& \underset{\sim}{E_{i}} \text { é o vetor }\left(e_{1 i}, e_{2 i}, \ldots, e_{k i}\right) .
\end{aligned}
$$

$$
\text { Admitimos que } e_{i} \sim N\left(0, \sigma^{2}\right) \text { para todo } i \text {. }
$$$$
\text { Determinamos as estimativas } \bar{\theta} \text { para os parâme }
$$
tros $\theta$ com os quais torna-se minima a soma de quadrados dos desvios dada por: 


$$
S(\theta)=\sum_{i=1}^{n}\left[Y_{i}-f\left(X_{i}, \theta\right)\right]^{2} \quad[4.2 \cdot 2 \cdot 1 . b]
$$

A função a ser utilizada é a 2ạ ap̣roximação de Mitscherlich dada por:

$$
\bar{I}\left(\mathrm{x}_{i} / \mathrm{A}, \mathrm{b}, \widetilde{\mathrm{C}}, \mathrm{k}\right)=\mathrm{Y}_{i}=\mathrm{A}\left[1-10^{-\mathrm{C}\left(\mathrm{X}_{i}+\mathrm{b}\right)}\right] 10^{-\mathrm{k}\left(\mathrm{X}_{i}+\mathrm{b}\right)^{2}}+\mathrm{e}_{i} \quad[4 \cdot 2 \cdot 2 \cdot 1 \cdot \mathrm{c}]
$$

onde $e_{i} \sim N\left(0, \sigma^{2}\right)$.

\subsubsection{2 - Processo iterativo}

o processo é iniciado com um dado ponto ${ }_{0}$ conhecido por valor inicial e a partir do qual geramos uma se quência de pontos $\theta_{1},{ }_{2}, \ldots$, que esperamos convergir para o ponto $\hat{\theta}$ com o qual $S(\hat{\theta})$ será mínima.

O cálculo de $\theta_{i+l}$ é de i-ésima iteração. A sequência termina na prática, apoós um número N, finito, de iterações e aceitamos $\theta_{\mathrm{N}}$ como uma aproximação de $\hat{\theta}$.

o vetor

$$
\sigma_{i}=\theta_{i+1}-\theta_{i} \quad[4.2 .2 .2 . a]
$$

é chamado de i-ésimò passo.

Desejamos que a cada passo nos aproximemos do minimo. Desde que não conhecemos o local do mínimo, não podemos testar para esta condição diretamente. Desse modo, verificamos se o i-ésimo passo melhora nossa situação, testando-se 


$$
s_{i+1}\left(\theta_{i+1}\right)<s_{i}\left(\theta_{i}\right) \quad[4 \cdot 2 \cdot 2 \cdot 2 \cdot b]
$$

Então, chamamos de i-ésimo passo aceitável se a desigualdade [4.2.2.2.b] for satisfeita.

Este método obedece ao seguinte esquema:

1) Seja $i=1$. Um valor $\theta_{0}$, inicial, é dado.

2) Determina-se um vetor $d_{i}$ na direção do i-ésimo passo proposto.

3) Determina-se um escalar $\rho_{i}$, tal que o passo

$$
\sigma_{i}=\rho_{i} \mathrm{~d}_{i}
$$

seja aceitável; tomamos então:

$$
\theta_{i+1}=\theta_{i}+p_{i} d_{i}
$$

4) Testamos se o término do critério foi encontrado. Em caso afirmativo, aceitamos $\theta_{i+1}$ como o valor $\bar{\theta}$. Se ocorrero contrário aumenta-se i por uma unidade e retornamos ao passo 2 .

$$
4.2 .2 .3-\text { Aceitabilidade }
$$

Consideremos a i-ésima iteração como um prọ cedimento de minimização de $\mathrm{S}(\theta)$.

Suponhamos que temos o valor $\theta_{i}$ e alquma di reção $\mathrm{d}_{i^{\prime}}$, então, 


$$
\theta(\rho)=\theta_{i}+\rho d_{i},(\rho \geq 0) \quad[4 \cdot 2 \cdot 2 \cdot 3 \cdot a]
$$

é uma função somente de $\rho$, a qual desiqnaremos por:

$$
D_{i}(\rho)=S[\theta(\rho)]=S\left(\theta_{i}+\rho d_{i}\right) \quad[4 \cdot 2 \cdot 2 \cdot 3 \cdot b]
$$

e sua derivada é dada por:

$$
\begin{array}{r}
D_{i}^{\prime}(\rho)=\frac{d}{d \rho} D_{i}(\rho)=\left(\frac{\partial S}{\partial \theta}\right)^{T} \frac{\partial \rho}{\partial o}=\left(\frac{\partial S}{\partial \theta}\right)^{T} \cdot d[4.2 \cdot 2 \cdot 3 \cdot c] \\
\text { Por outro lado, o gradiente de } S(\theta) \text { é } \frac{\partial S}{\partial \theta}
\end{array}
$$

que designaremos por $\varrho(\theta)$, então,

$$
D_{i}^{\prime}(\rho)=Q_{i}^{T} d_{i}
$$

onde $Q_{\text {i }}$ representa 0 vetor gradiente calculado no ponto $\theta=$ $=\theta_{i} \cdot$

Sabemos rue $D_{i}^{\prime}(\rho)$ é a derivada direcional de $S$ relativa a d e $\theta_{i} e \theta_{i} \neq 0$.

Se $D_{i}^{\prime}(\rho)<0$, então $S(\theta)$ decresce. Portanto se $\rho$ é um número suficientemente pequeno, o passo od é aceitável. Por outro lado, se $D_{i}^{\prime}(\rho) \geq 0$, pode não existir um valor positivo de p para o qual od seja um passo aceitável. Portanto, chamamos d uma direção aceitável se

$$
D_{i}^{\prime}(p)<0 .
$$

Temos então o seguinte teorema. 
TEOREMA 1. A direção d é aceitável se e somente se,exis te uma matriz $R$ definida positiva tal que $d=-R_{i}[4 \cdot 2 \cdot 2 \cdot 3 . e]$.

PROVA: Seja R uma matriz definida positiva e d dada pela equação [4.2.2.3.e]. Então de [4.2.2.3. a] e da definição de matriz definida positiva,

$$
D_{i}^{\prime}(\rho)=\varrho_{i}^{T} d=-\rho_{i}^{T} R \Omega_{i}<0 .
$$

Suponhamos que $D_{i}^{\prime}(\rho)>0$.

Seja

$$
R=\left[I-\frac{Q_{i} \Omega_{i}^{T}}{\Omega_{i}^{T} Q_{i}}-\frac{d d^{T}}{d^{T} \Omega_{i}}\right]
$$

então, a equação $[4.2 .2 .3 . e]$ se verifica e $R$ é uma matriz de finida positiva.

Vimos anteriormente que uma direção é aceitável se $D_{i}^{\prime}(\rho)<0$. O teorema diz que esta condição pode ser assegurada se a direção é determinada pela operação de gradientes negativos com uma matriz definida positiva.

o método de minimizacão no qual as direções são obtidas desta maneira é denominado de método gradiente aceitável.

A equação básica da i-ésima iteração do mê-todo mencionado é: 


$$
\theta_{i+1}=\theta_{i}-\rho_{i} R_{i} Q_{i}
$$

4.2 .2 .4 - Finalização do processo iterativo

É necessário idealizar um critério para finalizar o processo iterativo. Espera-se que haja convergência para um ponto estacionário $\mathrm{S}(\theta)$. Por isso, é natural tomar como critério de finalização a anulação do gradiente $\Omega_{i}$. Porém, em muitos casos, o computador fornece estimativas dos parāmetros muito próximas do mínimo, e ainda assim o gradien te continua com tamanho considerável, e seu anulamento torna-se inatingivel mesmo aproximadamente. Por outro lado, se o algoritmo diverge, esse critério de finalização torna o pro cesso iterativo interminável.

Um critério ideal é finalizar o processo lo go que iterações suplementares falhem na mudança significati vamente dos parâmetros. Isto é, dado um conjunto de $\varepsilon_{\alpha}\left(\alpha=l_{x}\right.$, $2, \ldots, k)$ aceitamos $\theta_{i+1}$ como a solução, $\bar{\sigma}$, se

$$
\left|\theta_{i+1, \alpha}-\theta_{i, \alpha}\right| \leq \varepsilon_{\alpha} \quad[4.2 .2 .4 . a]
$$

onde,

$$
\begin{array}{r}
\theta_{1, \alpha} \text { é o } \alpha \text {-ésimo componente de } \theta_{i} \\
\text { Os números } \varepsilon_{\alpha} \text { podem ser pré-estabelecidos ou } \\
\text { calculados como sugere MAROUARDT }(1953):
\end{array}
$$




$$
\varepsilon_{a}=10^{-4}\left(\theta_{i, \alpha}+10^{-3}\right)
$$

onde o termo aditivo $10^{-3}$ é colocado para evitar os casos em que $\theta_{i, \alpha}$ são próximos de zero.

Uma vez finalizado o processo iterativo com $\theta=\theta$, e queremos saber se $\theta$ * está ou não próximo do mínimo, assumimos então que conhecemos o gradiente $\rho^{*}=\rho\left(\theta^{*}\right)$ e a ma triz hessiana $\mathbf{M}^{*}=\mathbf{M}^{*}\left(\theta^{*}\right)$ (matriz das derivadas segundas) ou alguma aproximação sua.

$$
\text { Se seccionarmos a superficie } S(\theta) \text { ao longo }
$$
dos eixos $\theta_{a}$, temos uma curva cuja equação aproximada nas vi zinhanças de $\vartheta *$ é dada por:

$$
P\left(\theta_{\alpha}\right)=S^{*}+Q_{\alpha}^{T}\left(\theta_{\alpha}-\theta_{\alpha}^{*}\right)+\frac{1}{2}\left(\theta_{\alpha}-\theta_{\alpha}^{*}\right)^{\mathrm{T}} \mathrm{M}_{\alpha \alpha}^{*}\left(\theta_{\alpha}-\theta_{\alpha}^{*}\right)
$$

a qual tem um ponto estacionärio

$$
\theta_{\alpha}=\theta_{\alpha}^{*}-\frac{\partial^{*}}{n_{\alpha \alpha}^{*}}
$$

Portanto, o valor $\delta_{\alpha}=\left|\mathrm{Q}_{\alpha}^{*} / \mathrm{M}_{\alpha \alpha}^{*}\right|$ é uma medida do erro na determinação de $\theta_{\alpha}^{*}$.

$$
\text { Se cada } \delta_{\alpha} \text { é pequeno, na mesma escala na qual }
$$

- a é medido, então $\theta$ * está próximo do mínimo de $S(\theta)$. 


\subsubsection{5 - Método de Marquardt para as esti- mativas dos parâmetros}

O método de Marquardt é uma interpolação en tre os métodos: Linearização e Steenest Descent. Tal interpolação é baseada sobre a máxima proximidade na qual a série truncada de Taylor dá uma adequada representação do modelo não linear.

Inicialmente faz-se o desenvolvimento da fun ção $f\left(x_{i}, \theta\right)$, pela série de Taylor, no ponto $\theta=\theta_{0}$ e temos

$$
f\left(x_{i}, \theta\right)=f\left(x_{i}, \theta_{0}\right)+\sum_{i=1}^{k}\left(\frac{\partial f_{i}}{\partial \theta_{j}}\right)\left(d_{t}\right)_{j} \quad[4 \cdot 2 \cdot 2 \cdot 5 \cdot a]
$$

obtendo-se o sistema de equações

$$
\begin{gathered}
M d_{t}=-Q \\
O \text { valor } d_{t} \text { é uma nequena correção para } \theta \text { e }
\end{gathered}
$$
o subscrito t é usado para designar que d foi calculado usan do a série de Taylor.

Uma vez obtida a direção $d_{t}$ do passo, o parâmetro deve ser corrigido apenas uma fração de $d_{t}$, pois de outro modo, pode ocorrer um passo inaceitável, fazendo com que saiamos da região onde $f\left(x_{i}, \theta\right)$ pode ser representada por [4.2.2.5.a], causando assim, a divergēncia do processo. Vários métodos tomam o tamanho do passo $\rho d_{t^{\prime}} 0 \leq 0 \leq 1$. 
O método do "Steepest Descent" simplesmente para confronto, toma a direção do gradiente negativo de $\mathrm{S}(\theta)$, assim:

$$
\nabla \Phi=-\left[\frac{\partial S}{\partial \theta_{I}}, \frac{\partial S}{\partial \theta_{2}}, \cdots, \frac{\partial S}{\partial \theta_{k}}\right]^{T} \quad[4 \cdot 2 \cdot 2 \cdot 5 \cdot b]
$$

Tanto no método de Linearização, como no "Steepest Descent", como em outros, é necessário controlar cuidadosamente o tamanho do passo, uma vez estabelecida a di reção do vetor correção. Ainda assim, em muitos casos, a con vergência é lenta.

Devido a esses problemas, é necessário os principios fundamentais envolvidos. Inicialmente um método deverá resultar no vetor correção cuja direção está dentro de $90^{\circ}$ do gradiente negativo de $\mathrm{S}(\theta)$, pois de outra forma os va lores de $S\left(X_{i}, \theta\right)$ podem ser esperados maiores do que menores ao longo do vetor correção. Fm sequida, devido ao rigoroso alongamento da superfície de $S\left(x_{i}, \theta\right)$, na maioria dos problemas, $d_{t}$ é usualmente quase sempre $90^{\circ}$ afastado de $\nabla \mathbf{\varphi}$. Dessas considerações, é razoável interpolar entre $\mathrm{d}_{t} \mathrm{e} \nabla \phi$.

No método de Marquardt, a direção e o tamanho do passo são determinados simultaneamente.

Este método de Marquardt baseia-se no fato de que, se uma matriz qualquer é definida positiva $N$, consequentemente teremos $M+\lambda N$ definida positiva, para $\lambda$ sufici- 
entemente grande, qualquer que seja a matriz M.

A matriz M é a aproximação da matriz Hessia na do método de Gauss e s é uma matriz diagonal com elementos

$$
n_{i i}= \begin{cases}\left(m_{i i}\right)^{1 / 2}, & \text { se } m_{i i} \neq 0 \\ 1, & \text { se } m_{i i}=0\end{cases}
$$

A fórmula iterativa do método é dada nor:

$$
\theta_{i+1}=\theta_{i}-\left(M_{i}+\lambda_{i} N_{i}\right)^{-1} \Omega_{i} \quad[4 \cdot 2 \cdot 2 \cdot 5 \cdot \mathrm{C}]
$$

A descrição detalhada do método pode ser vista nos trabalhos de SILVA (1980) e UDO (1983).

De acordo com a equação [4.2.2.1.b], a condição necessária para que $\bar{\theta}$ seja um ponto de mínimo de $\mathrm{S}(\theta)$ é que, neste ponto seja anulado o vetor gradiente $\Omega(\theta)$ de $S$ e seja definida positiva a matriz Hessiana $M(\bar{\theta})$.

Para que se possa aplicar o método de Marquardt, devemos obter as derivadas parciais de primeira e de segunda ordem da função estudada.

Então é dado:

$$
\begin{aligned}
f_{i} & =f\left(x_{i}, \theta\right) \\
f_{i j} & =\frac{\partial f\left(x_{i}, 0\right)}{\partial \theta_{j}}
\end{aligned} \quad(i=1,2, \ldots, n ; j, k=1,2,3,4)
$$




$$
f_{i j k}=\frac{\partial^{2} f\left(x_{i}, \theta\right)}{\partial \theta_{j} \partial \theta_{k}}
$$

Desta forma, as derivadas parciais de primei-

ra ordem nara a equação:

$$
y_{i}=A\left[1-10^{-C\left(X_{i}+b\right)}\right] 10^{-k\left(x_{i}+b\right)^{2}}
$$

com uma variável independente e guatro parâmetros: ${ }_{1}^{0}=\mathrm{A}$, ${ }_{\theta_{2}}=C, \theta_{3}=b$ e $\theta_{4}=k$, são dadas por:

$$
\begin{aligned}
& \frac{\partial f\left(X_{i}, \theta\right)}{\partial \theta_{1}}=f_{1}=\left[1-10^{-C\left(X_{i}+b\right)}\right] 10^{-k\left(X_{i}+b\right)^{2}} \\
& \frac{\partial f\left(X_{i}, \theta\right)}{\partial \theta_{2}}=f_{2}=A(L I 0)\left(X_{i}+b\right) 10^{-C\left(X_{i}+b\right)} 10^{-k\left(X_{i}+b\right)^{2}} \\
& \frac{\partial f\left(X_{i}, \theta\right)}{\partial \theta_{3}}=f_{3}=A(L 10) 10^{-k\left(X_{i}+b\right)^{2}}\left[C \cdot 10^{-c\left(X_{i}+b\right)}-2 k\left(X_{i}+b\right)\right]\left[I-10^{-C\left(X_{i}+b\right)}\right] \\
& \frac{\partial f\left(X_{i}, \theta\right)}{\partial \theta_{4}}=f_{4}=-\left(X_{i}+b\right)^{2} A(L I 0) 10^{-k\left(X_{i}+b\right)^{2}}\left[I-10^{-C\left(X_{i}+b\right)}\right]
\end{aligned}
$$

Através da equação $[4 \cdot 2 \cdot 2 \cdot 5 . e]$, poodemos obter as derivadas parciais de 2 a ordem para os parámetros:

$$
\begin{aligned}
& \frac{\partial f\left(X_{i}, \theta\right)}{\partial \theta_{1}{ }^{\partial \theta_{1}}}=0 \quad ; \frac{\partial f\left(X_{i}, \theta\right)}{\partial \theta_{1} \partial \theta_{2}}=(I, 10)\left(X_{i}+b\right) 10^{-C\left(X_{i}+b\right)} 10^{-k\left(X_{i}+b\right)^{2}} \\
& \frac{\partial f\left(x_{i}, \theta\right)}{\partial \theta_{1} \partial \theta_{3}}=(\operatorname{Lr} 10) 10^{-k\left(x_{i}+b\right)^{2}}\left\{c \cdot i 0^{-C\left(X_{i}+b\right)}-2 k\left(x_{i}+b\right)\left[1-10^{-C\left(x_{i}+b\right)}\right]\right\}
\end{aligned}
$$




$$
\begin{aligned}
& \frac{\partial \mathrm{f}\left(\mathrm{x}_{i}, \theta\right)}{\partial \theta_{1} \partial \theta_{4}}=-\mathrm{L}(10)\left(\mathrm{x}_{i}+\mathrm{b}\right)^{2} 10^{-\mathrm{k}\left(\mathrm{x}_{i}+\mathrm{b}\right)^{2}}\left[1-10^{-\mathrm{C}\left(\mathrm{x}_{\mathrm{i}}+\mathrm{b}\right)}\right] \\
& \frac{\partial \mathrm{f}\left(\mathrm{x}_{\mathrm{i}}, \theta\right)}{\partial \theta_{2} \partial \theta_{2}}=-\mathrm{A}(\mathrm{L} L \mathrm{l})^{2} \quad\left[10^{-\mathrm{C}\left(\mathrm{x}_{\mathrm{i}}+\mathrm{b}\right)} 10^{-\mathrm{k}\left(\mathrm{x}_{\mathrm{i}}+\mathrm{b}\right)^{2}}\left(\mathrm{x}_{\mathrm{i}}+\mathrm{b}\right)^{2}\right] \\
& \frac{\partial f\left(X_{i}, \theta\right)}{\partial \theta_{2} \partial \theta_{3}}=A(L 10) 10^{-c\left(X_{i}+b\right)} 10^{-k\left(X_{i}+b\right)^{2}}\left\langle I-\left(X_{i}+b\right)(L I 0)\left[c+2 k\left(X_{i}+b\right)\right]\right\rangle \\
& \frac{\partial \mathrm{f}\left(\mathrm{x}_{i}, \theta\right)}{\partial \theta_{2}{ }^{\partial \theta} 4}=-\mathrm{A}(\mathrm{LIO})^{2}\left[\left(\mathrm{x}_{i}+\mathrm{b}\right)^{3} 10^{-\mathrm{C}\left(\mathrm{x}_{i}+\mathrm{b}\right)} 10^{-\mathrm{k}\left(\mathrm{x}_{i}+\mathrm{b}\right)^{2}}\right] \\
& \frac{\partial f\left(x_{i}, \theta\right)}{\partial \theta_{3} \partial \theta_{3}}=-A(L 10) 10^{-k\left(x_{i}+b\right)^{2}}\left\{\begin{array}{l}
c(L I 0) 10^{-c\left(x_{i}+b\right)}\left[c+4 k\left(x_{i}+b\right)\right]+ \\
+2 k\left[1-10^{-c\left(x_{i}+b\right)}\right]\left[1-2 k(L 10)\left(x_{i}+b\right)^{2}\right]
\end{array}\right\}
\end{aligned}
$$

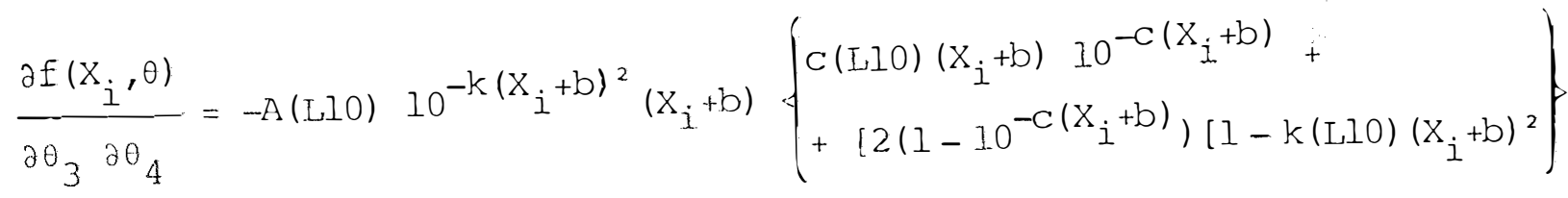

$$
\begin{aligned}
& \frac{\partial f\left(x_{i}, \theta\right)}{\partial \theta_{4} \partial_{4}}=A(L 10)^{2}\left(x_{i}+b\right)^{4} 10^{-k\left(x_{i}+b\right)^{2}}\left[1-10^{-c\left(x_{i}+b\right)}\right] \\
& \frac{\partial \mathrm{f}\left(\mathrm{X}_{i^{\prime}}, \theta\right)}{\partial \theta_{2} \partial \theta_{1}}=\frac{\partial \mathrm{f}\left(\mathrm{X}_{i^{\prime}}, \theta\right)}{\partial \theta_{1} \partial \theta_{2}} \\
& \frac{\partial \mathrm{f}\left(\mathrm{X}_{\mathbf{i}}, \theta\right)}{\partial \theta_{3} \partial \theta_{1}}=\frac{\partial \mathrm{f}\left(\mathrm{X}_{\dot{i}}, \theta\right)}{\partial \theta_{1}{ }^{\partial \theta}{ }_{3}}
\end{aligned}
$$


43.

$$
\begin{aligned}
& \frac{\partial f\left(X_{i}, \theta\right)}{\partial \theta_{3} \partial \theta_{2}}=\frac{\partial f\left(X_{i}, \theta\right)}{\partial \theta_{2} \partial \theta_{3}} \\
& \frac{\partial f\left(X_{i}, \theta\right)}{\partial \theta_{4} \partial \theta_{1}}-\frac{\partial f\left(X_{i}, \theta\right)}{\partial \theta_{I} \partial \theta_{4}} \\
& \frac{\partial f\left(X_{i}, \theta\right)}{\partial \theta_{4} \partial \theta_{2}}-\frac{\partial f\left(X_{i}, \theta\right)}{\partial \theta_{2} \frac{\partial \theta_{4}}{}} \\
& \frac{\partial f\left(X_{i}, \theta\right)}{\partial \theta_{4} \partial \theta_{3}}=\frac{\partial f\left(X_{i}, \theta\right)}{\partial \theta_{3} \partial \theta_{4}}
\end{aligned}
$$

Para a soma de quadrados dos erros $\mathrm{S}(\theta)$ obtém-se um vetor gradiente $Q$ de componentes $o_{j}(j=1,2,3,4)$ :

$$
Q_{j}=\frac{\partial S}{\partial \theta_{j}}=-2 \sum_{i=1}^{n}\left(Y_{j}-f_{i}\right) E_{i j},
$$

e a matriz Hessiana de elementos $m_{j k}(j, k=1,2,3,4)$ :

$$
m_{j k}=\frac{\partial^{2} S}{\partial \theta_{j} \partial \theta_{k}}=2 \sum_{i=1}^{n} f_{i j} f_{i k}-2 \sum_{i=1}^{n}\left(Y_{i}-f_{i}\right) f_{i j k} \cdot
$$


4.3 - Cálculo do Máximo das Funções

4.3 .1 - Modelo quadrático

o ponto de máximo para esse modelo foi calculado através da derivada da função em relação a $x$.

Dado o modelo:

$$
\begin{aligned}
Y & =A+B X+C X^{2} \\
\frac{\partial Y}{\partial X} & =Y^{\prime}=B+2 C X
\end{aligned}
$$

Fazendo $\frac{\partial Y}{\partial X}=0$, tem-se o ponto critico:

$$
\begin{aligned}
B+2 C X & =0 \\
x & =\frac{-B}{2 C} .
\end{aligned}
$$

A condição necessária para que haja o ponto de máximo, é que a derivada sequnda $\frac{\partial^{2} Y}{\partial X^{2}}<0$. Loqo

$$
\frac{\partial^{2} Y}{\partial X^{2}}=Y^{\prime \prime}=2 C
$$

Mas $\frac{\partial^{2} y}{\partial X^{2}}$ só será negativa se $C<0$.

Assim, a dose de calcário que irá proporcionar a maior produção de soja, a produção máxima, será dada nor: 


$$
Y=A-\frac{B^{2}}{4 C}
$$

isto quando substituimos o ponto crítico na função oriquinal.

$$
4.3 .2 \text { - Modelo raiz quadrada }
$$

De maneira semelhante ao modelo quadrático,

obtemos:

tico:

$$
\frac{\partial Y}{\partial X}=Y^{\prime}=\frac{B}{2 \sqrt{X}}+C \text {. }
$$

Fazendo $\frac{\partial Y}{\partial X}=0$, obtemos então o ponto crí-

$$
\begin{aligned}
\frac{B}{2 \sqrt{X}}+C & =0 \\
B+2 C \sqrt{X} & =0 \\
\sqrt{X} & =\frac{-B}{2 C} \\
X & =\frac{B^{2}}{4 C^{2}} .
\end{aligned}
$$

A derivada segunda da função será:

$$
\begin{aligned}
& \frac{\partial^{2} Y}{\partial X^{2}}=-\frac{B}{4 \sqrt[3]{X}} \\
& \frac{\partial^{2} Y}{\partial X^{2}}<0
\end{aligned}
$$

haverá um ponto de máxímo se $B>0$. 
Substituindo o ponto crítico na função, obtemos a produção máxima.

$$
X=\frac{B^{2}}{4 C^{2}} \text { e } \sqrt{X}=\frac{-B}{2 C},
$$

entล่อ

$$
\begin{aligned}
& Y=A+B \sqrt{X}+C X \\
& Y=A+B\left(\frac{-B}{2 C}\right)+C\left(\frac{B^{2}}{4 C^{2}}\right) \\
& Y=A-\frac{2 B^{2}}{4 C}
\end{aligned}
$$

4.3 .3 - 2ạ aproximação de Mitscherlich

Como esta função é não linear nos parãmetros a determinação do seu ponto de máximo é um tanto complexa, e serā necessário utilizar métodos específicos para este fim.

$$
\text { Após as estimativas dos parâmetros da } 2 \text { ạ apro }
$$
ximação de Mitscherlich, expressa por:

$$
Y_{i}=A\left[1-10^{-C\left(X_{i}+b\right)}\right] 10^{-k\left(X_{i}+b\right)^{2}}+e_{i}
$$

verifica-se o valor da estimativa $\hat{k}$. Se $\vec{k}>0$ haverá um ponto de máximo, o qual poderá ser determinado nelo métoro de Newton-Raphson, ou através do teorema de Rolle diretamente. 
4.3.3.1 - Método de Newton Raphson

Este método é baseado na fórmula iterativa

dada por:

$$
r_{i+1}=r_{i}-F\left(r_{i}\right) / F^{\prime}\left(r_{i}\right)
$$

onde:

$$
\begin{aligned}
& F(r)=\frac{d f(r, \hat{\theta})}{d r} \\
& F^{\prime}(r)=\frac{d^{2} f(r, \hat{\theta})}{d r^{2}} .
\end{aligned}
$$

O programa de computador utilizado para o cálculo do ponto de máximo encontra-se no Apêndice, e foi de senvolvido por MAGNANI (1985).

$$
\begin{aligned}
& 4.3 .3 .2 \text { - Método direto através do teorema } \\
& \text { de Rolle }
\end{aligned}
$$

Consiste este processo em verificar em que ponto a função muda de crescente para decrescente. Com este objetivo, inicia-se o processo, tomando-se um valor $\Delta x$ arbitrário. A partir de um valor inicial $\mathrm{x}$ acrescemos a ele o va lor $\Delta X$, verificando-se, em cada ponto, o sinal de $\Delta Y$. Quando há uma mudança de sinal, reoete-se o processo tomando-se como $\wedge \mathrm{X} \circ \operatorname{valor} \frac{\Delta \mathrm{X}}{2}$ e como $\mathrm{X}$ inicial $\mathrm{X}$ anterior à mudança de 
sinal. Repete-se este processo até obter

$$
\left|\hat{Y}_{i+1}-\hat{Y}_{i}\right|<\varepsilon \quad,
$$

isto é, até que a diferença entre o passo atual e o anterior seja menor que um valor pequeno pré-determinado.

o programa de computador usado no trabalho foi desenvolvido por UDO (1983), e encontra-se no Aọendice.

4.4 - Dose Econômica do Calcário

Uma dose de calcário é denominada economica mente ótima quando, através dela, pode-se maximizar a função da renda líquida da produção.

A função da renda líquida é representada por:

$$
L=V Y-E_{I} X-E_{O}
$$

onde, y é a produção de soja obtida com as doses de calcário; V é o preço da soja, em kg;

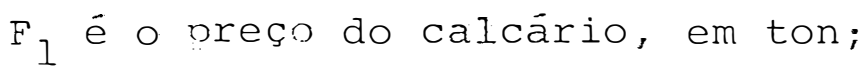
Fo são os custos fixos. 
49.

Para se determinar a dose de calcário que torne a renda İquida máxima, é necessário que:

$$
\frac{\partial I}{\partial X}=0
$$

Considerando a função [4.4.a] obtemos:

$$
\begin{aligned}
& \frac{\partial L}{\partial X}=\frac{\partial Y}{\partial X} \cdot V-F_{I} \\
& \frac{\partial Y}{\partial X} \cdot V-F_{I}=0 \\
& \frac{\partial Y}{\partial X}=\frac{E_{I}}{V}
\end{aligned}
$$

Seja $x^{*}$. o valor que satisfaz a equação [4.4.b]. Para que a função [4.4.a] atinja um máximo no ponto de abcissa $x^{*}$, deve-se ter:

$$
\frac{\partial^{2} Y}{\partial X^{2}}<0
$$


4.5 - Análise de Variāncia

As análises de variância para os experimentos de Campo Mourāo e de Guarapuava serão feitas de maneira usual, como o esquema da Tabela 2.

Tabela 2 - Esquema de anālise de variāncia.

\begin{tabular}{lc}
\hline Causas de Variação & Graus de Liberdade \\
\hline Blocos & $(b-1)$ \\
Calcário & $(t-1)$ \\
Resíduo & $(b-1)(t-1)$ \\
\hline Total & $b t-1$ \\
\hline
\end{tabular}

onde,

b é o número de blocos;

t é o número de tratamentos (doses de calcário).

Independente da significāncia do teste $F$ p̣a ra tratamentos, foram realizadas as análises de regressão pạ ra os três modelos, nos dois locais, conforme o esquema da Tabela 3 . 
Tabela 3 - Esquema de análise de regressão.

\begin{tabular}{lc}
\hline Causas de Variação & Graus de Liberade \\
\hline Regressão & $p-1$ \\
Desvios da Regressão & $t-p$ \\
\hline (Calcário) & $(t-1)$ \\
Blocos & $b-1$ \\
Resíduo & $(b-1)(t-1)$ \\
\hline Total & $b t-1$
\end{tabular}

onde p é o número de parâmetros do modelo de regressão.

Para os modelos quadrático e raiz quadrada, as somas de quadrados de regressão serão:

$$
S \Omega \text { Reg. }=r\left(\bar{\beta} X^{\prime} Y-C\right)
$$

e a soma de quadrados dos desvios de regressão será:

SQ Desv.Reg. = SQ Calcário - Sọ Reg.

Para a 2ạ aproximação de Mitscherlich a soma de quadrados dos desvios será:

$$
\mathrm{SQ} \text { Desv.Req. }=r \sum_{i=1}^{\mathrm{n}}\left(\bar{Y}_{i}-\underline{\underline{Y}}_{i}\right)^{2},
$$

e a soma de quadrados de reqressão é expressa nor:

$$
\text { So Req. = SQ Calcário - So Desv.Req. }
$$


Os coeficientes de determinação $R^{2}$ e $\bar{R}_{A}^{2}$ para os três modelos, serão calculados por:

$$
\mathrm{R}^{2}=\frac{\mathrm{SQR \text {Reg. }}}{\mathrm{S} Q \text { Calcário }}
$$

quando o resíduo não se confunde com os desvios de regressão, e

$$
\bar{R}_{A}^{2}=R^{2}-\frac{p-I}{t-p}\left(I-R^{2}\right),
$$

onde,

p é o número de parâmetros do modelo de regressão;

t é o número de tratamentos.

o coeficiente de determinação ajustado foi proposto por HOFFMANN e VIEIRA (1983). Os autores afirmam que o coeficiente de determinação é uma medida descritiva da qua lidade do ajustamento obtido. Como o valor de $\mathrm{R}^{2}$ depende do nümero de observações da amostra, os autores aconselham o uso do $\overline{\mathrm{R}}_{\mathrm{A}}^{2}$ ajustado para graus de Iiberdade. 


\section{6 - Critérios para Avaliar o Ajuste dos Modelos Estuda- dos}

\section{Frequentemente encontra-se na literatura a}

utilização dos valores de $\mathrm{R}^{2}, \overline{\mathrm{R}}_{\mathrm{A}}^{2}$ e do Desvio de Regressão para avaliar a qualidade do ajustamento de um modelo. Muitos são os autores que utilizam dessas estatisticas. Podemos citar DRAPER e SMITH (1966), NETER e WASSERMAN (1974), PIMENTEL GOMES (1973), HOFFMANN e VIEIRA (1983), entre outros.

Existem também autores que acham necessários outros critérios além desses mencionados acima. NELDER (1966), SPARROW (1979), em trabalhos com dados experimentais de adubação, afirmam que um valor alto para o coeficiente de deter minação $\left(\mathrm{R}^{2}\right)$ ou quadrado médio do Desvio de Reqressão em experimentos simples, não deve ser qarantia de um modelo bem ajustado.

Considerando as afirmações de NELDER (1966) e SPARROW (1979), serão aplicados os critérios: Critério da Informação de Akaike e o Critério do Total de Postos, para os dados deste trabalho. 


\subsection{1 - Critério de informação de Akaike}

Este critério foi desenvolvido por AKAIKE (1971) e será utilizado na comparação de modelos matemáticos, com o objetivo de se detectar os que melhor se ajustam aos dạ dos experimentais. Foi citado por SPARRON (1979) e pode ser aplicado a modelos que tenham diferentes números de parâmetros.

$$
\begin{aligned}
& \text { A exporessão deste critério é dada por: } \\
& \text { AIC }=-2 \text { ln (máxima verossimilhança) }+ \\
& +2 \text { (no de parâmetros indep̣endentes ajustados) } \\
& \text { Assumindo-se que os erros têm distribuição }
\end{aligned}
$$

normal, esta expressão terá a seguinte forma:

$$
\operatorname{AIC}_{(k)}=n \text { ln SQ Residual }(k)+2 k \text {, }
$$

onde,

n é o nümero de pontos estimados;

k é o número de parâmetros de cada modelo ajustado;

sores. (k) é a soma de quadrados do desvio de regressão.

A avaliação do modelo ajustado com este cri tério será feita considerando o AIC mỉnimo, devendo coincidir também com o Suadrado Médio do Desvio de Regressão Mínimo ( MMRM) . 
4.6.2 - Critério do total de postos (estatística de ordem

Este critério foi também utilizado por SPAR ROW (1979), com o objetivo de confirmar os resultados obtidos através dos critérios mencionados anteriormente.

Baseia-se na avaliação do quadrado médio re sidual após o ajuste do modelo. Com este objetivo, o autor atribuiu diferentes valores de postos. Para o quadrado médio de desvio de regressão mínimo, atribuiu-se o posto 3 , para o quadrado médio de desvio de regressão intermediário o nosto 2, e para o quadrado médio de desvio de regressão máximo o posto 1 .

Portanto, o modelo que obtivesse o maior to tal de postos seria o modelo que melhor se ajustaria aos dados.

O procedimento do critério está descrito abaixo .

Dado $n$ conjuntos de experimentos com $n$ variāncias residuais, e estes experimentos ajustados a $n$ modelos, calculamos os totais de postos para cada modelo sequndo o quadro a seguir. 


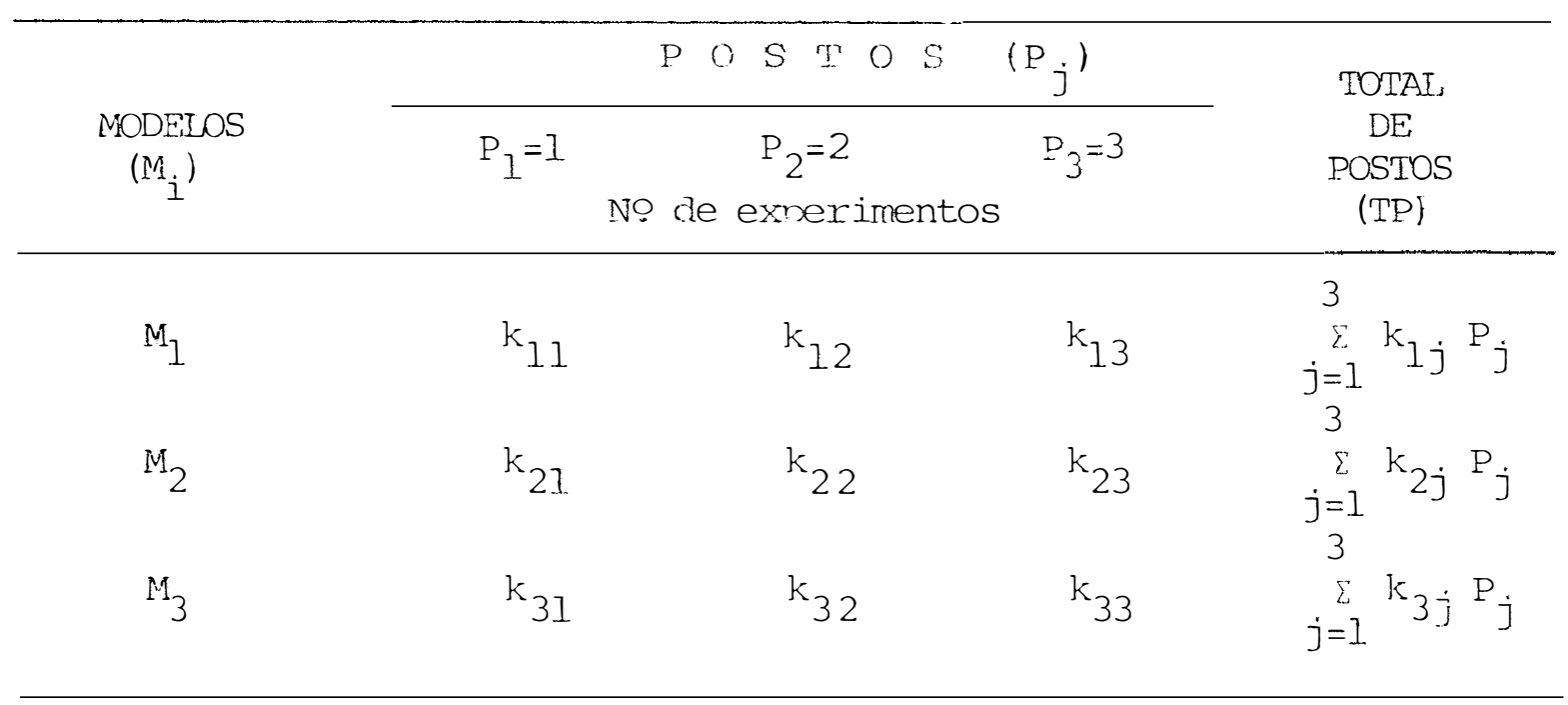

onde, $M_{i}$ são os modelos estudados, $i=1,2,3$;

$P_{j}$ são os postos dados aos nuadrados Médios de Desvios de Regressão, $j=1,2,3$;

$k_{i j}$ são os totais de experimentos com ouadrados Médios de Desvios de Regressão máximos, intermediários e mí nimos, $i=1,2,3 ; j=1,2,3$.

Log̣o, o total de postos para cada modelo é dạ do por:

$$
T P=\sum_{i, j=1}^{3} k_{i j} \quad P_{j} \text {. }
$$


4.7 - Programação da Metodologia

Foram utilizados inicialmente o processamen to das análises feitas através dos computadores IBM 4341 da EMBRAPA de Brasilia, POLYMAX 201 DP do Centro Nacional de Pes quisa de Soja, de Londrina. O programa utilizado para estimar os parâmetros da equação da 2 ạ ap̣roximação de Mitscherli ch e a determinação do ponto de máximo foi desenvolvido por MAGNANI (1985). Foi utilizado também o programa de UDO (1983) para a determinação do ponto de máximo.

Os procramas de MAGNANI (1985) e UDO (1983) foram processados nos computadores de várias instituições de pesquisa, como Planalsucar e Instituto Agronōmico do Paraná. 
58.

5. RESULTADOS E DISCUSSÃO

Neste capitulo são apresentados e discuti dos os resultados dos valores iniciais utilizados para este trabalho, bem como as estimativas dos parâmetros, valores do teste $F$ para calcário, teste $F$ para a Reqressão e para Desvios de Regressão. São apresentados também os resultados dos critêrios utilizados para a comparação dos três modelos, nos dois locais, e os gráficos correspondentes a cada modelo e local.

Os resultados das análises de variāncia,aná lises de regressão, os valores de $Y$ observados, $\widehat{Y}$ estimados, desvios, e equações de regressão, considerados resultados com plementares, estão nas Tabelas de nümeros 34 a 35 e 47 a 124 do Apêndice. 
5.1 - Valores Iniciais das Estimativas dos Parâmetros da 2ạ Aproximação de Mitscherlich

Em estudos de modelos não lineares nos parâ metros, é semp̣re exigido que o processo de estimação seja itẹ rativo. O processo necessita de valores $\theta_{0_{i}}(i=1,2, \ldots, k)$ dos parâmetros $\theta_{i}(i=1,2, \ldots, k)$.

Estes valores devem ser bem selecionados, pois depende deles a rápida converqência do modelo.

Segundo Draper e Smith (1966), citados Dor SILVA (1978), pode ser usado como valor inicial $\theta_{0}$, qualquer informação anteriormente obtida de $\theta$.

Neste trabalho foram utilizados como valores iniciais de alguns parâmetros, valores próximos dos resultados obtidos por SILVA (1978). O valor inicial de A uti lizado foi o mais próximo possivel da maior produção experimental. Inicialmente, quando obtidas as estimativas dos parâa metros, foi observado o número de iterações. Se este número era alto, variava-se o valor de Ao próximo ao obtido anteriormente. Este procedimento ocasionou desvantagens quando comparado com o método utilizado oor UDO (1983). Esta autora fixou intervalos para todos os parâmetros, fazendo todas as combinações possíveis. Para cada combinação, calculou as somas de quadrados dos desvios. Onde as somas de quadrados fo- 
ram minimas, selecionou o valor inicial dos parāmetros, obtendo valores mais confiáveis dessas estimativas. Entretanto, devido ao desconhecimento dos parāmetros, optou-se pelo procedimento citado para poder sentir melhor o método.

Os valores iniciais utilizados para este tra balho estão nas Tabelas 20 e 21 do Apêndice.

5.2 - Ajuste dos Modelos

5.2.1 - Ajustamento dos modelos aos dados experimen tais de Campo Mourão

Pelos resultados da Tabela 46 do Ap̣êndicẹ, verificou-se a possibilidade de desdobrar os graus de liberdade do calcário, levando em conta a regressão para os três modelos.

\subsubsection{1 - Modelo quadrático e modelo raiz quadrada}

As estimativas dos parâmetros para estes mo delos foram obtidos pelo método dos quadrados mínimos, conforme apresentado em 4.2.1.

Estas estimativas estão nas Tabelas 4 e 5, e pode-se notar que houve um ponto de minimo quando foi utilizado o modelo raiz quadrada, com os dados experimentais do ano agricola $81 / 82$. 
Tabela 4 - Estimativas dos parâmetros do modelo quadrático, para os expe rimentos de Carmpo Mourão. Anos: 78/79 a 83/84.

\begin{tabular}{|c|c|c|c|}
\hline \multirow{2}{*}{ ANOS } & \multicolumn{3}{|c|}{$\mathrm{P} A \mathrm{~A} \overline{\mathrm{A}} \mathrm{METR} \mathrm{OS}$} \\
\hline & $\widehat{\mathrm{A}}$ & $\widehat{\mathrm{B}}$ & $\widehat{\mathrm{C}}$ \\
\hline $78 / 79$ & $2.066,00$ & 63,9120 & $-3,7890$ \\
\hline $79 / 80$ & $1.892,00$ & 251,2486 & $-18,0948$ \\
\hline $80 / 81$ & $2.658,30$ & 278,8035 & $-18,9642$ \\
\hline $81 / 82$ & $1.646,00$ & 95,1535 & $-1,0892$ \\
\hline $82 / 83$ & $2.479,00$ & 279,2826 & $-19,5279$ \\
\hline $83 / 84$ & $2.32 .5,00$ & 215,3361 & $-12,9296$ \\
\hline
\end{tabular}

Tabela 5 - Estimativas dos parâmetros do modelo raiz quadrada para cs ex perimentos de Campo Mourão. Anos: 78/79 a 83/84.

\begin{tabular}{cccc}
\hline \multirow{2}{*}{ ANOS } & \multicolumn{3}{c}{ P A R A M E T R O S } \\
\cline { 2 - 4 } & $\overline{\mathrm{A}}$ & $\overline{\mathrm{B}}$ & \multicolumn{1}{c}{$\mathrm{C}$} \\
\hline $78 / 79$ & $2.069,00$ & 89,5807 & - \\
$79 / 80$ & $1.756,00$ & 738,1154 & $-145,9005$ \\
$80 / 81$ & $2.577,00$ & 654,5372 & $-102,5578$ \\
$81 / 82$ & $1.654,00$ & 13,0182 & 80,4520 \\
$82 / 83$ & $2.423,00$ & 618,5724 & $-97,1804$ \\
$83 / 84$ & $2.332,00$ & 301,2572 & - \\
\hline
\end{tabular}


5.2.1.2 - Modelo da 2ạ aproximação de MitscherIich

Para este modelo, as estimativas dos parâme tros foram obtidas pelo método de Marquardt, devido a este modelo ser não linear nos parâmetros, de acordo com 4.2.6. Estas estimativas são apresentadas na Tabela 6 .

Tabela 6 - Estimativa dos parāmetros da 2ạ aproximação de Mitscherlich, para os experimentos de Campo Mourão. Anos: 78/79 a 83/84.

\begin{tabular}{lcrrrr}
\hline & & \multicolumn{5}{c}{ P A R A M E T R O S } \\
\cline { 3 - 6 } ANOS & I T* & \multicolumn{1}{c}{$\overline{\mathrm{A}}$} & \multicolumn{1}{c}{$\mathrm{C}$} & $\hat{\mathrm{K}}$ \\
\hline $78 / 79$ & 34 & $5.331,85$ & 15,1134 & 0,0166 & 0,000238 \\
$79 / 80$ & 30 & $2.596,78$ & 0,4844 & 0,9909 & $-0,000130$ \\
$80 / 81$ & 28 & $3.603,01$ & 2,2707 & 0,2416 & $-0,000012$ \\
$81 / 82$ & 33 & $2.662,90$ & 11,5725 & 0,0338 & $-0,000131$ \\
$82 / 83$ & 12 & $4.038,23$ & 3,7271 & 0,1104 & 0,000358 \\
$83 / 84$ & 15 & $4.078,00$ & 5,3984 & 0,0692 & 0,000281 \\
\hline
\end{tabular}

$\overline{\mathrm{X}}_{I T}=25$

* IT = No de iterações necessárias para a convergência do modelo.

Na Tabela 6 pode-se verificar que, em média, foram necessárias 25 iterações para que o modelo convergisse. Outro ponto a ressaltar é que o parâmetro k na 2ạ aproximação de Mitscherlich deve ser positivo, pois isso é uma exigência para a obtenção do ponto de máximo, o que não ocor 
reu, entretanto, com todos os anos agricolas deste conjunto de dados experimentais. Para o solo de Campo Mourão, não hou ve grandes acréscimos na produção com a aplicação do cal cário, devido a baixa concentracão de aluminio trocável.

Com estas estimativas, pōde-se fazer as anā lises de regressão para os três modelos, com os experimentos de Campo Mourão, de acordo com o indicado no Capitulo 4.5. Os valores do teste $F$ para a regressão e desvios da re gressão são apresentados na Tabela 7 .

Tabela 7 - Valores do teste $\mathrm{F}$ para regressão e desvios de reqressão para os modelos: quadrático, raiz quadrada e 2ạ aproximação de Mitscherlich, para os experimentos de Campo Mourão.

\begin{tabular}{|c|c|c|c|c|c|c|}
\hline \multirow{2}{*}{ ANOS } & \multicolumn{2}{|c|}{ Quadrātico } & \multicolumn{2}{|c|}{ Raiz Quadrada } & \multicolumn{2}{|c|}{$\begin{array}{l}\text { 2a Anroximação } \\
\text { de Mitscherlich }\end{array}$} \\
\hline & Regressão & $\begin{array}{l}\text { Desvios } \\
\text { de Reg. }\end{array}$ & Regressão & $\begin{array}{l}\text { Desvios } \\
\text { de Reg. }\end{array}$ & Regressão & $\begin{array}{l}\text { Desvios } \\
\text { de Reg. }\end{array}$ \\
\hline $78 / 79$ & $12,06 * \star$ & $0,76 \mathrm{NS}$ & $22,75 * \star$ & $0,91 \mathrm{NS}$ & $8,04 * *$ & $1,13 \mathrm{NS}$ \\
\hline $79 / 80$ & $12,08 * *$ & $2,06 \mathrm{NS}$ & $14,68 * *$ & $0,32 \mathrm{NS}$ & $10,05 * *$ & $0,09 \mathrm{NS}$ \\
\hline $80 / 81$ & $54,74 * \star$ & $2,08 \mathrm{NS}$ & $56,91 * *$ & $0,62 \mathrm{NS}$ & $37,73 * \star$ & $1,26 \mathrm{NS}$ \\
\hline $81 / 82$ & $24,39 * *$ & $1,17 \mathrm{NS}$ & $24,36 * \star$ & $1,19 \mathrm{NS}$ & $16,26 * \star$ & $1,75 \mathrm{NS}$ \\
\hline $82 / 83$ & $15,35 * \star$ & $0,22 \mathrm{NS}$ & $15,17 \star \star$ & $0,35 \mathrm{NS}$ & $10,33 * \star$ & $0,20 \mathrm{NS}$ \\
\hline $83 / 84$ & $33,81 * *$ & $0,64 \mathrm{NS}$ & $65,32 * \star$ & $1,06 \mathrm{NS}$ & $22,63 * *$ & $0,83 \mathrm{NS}$ \\
\hline
\end{tabular}


Nota-se que, para os três modelos, os valores do teste $F$ para regressão foram altamente significativos, dificultando assim detectar qual o modelo que melhor se ajustou, visto que os desvios de reqressão para os três modelos não foram significativos em nenhum dos anos agrícolas, para os dados experimentais de Campo Mourão.

Este resultado contraria em parte os dos es tudos realizados por UDO (1983) e SILVA (1978), onde as autoras encontraram, para os modelos quadrático e raiz quadra da, valores do teste $F$ significativos para os desvios de re gressão.

Como este critério estatístico não foi sufi ciente para detectar quais dos modelos melhor se ajustaram aos dados, fez-se a comparação dos mesmos através da aplica ção de outros critérios de avaliação além do $\mathrm{R}^{2}, \overline{\mathrm{R}}_{\mathrm{A}}^{2}$ e do Quadrado Médio do Desvio de Regressão Mínimo. Estes critérios são: o Critério de Informação de Akaike (AIC) e o Total de Postos (TP), apresentados nas Tabelas 8 e 9 . 
Tabela 8 - Valores de $\mathrm{R}^{2}, \overline{\mathrm{R}}_{\mathrm{A}}^{2}$, MDRM e AIC, para os modelos quadráticos, raiz quadrada e 2ạ aproximação de Mitscherlich, com os experimentos de Campo Mourão. Anos: 78/79 a 83/84.

\begin{tabular}{|c|c|c|c|c|c|}
\hline ANOS & MODEIOS & $\mathrm{R}^{2}$ & $\overline{\mathrm{R}}_{\mathrm{A}}^{2}$ & SMDRM & AIC* \\
\hline & Quadrático & 0,91 & 0,85 & $7.086,52$ & 65,78 \\
\hline \multirow[t]{3}{*}{$78 / 79$} & Raiz quadrada & 0,86 & 0,83 & $8.497,94$ & 66,60 \\
\hline & 2ạ aprox. Mitscherlich & 0,78 & 0,45 & $10.556,72$ & 67,74 \\
\hline & Quadrático & 0,80 & 0,67 & $185.082,21$ & 85,36 \\
\hline \multirow[t]{3}{*}{$79 / 80$} & Raiz quadrada & 0,97 & 0,95 & $29.480,13$ & 74,34 \\
\hline & 2ạ aprox. Mitscherlich & 0,98 & 0,95 & $7.995,44$ & 66,07 \\
\hline & Quadrático & 0,95 & 0,92 & $58.602,81$ & 78,46 \\
\hline \multirow[t]{3}{*}{$80 / 81$} & Raiz quadrada & 0,98 & 0,97 & $17.616,41$ & 71,25 \\
\hline & 2ạ aprox. Mitscherlich & 0,94 & 0,85 & $35.500,80$ & 75,02 \\
\hline & Quadrático & 0,93 & 0,88 & $47.740,87$ & 77,23 \\
\hline \multirow[t]{3}{*}{$81 / 82$} & Raiz quadrada & 0,93 & 0,88 & $48.546,62$ & 77,33 \\
\hline & 2ạ aprox. Mitscherlich & 0,83 & 0,57 & $71.545,80$ & 79,22 \\
\hline & Quadrático & 0,98 & 0,97 & $21.559,95$ & 72,46 \\
\hline \multirow[t]{3}{*}{$82 / 83$} & Raiz quadrada & 0,97 & 0,95 & $32.841,43$ & 74,98 \\
\hline & 2ạ aprox. Mitscherlich & 0,97 & 0,92 & $18.986,44$ & 71,26 \\
\hline & Quadrático & 0,97 & 0,95 & $23.660,20$ & 73,02 \\
\hline \multirow[t]{2}{*}{$83 / 84$} & Raiz quadrada & 0,94 & 0,92 & $38.757,77$ & 75,70 \\
\hline & 2ạ aprox. Mitscherlich & 0,94 & 0,85 & $30.525,60$ & 74,11 \\
\hline
\end{tabular}

* $\mathrm{AIC}=\mathrm{n}$ ln SQ Desv.Reg. $+2 \mathrm{k}$

$\mathrm{n}=\mathrm{n}$ ? de pontos estimados;

$k=n$ o de parârnetros do rnodelo ajustado. 
Tabela 9 - Número total de postos para os três modelos em relação aos experimentos de Campo Mourão.

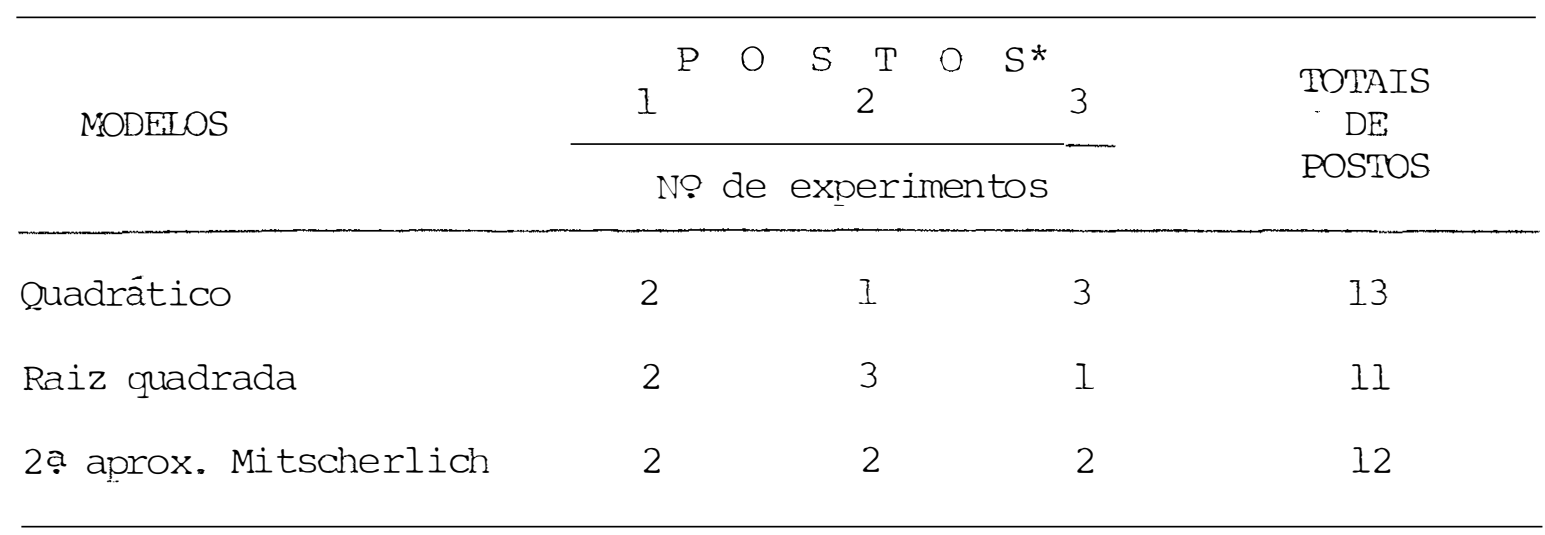

* Posto 1 = Quadrado Médio de Desvio de Reuressão Máximo;

Posto 2 = Quadrado Médio de Desvio de Req̣ressão Intermediário;

Posto 3 = Quadrado Médio de Desvio de Regressão Mínimo.

Indiscutivelmente, com estes resultados das

Tabelas 8 e 9, pode-se verificar que o modelo quadrático se adequou melhor aos dados experimentais de Campo Mourão.

Houve, na maioria das vezes, a concoraância entre os critérios, tornando-se bem visível a adequação do modelo quadrático. Neste modelo, em 6 anos de experimentacão, obtiveram-se os quatro maiores valores para o coeficiente de determinação $\left(R^{2}\right)$, quatmmaiores valores do coeficiente de determinação ajustado $\left(\bar{R}_{A}^{2}\right)$, três menores valores dos quadrados médios des desvios de regressão mínimos e os triês menores valores de AIC, sendo que houve coincidência qua se total nos resultados dos critérios aplicados. 
Após o modelo quadrático, o modelo que melhor se adequou foi o da 2 ạ aproximação de Mitscherlich.

Estes resultados concordam com os encontra dos no trabalho de UDO (1983), quando a autora concluiu, em seus estudos, que o melhor ajuste foi para o modelo quadrático.

$$
\text { 5.2.2 - Ajustamento dos modelos aos dados experi- }
$$
mentais de Guarapuava

Utilizando-se da Tabela 46 do Apêndice, des dobraram-se os graus de liberdade do calcário, levando em conta a regressão, para os modelos: quadrático, raiz quadra da e 2ạ aproximação de Mitscherlich.

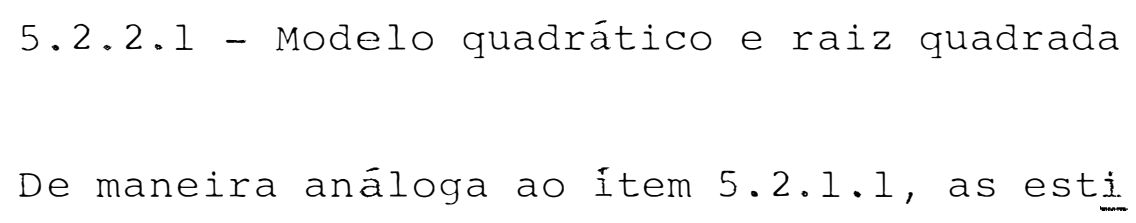


Tabela 10 - Estirnativas dos parâmetros do modelo quadrático para os experimentos de Guarapuava. Anos: 78/79 a 83/84.

\begin{tabular}{cccc}
\hline \multirow{2}{*}{ ANOS } & \multicolumn{3}{c}{$\mathrm{PAR} \AA \mathrm{METROS}$} \\
\cline { 2 - 4 } & $\overline{\mathrm{A}}$ & $\overline{\mathrm{B}}$ & \multicolumn{1}{c}{$\mathrm{C}$} \\
\hline $78 / 79$ & $1.204,00$ & 69,6333 & $-2,6342$ \\
$79 / 80$ & $2.150,00$ & 140,6404 & $-5,3931$ \\
$80 / 81$ & $2.385,00$ & 136,1011 & $-5,3048$ \\
$81 / 82$ & $1.571,00$ & 103,1214 & $-3,8361$ \\
$82 / 83$ & $1.633,00$ & 201,9488 & $-10,7096$ \\
$83 / 84$ & $1.777,00$ & 228,9571 & $-10,0449$ \\
\hline
\end{tabular}

Tabela 11 - Estinativas dos parâmetros do modelo raiz quadrada vara os experimentos de Guarapuava. Anos: 78/79 a 83/84.

\begin{tabular}{cccc}
\hline \multirow{2}{*}{ ANOS } & \multicolumn{3}{c}{ P A R A M T R O S } \\
\cline { 2 - 4 } & $\bar{A}$ & $\bar{B}$ & \multicolumn{1}{c}{$\mathrm{C}$} \\
\hline $78 / 79$ & $1.169,00$ & 206,9515 & $-22,8432$ \\
$79 / 80$ & $2.076,00$ & 429,4135 & $-49,9340$ \\
$80 / 81$ & $2.287,00$ & 455,4593 & $-58,5553$ \\
$81 / 82$ & $1.512,00$ & 316,4763 & $-35,9164$ \\
$82 / 83$ & $1.527,00$ & 796,0020 & $-164,1405$ \\
$83 / 84$ & $1.542,00$ & 929,9405 & $-154,3310$ \\
\hline
\end{tabular}




\subsubsection{2 - Modelo da 2 ạ aproximação de Mits- cherlich}

Como este modelo é não linear nos parâmetros, as estimativas dos parāmetros podem ser obtidas da mes ma forma que no item 5.2.1.2, e as mesmas são apresentadas na Tabela 12 .

Tabela 12 - Estimativas dos parânetros da 2ạ abroximação de Mitscherlich, para os experimentos de Guaranuava. Anos: 78/79 a 83/84.

\begin{tabular}{lrrrrr}
\hline & & \multicolumn{5}{c}{ P A R A M E T R O S } \\
\cline { 3 - 6 } ANOS & \multicolumn{1}{c}{$\hat{\mathrm{A}}$} & $\hat{\mathrm{B}}$ & $\hat{C}$ & $\tilde{R}$ \\
\hline $78 / 79$ & 5 & $1.861,27$ & 6,8356 & 0,0654 & 0,000083 \\
$79 / 80$ & 3 & $3.205,98$ & 5,1127 & 0,0906 & 0,000057 \\
$80 / 81$ & 4 & $3.203,22$ & 3,7447 & 0,1459 & 0,000012 \\
$81 / 82$ & 5 & $2.304,31$ & 4,7318 & 0,0997 & 0,000039 \\
$82 / 83$ & 91 & $11.252,60$ & 5,4711 & 0,0130 & 0,000893 \\
$83 / 84$ & 4 & $2.956,88$ & 1,0861 & 0,2903 & 0,000085 \\
\hline
\end{tabular}

$\overline{\mathrm{X}}_{\mathrm{IT}}=19$

*IT $=$ No de iterações necessárias para a converqēncia do modelo.

Verificando a Tabela 12 e combarando com a Tabela 6, notou-se, para os experimentos de Guaranuava, que o nümero médio de iterações decresceu em relação aos experimentos de Campo Mourão, convergindo o modelo mais rapidamente. 
Com estas estimativas dos narânetros dos três modelos, pôde-se obter a análise de rearessão para os experimentos de Guaranuava. Na Tabela 13 são apresentados os resultados do teste $F$ nara rearessão e desvios de regressão.

Os valores do teste $F$ para rerressão e desvios de regressão são simificativos quando emreqados os modelos quadráticos e raiz quadrada. Para este conjunto de dados experimentais existem concordância com os resultados obtidos por UDO (1983), SILVA (1978) e outros.

Tabela'13 - Valores do teste F para regressão e desvios de regressão para os modelos: quadrático, raiz quadrada e 2ạ aproximação de Mitscherlich, com os experimentos de Guarabuava.

\begin{tabular}{|c|c|c|c|c|c|c|}
\hline \multirow{2}{*}{ ANOS } & \multicolumn{2}{|c|}{ Quadrático } & \multicolumn{2}{|c|}{ Raiz Quadrada } & \multicolumn{2}{|c|}{$\begin{array}{l}\text { 2a Anroximação } \\
\text { de Mitscherlich }\end{array}$} \\
\hline & Regressão & $\begin{array}{l}\text { Desvios } \\
\text { de Reg. }\end{array}$ & Regressão & $\begin{array}{l}\text { Desvios } \\
\text { de Reg. }\end{array}$ & Reqressão & $\begin{array}{l}\text { Desvios } \\
\text { de Reg. }\end{array}$ \\
\hline $78 / 79$ & $23,76 * *$ & $0,79 \mathrm{NS}$ & $23,75 * \star$ & $0,80 \mathrm{NS}$ & $15,97 \star \star$ & $1,00 \mathrm{NS}$ \\
\hline $79 / 80$ & $92,70 * *$ & $1,6 \pi \mathrm{NS}$ & $93,49 * *$ & $1,14 \mathrm{NS}$ & $63,20 * *$ & $0,40 \mathrm{NS}$ \\
\hline $80 / 81$ & $11,96 * *$ & $0,78 \mathrm{NS}$ & $12,78^{* *}$ & $0,23 \mathrm{NS}$ & $8,60 * \star$ & $0,23 \mathrm{NS}$ \\
\hline $81 / 82$ & $15,53 * *$ & $1,77 \mathrm{NS}$ & $15,86 * *$ & $1,56 \mathrm{NS}$ & $10,75^{* \star}$ & $2,05 \mathrm{NS}$ \\
\hline $82 / 83$ & $34,94 * *$ & $0,87 \mathrm{NS}$ & $31,31 * *$ & $3,29 *$ & $23,20 * *$ & $1,44 \mathrm{NS}$ \\
\hline $83 / 84$ & $34,82^{\star *}$ & $5,48 * \star$ & $42,70 * *$ & $0,23 \mathrm{NS}$ & $28,58 * *$ & $0,18 \mathrm{NS}$ \\
\hline
\end{tabular}

Aqui também são aplicados os mesmos critérios de avaliação utilizados para os experimentos de Campo Mourão, como os valores de $R^{2}, \bar{R}_{A}^{2}$, OMDRM, AIC e TP, como segue nas Tabelas 14 e 15. 
Tabela 14 - Valores de $\mathrm{R}^{2}, \overline{\mathrm{R}}_{\mathrm{A}}^{2}$, MMDRM e AIC para os modelos quadrático, raiz quadrada e 2a aproximação de Mitscherlich, com os experimentos de Guarapuava. Anos: 78/79 a 83/84.

\begin{tabular}{|c|c|c|c|c|c|}
\hline ANOS & MODEIOS & $\mathrm{R}^{2}$ & $\overline{\mathrm{R}}_{\mathrm{A}}^{2}$ & QMDRM & $A I C^{*}$ \\
\hline \multirow{3}{*}{$78 / 79$} & Quadrático & 0,95 & 0,92 & $10.105,77$ & 67,91 \\
\hline & Raiz quadrada & 0,95 & 0,92 & $10.184,49$ & 67,96 \\
\hline & 2ạ aprox. Mitscherlich & 0,89 & 0,72 & $12.702,36$ & 68,85 \\
\hline \multirow{3}{*}{$79 / 80$} & Quadrático & 0,97 & 0,95 & $21.520,65$ & 72,45 \\
\hline & Raiz quadrada & 0,98 & 0,97 & $14.698,00$ & 70,16 \\
\hline & 2a aprox. Mitscherlich & 0,99 & 0,97 & $5.215,58$ & 63,51 \\
\hline \multirow{3}{*}{$80 / 81$} & Quadrático & 0,91 & 0,85 & $70.589,97$ & 79,57 \\
\hline & Raiz quadrada & 0,97 & 0,95 & $21.369,78$ & 72,41 \\
\hline & 2a aprox. Mitscherlich & 0,95 & 0,87 & $20.895,60$ & 71,84 \\
\hline \multirow{3}{*}{$81 / 82$} & Quadrático & 0,85 & 0,75 & $75.853,76$ & 80,01 \\
\hline & Raiz quadrada & 0,87 & 0,78 & $66.533,87$ & 79,22 \\
\hline & 2a aprox. Mitscherlich & 0,72 & 0,30 & $87.815,40$ & 80,49 \\
\hline \multirow{3}{*}{$82 / 83$} & Quadrático & 0,96 & 0,93 & $40.086,11$ & 76,18 \\
\hline & Raiz quadrada & 0,86 & 0,77 & $150.446,72$ & 84,11 \\
\hline & 2a aprox. Mitscherlich & 0,90 & 0,75 & $65.703,60$ & 78,71 \\
\hline \multirow{3}{*}{$83 / 84$} & Quadrático & 0,81 & 0,68 & $369.958,64$ & 89,51 \\
\hline & Raiz quadrada & 0,99 & 0,98 & $15.818,96$ & 70,60 \\
\hline & 2a aprox. Mitscherlich & 0,99 & 0,99 & $12.150,56$ & 68,58 \\
\hline
\end{tabular}

* $\mathrm{AIC}=\mathrm{n}$ ln SQ Desv.Reg. + $2 \mathrm{k}$

onde, $\mathrm{n}=\mathrm{n}$ \% de pontos estimados;

$k=n$ o de parâmetros do modelo ajustado. 
Tabela 15 - Número total de postos para os experimentos de Guarapuava, quando ajustados pelos modelos: quadrático, raiz quadrada, e pela 2ạ aproximação de Mitscherlich.

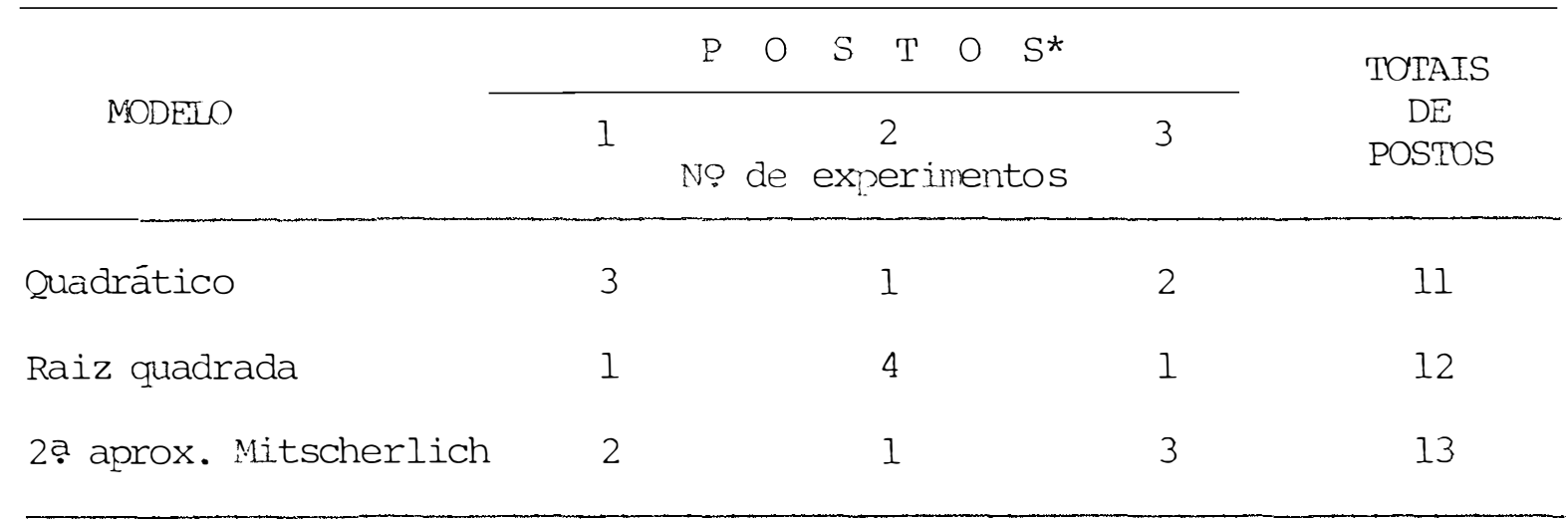

*Posto 1 = Quadrado Médio de Desvio de Regressão Máximo:

Posto 2 = Quadrado Médio de Desvio de Regressão Intermediário;

Posto 3 = Quadrado Médio de Desvio de Regressão Mínimo.

os resultados da Tabela 14 diferem dos encontrados na Tabela 8, onde o modelo quadrático foi o que me lhor se adaptou aos dados, seguido da 2 ạ aproximação de Mits cherlich.

Neste caso, para os experimentos de Guarapuava, verifica-se nitidamente que a 2 ạ aproximação de Mitscherlich ajustou-șe melhor aos dados exoerimentais, tendo um segundo melhor ajuste o modelo raiz quadrada. (Tabelas 14 e 15). Houve também para estes resultados concordâncias entre os critérios utilizados para comparar os modelos. 
5.3 - Cálculo do Ponto de Máximo

5.3.l - Cálculo do ponto de máximo para os modelos: quadrático, raiz quadrada e 2 ạ aproximação de Mitscherlich, com os dados experimentais de Campo Mourão

os pontos de máximo para o modelo quadrático variam entre 6,94 a 8,43 toneladas de calcário por hectare (Tabela 16 e Figuras 1 a 6), com exceção do ano 81/82, no qual o ponto de máximo ultrapassou os limites estudados, o que é devido à não significância do ajuste da reqressão quadrática.

Para o modelo raiz quadrada, só houve ponto de máximo em 3 anos, variando entre 6,40 a 10,18 toneladas de calcário por hectare. Pode-se verificar que, através do emprego deste modelo, dos 3 pontos de máximo encontrados, 2 de les encontram-se fora dos limites estudados.

Estes resultados coincidem com os obtidos por UDO (1983), onde a autora não recomenda o emprego do modelo raiz quadrada para curvas de resposta.

Com a 2ạ aproximação de Mitscherlich, apenas em 3 anos houve pontos de máximo, os quais variaram entre 7,02 a 8,54 toneladas de calcário por hectare, não tendo nenhum dos pontos encontrados Fora do limite estudado. 
Assim, o modelo quadrático foi o que apresentou maior número de casos com máximo, os quais são muito próximos dos obtidos através da 2 ạ aproximação de Mitscherli ch, quando esta permitiu a obtenção desse ponto.

Tabela 16 - Valores dos pontos de máximo, em ton/ha, para os modelos:qua drático, raiz quadrada e 2ạ aroroximação de Mitscherlich, com os experimentos de Campo Mourão.

\begin{tabular}{lccc}
\hline & \multicolumn{4}{c}{ M O D E L O S } \\
\cline { 2 - 4 } Quadrático & Raiz quadrada & $\begin{array}{l}\text { 2á Aproxinação } \\
\text { dé Mitscherlich }\end{array}$ \\
\hline $78 / 79$ & 8,43 & - & 8,54 \\
$79 / 80$ & 6,94 & 6,40 & - \\
$80 / 81$ & 7,35 & 10,18 & - \\
$81 / 82$ & 43,68 & - & 7,02 \\
$82 / 83$ & 7,15 & 10,13 & 8,83 \\
$83 / 84$ & 8,32 & - & \\
\hline
\end{tabular}




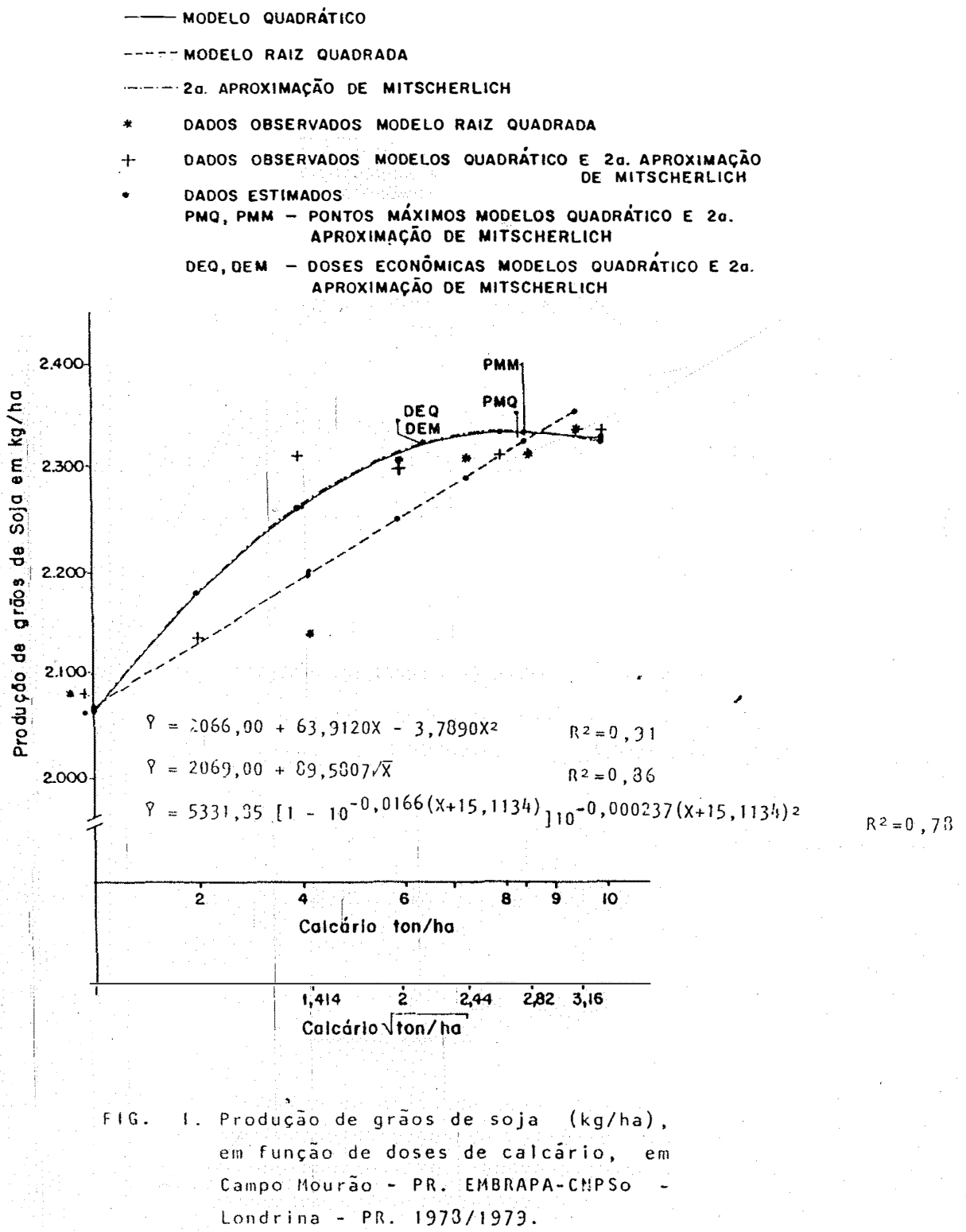




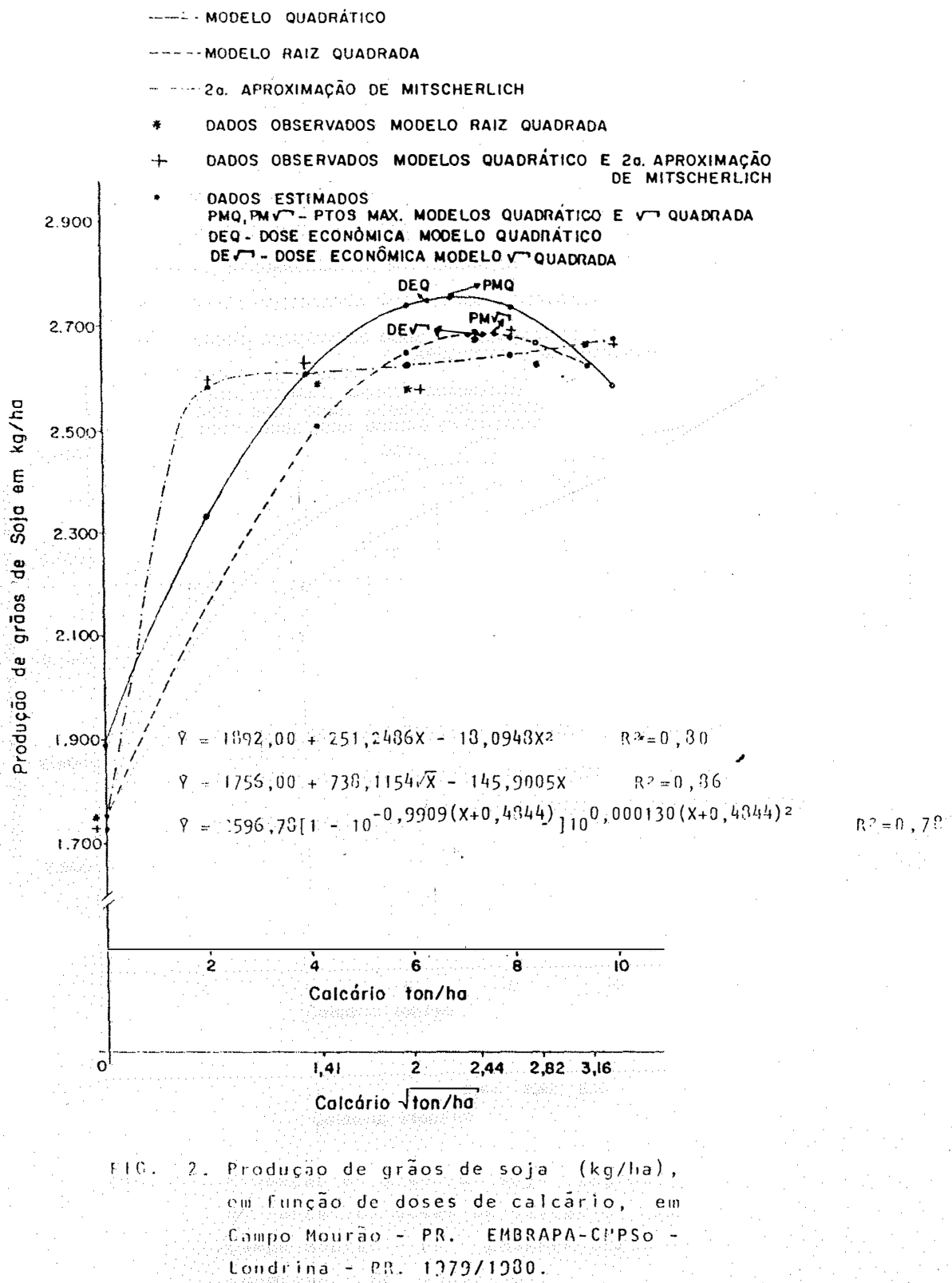


.77.

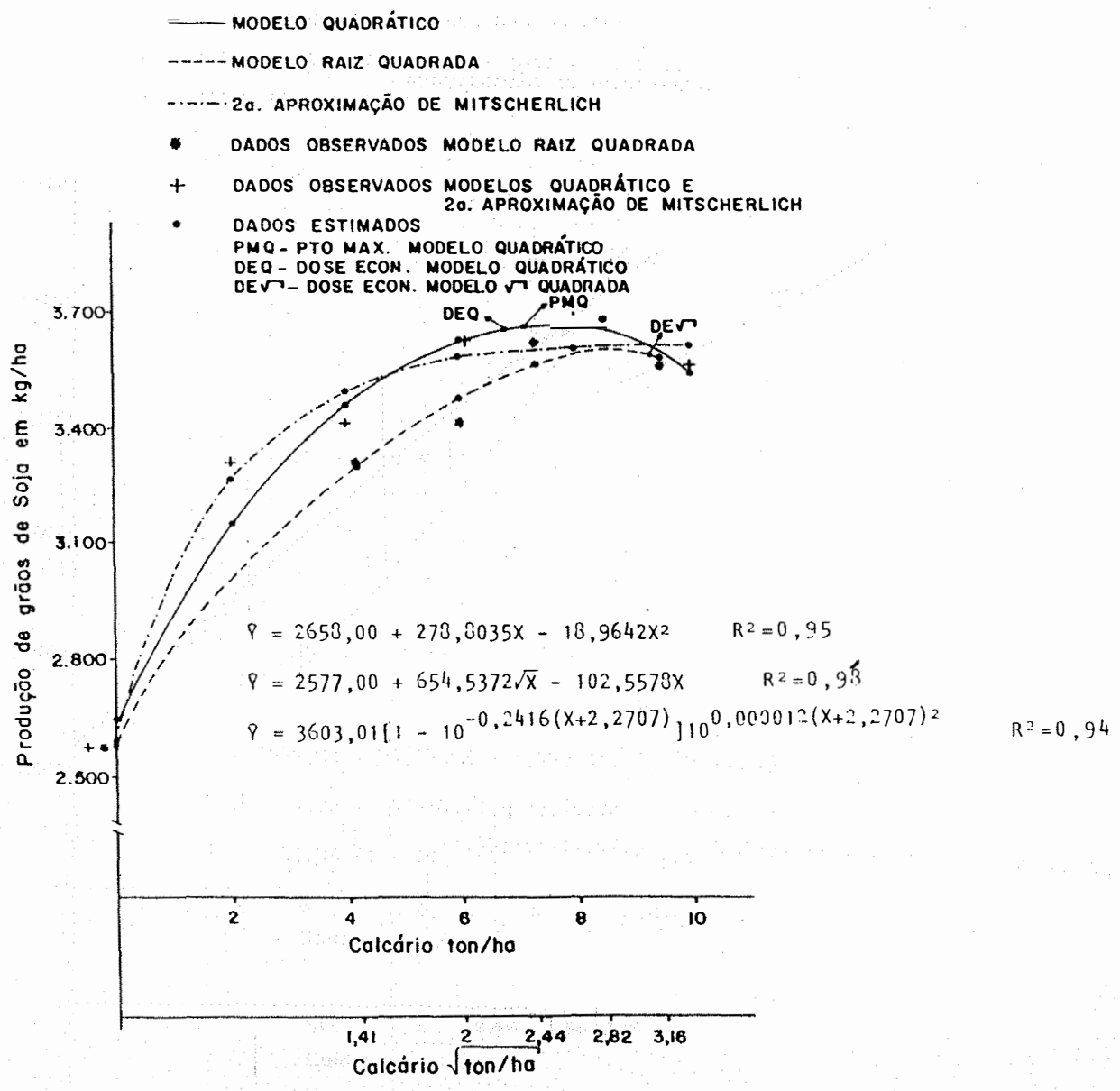

Fic. 3. produção de grãos de soja (kg/ha), en função de doses de calcário, em Canipo hourão - PR. EMBRAPA-CNPSo Londrina - PR. 1930/1931. 


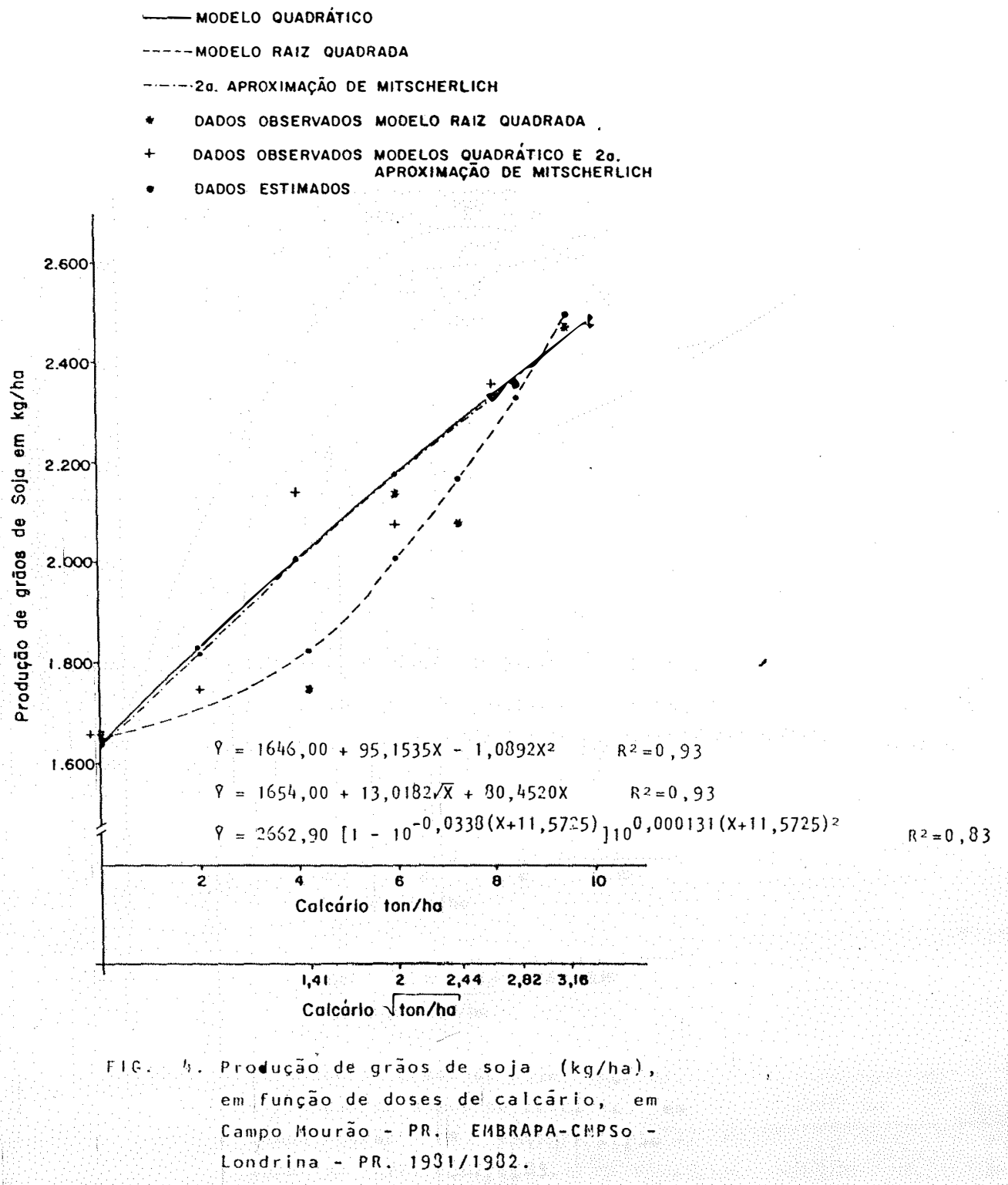




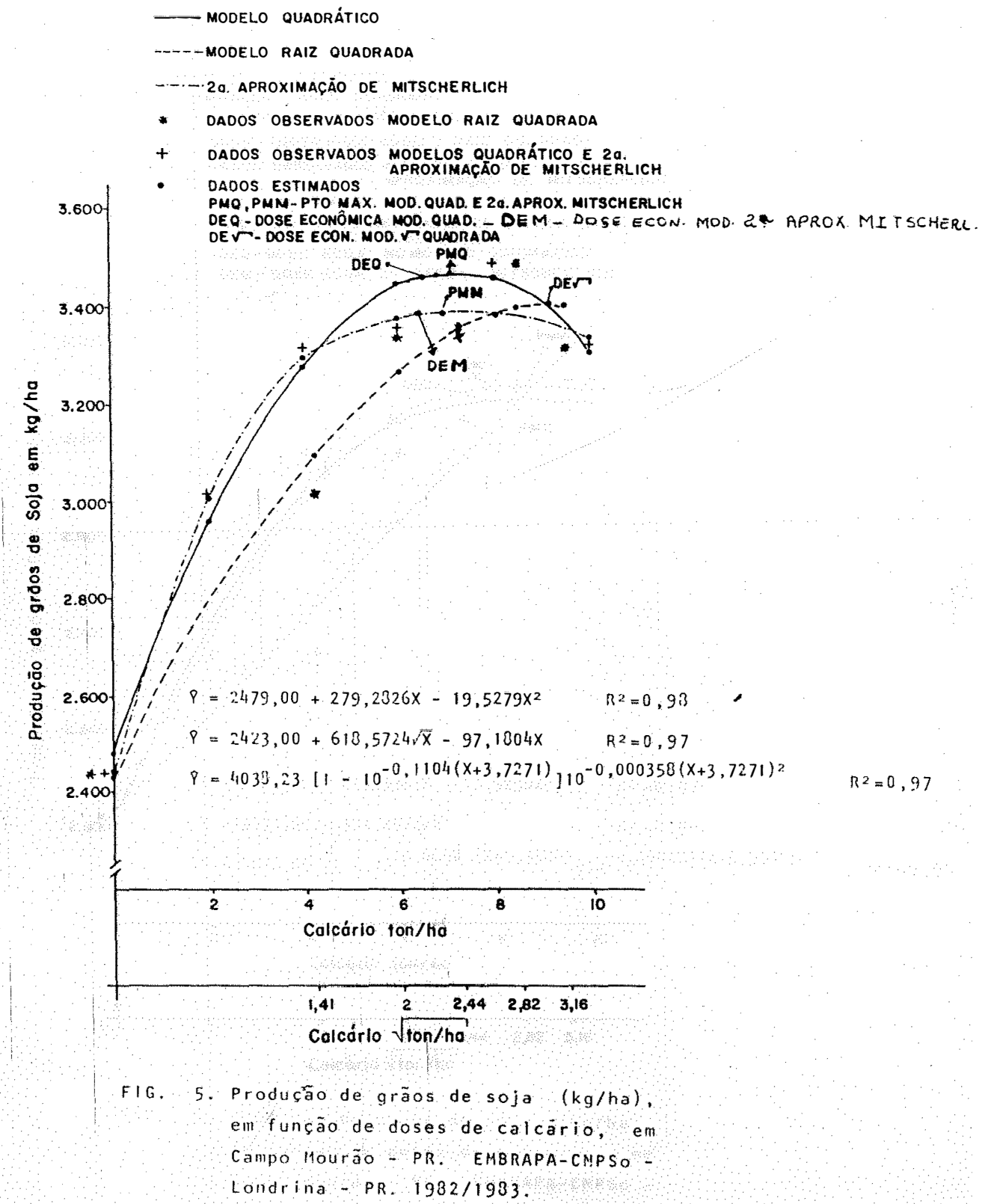




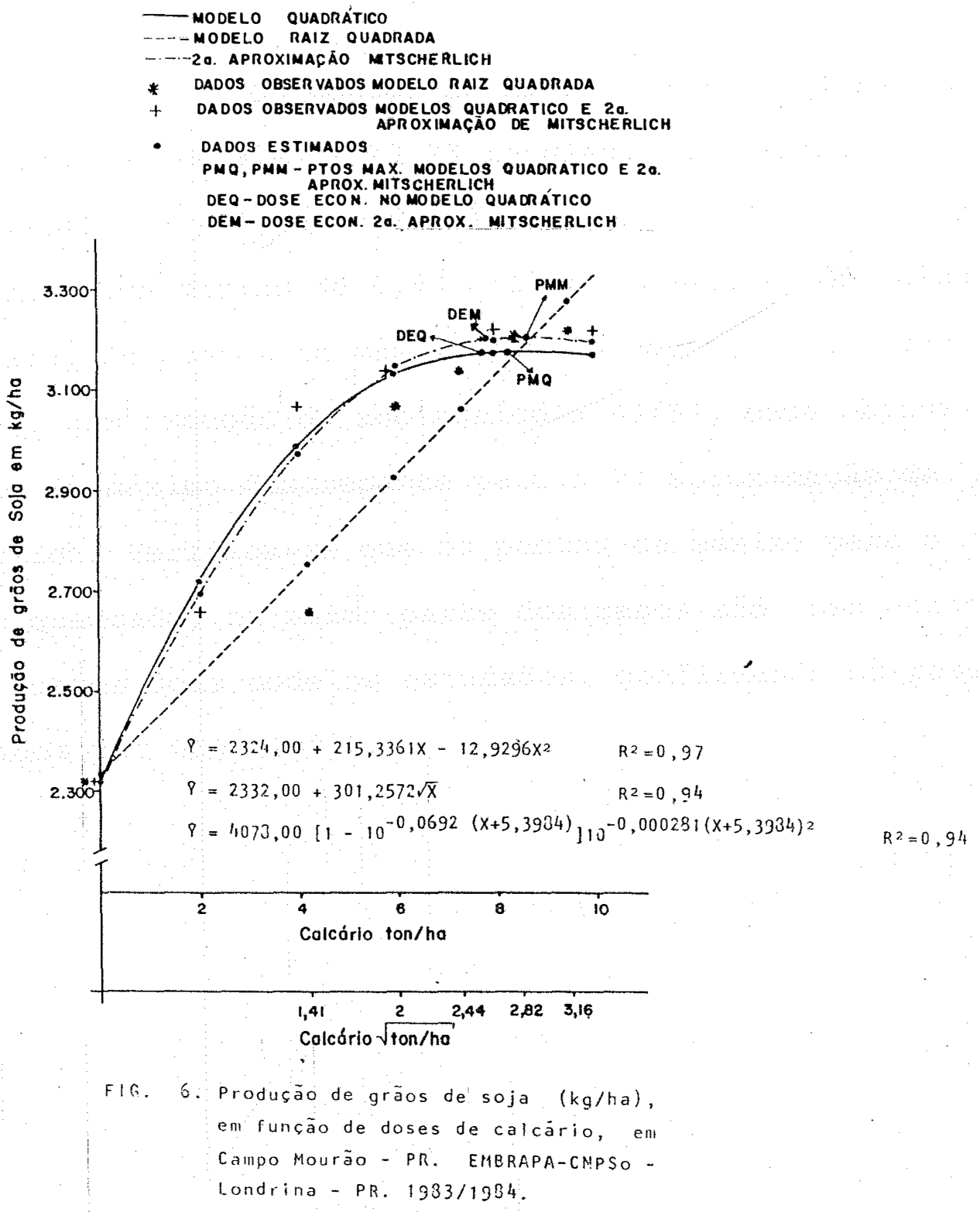


5.3.2 - Cálculo do ponto de máximo para os modelos: quadrático, raiz quadrada e 2 ạ aproximação de Mitscherlich, para os experimentos de Gua rapuava

os pontos de máximo para o modelo quadrático variam entre 9,43 a 13,23 toneladas de calcário por hecta re (Tabela 17 e Figuras 7 a 12), e para a 2ạ aproximação de Mitscherlich variam de 6,93 a 13,69 toneladas de calcáriopor hectare. Os pontos de máximo para os dois modelos são bempró ximos, com exceção do ano agrícola 83/84, onde obteve-se um ponto de máximo discrepante para a 2 a aproximação de Mitscherlich. Verifica-se que os pontos de máximo para o modelo raiz quadrada, na maior parte dos casos são bem superiores aos outros dois modelos estudados, confirmando os resultados obtidos por UDO (1983). 
Tabela 17 - Valores dos pontos de máximo, em ton/ha, para os modelos: quadrático, raiz quadrada e 2ạ aproximação de Mitscherlich, para os experimentos de Guarapuava.

\begin{tabular}{lccc}
\hline \multirow{3}{*}{ ANOS } & M O D E L O S \\
\cline { 2 - 4 } & Raiz quadradico & $\begin{array}{c}\text { 2á Aproximação } \\
\text { de Mitscherlich }\end{array}$ \\
\hline $78 / 79$ & 13,21 & 20,52 & 13,22 \\
$79 / 80$ & 13,03 & 18,48 & 13,05 \\
$80 / 81$ & 12,83 & 15,12 & 13,49 \\
$81 / 82$ & 13,23 & 19,41 & 13,69 \\
$82 / 83$ & 9,43 & 5,88 & 8,51 \\
$83 / 84$ & 11,40 & 9,08 & 6,93 \\
\hline
\end{tabular}




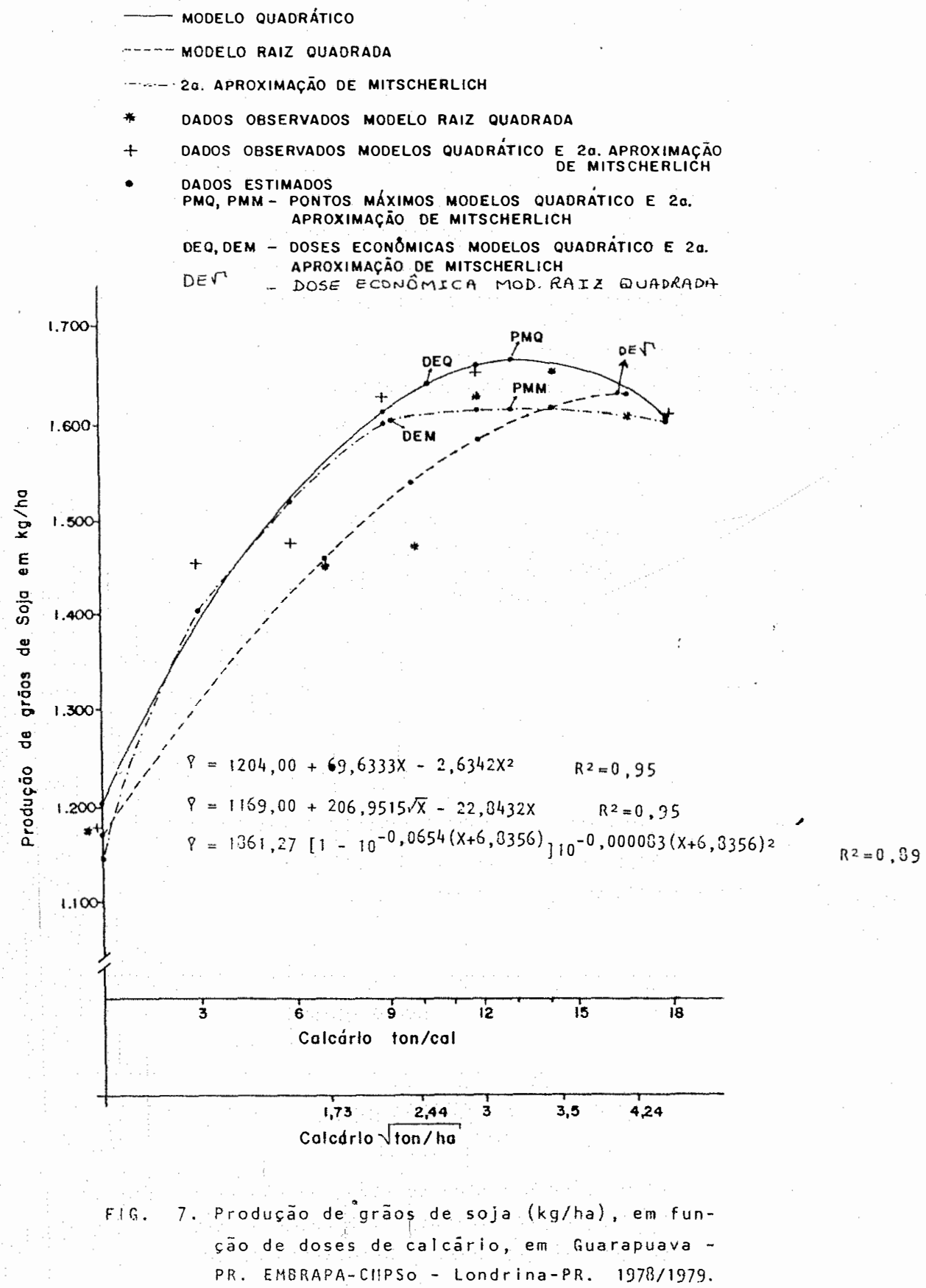


.84.

- MODELO QUADRÁtico

-...- MODELO RAIZ UUADRADA

-.... 20. APROXIMAÇĀO DE MITSCHERLICH

* dados observados modelo ralz quadrada

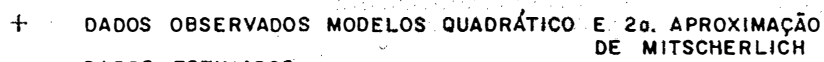

- dados estimados

PMQ, PMM - PONTOS MÁXIMOS MODELOS QUADRÁTICO E 2a. APROXIMAÇĀO

DEQ, DEV, OEM- DOSES ECON MOD. QUAARÁTICOS, VT QUADRADA E 20 . APROXI.

DE MITSCHERLICH

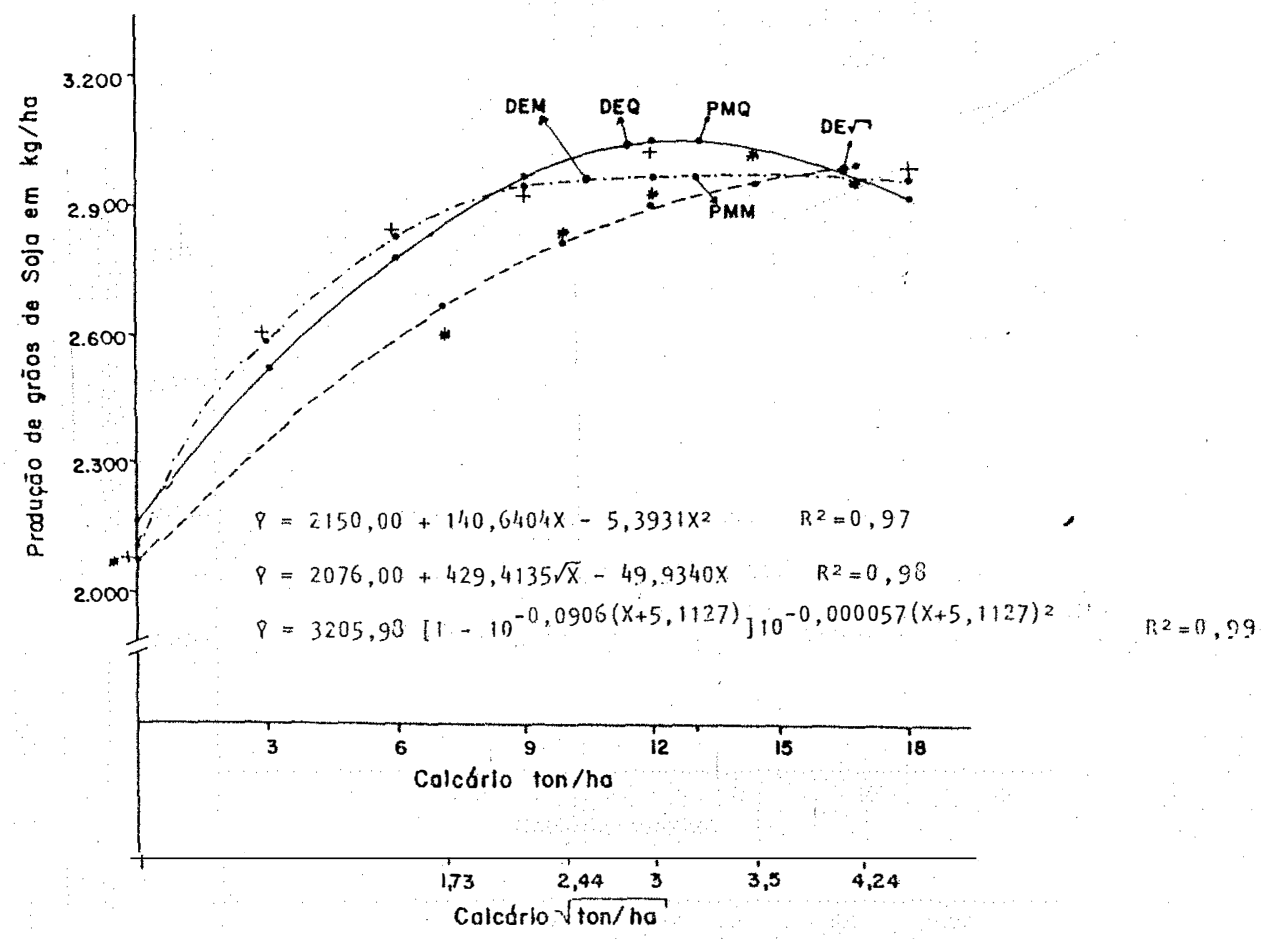

FIG. 3. Produção de grãos de soja (kg/ha), em funcão de doses de calcário, em GuarapuavaPR. EMBRAPA-CNPSO - Londrina-PR. 1979/1980. 


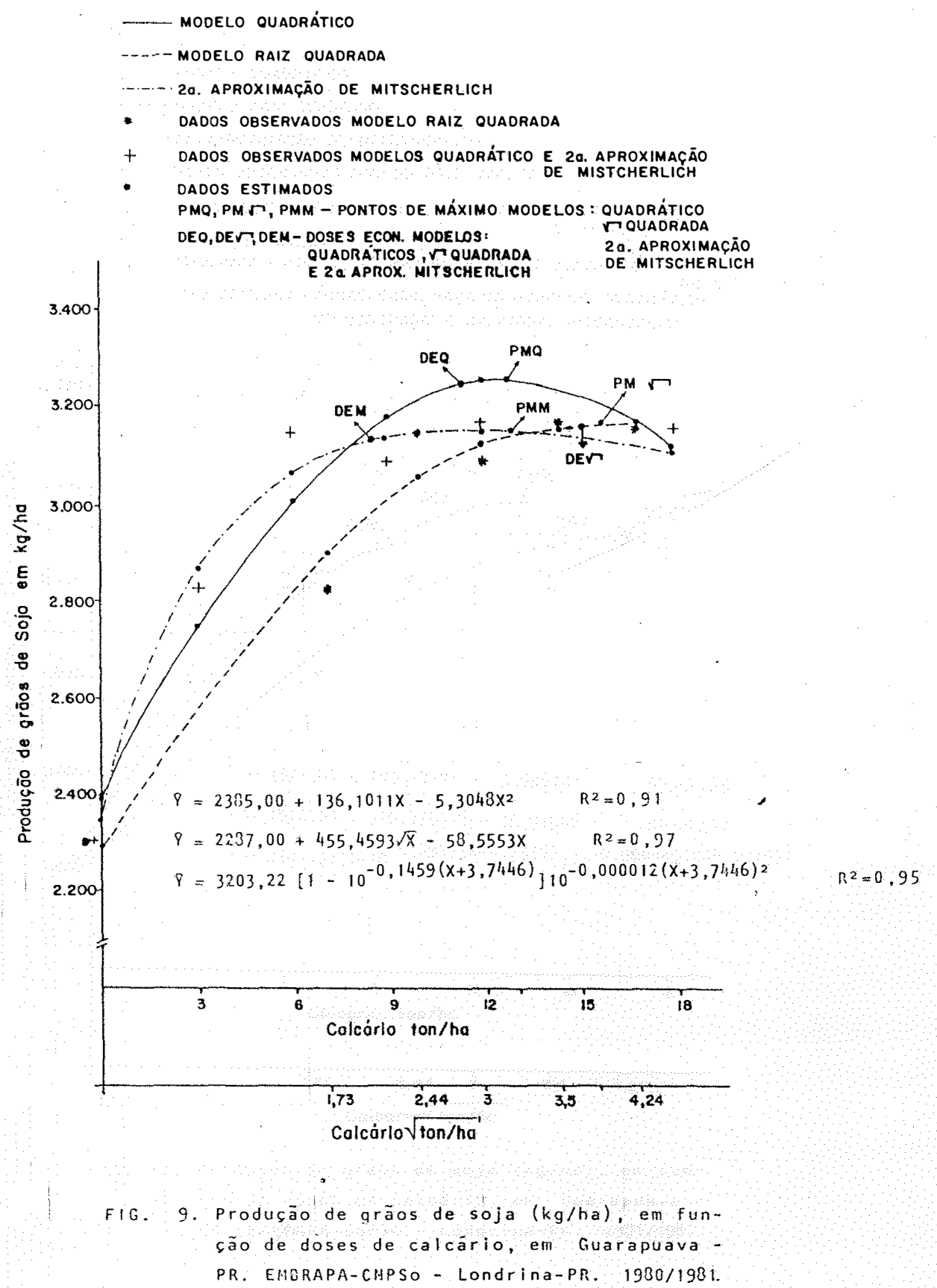


- MOOELO QUADrático

- MODELO RAIZ OUADRADA

- 20. APRoXIMAGáo de MITSCHERLICH

* dados observados modelo raiz quadrada

+ dados observados modelos quadrático e 20. aproximaçóo

DE MITSCHERLICH

PMO, PMM - PONTOS DE MÁXIMO MODELOS QUADRÁTICO E 2O. APROXIMAÇĀO DEO, DES, DEM - DOSES ECON. PARA OS MODELOS QUADRÁTICO MITSCHERLICH VI RUadrada E 2 Q a ARROX. MITSCHERLICH.

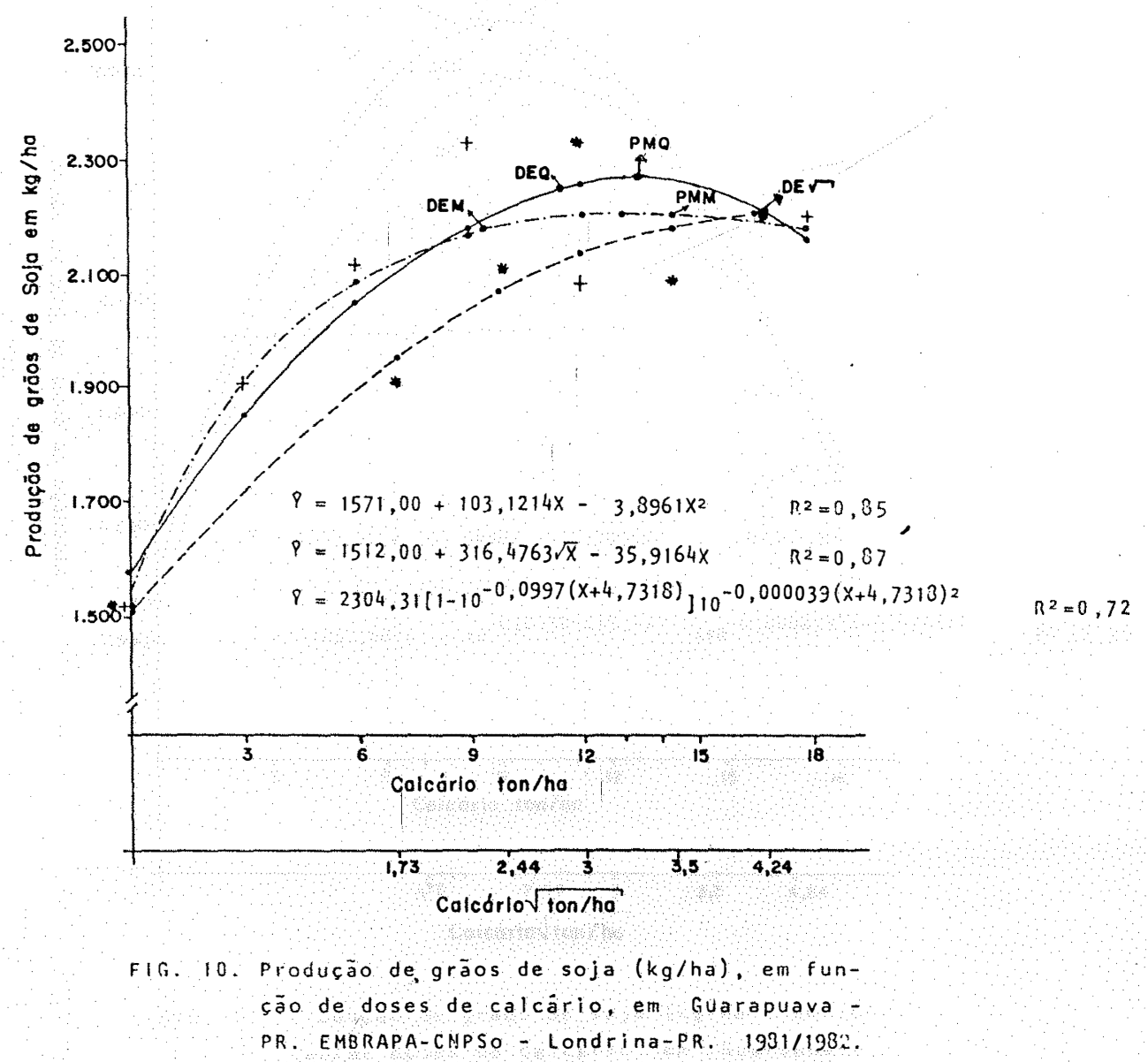




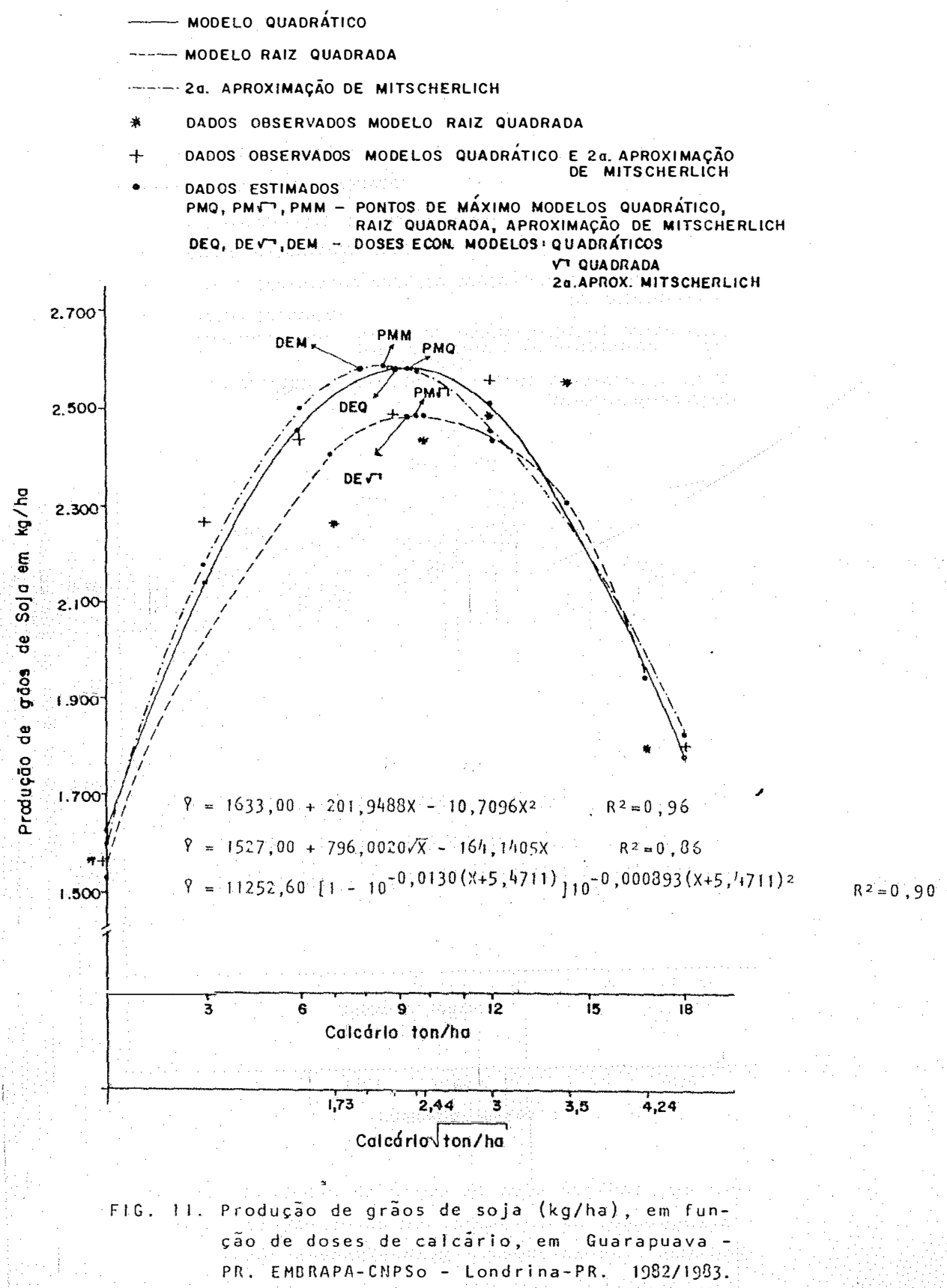




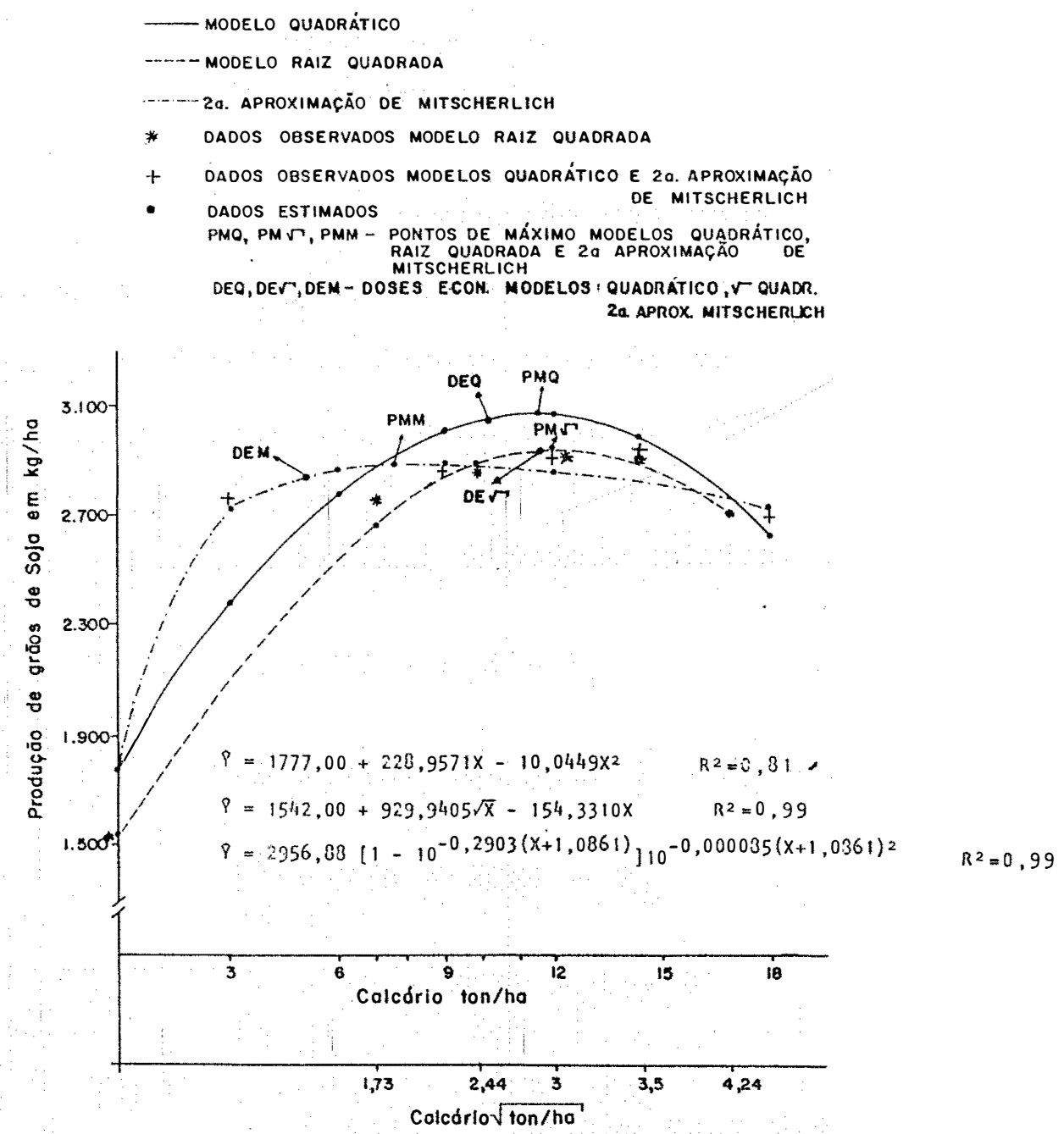

FIG. 12. Produção de grãos de soja ( $\mathrm{kg} / \mathrm{ha})$, em funçáo de doses de calcärio, em Guarapuava PR. ENCRAPA-CNPSO - Londrina-PR. 1933/1984. 
5.4 - Determinação da Dose Econômica

5.4.1 - Determinação da dose econômica aconselhável para os experimentos de Campo Mourão e de Guarapuava

A determinação das doses econômicas utilizando os modelos quadrático, raiz quadrada e a 2ạ aproximação de Mitscherlich, fez-se através da função da receita liquida, cujos detalhes estão contidos no item 4.2.8.

$$
\begin{aligned}
& 5.4 . I-\text { Modelo quadrático } \\
L & =V Y-F_{I} X-F_{O} \\
L & =V\left(A+B X+C X^{2}\right)-F_{O}-F_{I} X \\
\frac{\partial L}{\partial X} & =V(B+2 C X)-F_{I} \\
\frac{V}{F_{I}} & =(B+2 C X)-I=0 \\
& 5 \cdot 4 \cdot I .2-M o d e I 0 \text { raiz quadrada } \\
I & =V Y-F_{0}-F_{I} X \\
I & =V(A+B \sqrt{X}+C X)-F_{0}-E_{I} X \\
\frac{\partial I}{\partial X} & =V\left(\frac{B}{2 \sqrt{X}}+C\right)-F_{I}
\end{aligned}
$$




$$
\frac{\mathrm{V}}{\mathrm{F}_{1}}\left(\frac{\mathrm{B}}{2 \sqrt{\mathrm{X}}}+\mathrm{C}\right)-1=0 \quad[5 \cdot 4 \cdot 1 \cdot 2 . \mathrm{a}]
$$

5.4.1.3 - 2ạ aproximação de Mitscherlich

$$
\begin{aligned}
L & =V Y-F_{O}-F_{1} X \\
L & =V \cdot A\left[1-10^{-C\left(X_{i}+b\right)}\right] 10^{-K\left(X_{i}+b\right)^{2}}-F_{O}-F_{I} X \\
\frac{\partial L}{\partial X} & =0 \\
\frac{\partial L}{\partial X} & =\frac{V}{F_{I}} A(L 10) 10^{-k\left(X_{i}+b\right)^{2}}\left\{\begin{array}{l}
-2 k\left(X_{i}^{*}+b\right)\left[1-10^{-C\left(X_{i}^{*}+b\right)}\right]+ \\
+C 10^{-C\left(X_{i}^{*}+b\right)}
\end{array}\right]>-I=0 \text { [5.4.1.3.a] }
\end{aligned}
$$

O valor da abcissa $x_{i}^{*}$ que satisfaz às equações [5.4.1.1.a], [5.4.1.2.a] e [5.4.1.3.a] foi determinado através do processo de acréscimos finitos de Cauchy, a partir de pontos próximos aos pontos máximos, até obter-se

$$
\frac{\partial L}{\partial X}=0
$$

Os cálculos das doses econômicas para os dois locais foram obtidos utilizando a relação $\frac{V}{F_{I}}=0,075$, e são apresentados nas Tabelas 18 e 19. 
Tabela 18 - Valores das doses econômicas, em ton/ha, para os modelos: cuadrático, raiz quadrada e 2ạ aproximação de Mitscherlich, para os experimentos de Campo Mourão.

\begin{tabular}{lccc}
\hline & \multicolumn{4}{c}{ M O D E L O S } \\
\cline { 2 - 4 } ANOS & Ruadrático & Raiz quadrada & $\begin{array}{l}\text { 2á aproxinação } \\
\text { de Mitscherlich }\end{array}$ \\
\hline $78 / 79$ & 6,67 & - & 6,61 \\
$79 / 80$ & 6,57 & 6,16 & - \\
$80 / 81$ & 6,99 & 9,77 & - \\
$81 / 82$ & 37,56 & - & 6,45 \\
$82 / 83$ & 6,81 & 9,69 & 7,98 \\
$83 / 84$ & 7,81 & - & - \\
\hline
\end{tabular}

Tabela 19 - Valores das doses econômicas, em ton/ha, para os modelos: quadrático, raiz quadrada e 2ạ aproximação de Mitscherlich, para os experimentos de Guarapuava.

\begin{tabular}{lccc}
\hline & \multicolumn{3}{c}{ M O D E L O S } \\
\cline { 2 - 4 } ANOS & Quadrático & Raiz quadrada & $\begin{array}{r}\text { 2a } \begin{array}{c}\text { aproximação } \\
\text { de Mitscherlich }\end{array} \\
78 / 79\end{array}$ \\
\cline { 2 - 4 } $79 / 80$ & 10,68 & 17,96 & 9,32 \\
$80 / 81$ & 11,80 & 17,36 & 10,37 \\
$81 / 82$ & 11,57 & 14,25 & 8,82 \\
$82 / 83$ & 11,52 & 17,81 & 9,65 \\
$83 / 84$ & 8,80 & 5,68 & 7,96 \\
\hline
\end{tabular}


A partir das Tabelas 18 e 19 verifica-se que as doses econômicas obtidas para os modelos quadrático e 2 ạ aproximação de Mitscherlich, com os dados experimentais de Campo Mourão, encontram-se próximas das doses recomendadas pe lo método de Saturação de Bases (70\%), conforme estudos de PALHANO et atii (1984) (Tabela 1). As doses econômicas para o modelo raiz quadrada foram mais altas em relação aos dois modelos anteriores, portanto, com este modelo o estudo econô mico é prejudicado, discordando dos resultados encontrados por PESEK e HEADY (1956) e concordantes com COSTA (1977).

Para os experimentos de Guarapuava, confir ma-se novamente os resultados encontrados em Campo Mourão pa ra os modelos quadrático e 2ạ ap̣roximação de Mitscherlich. Os valores das doses econômicas para estes experimentos, utilizando os dois modelos, encontram-se próximos das doses recomendadas pelo método de Saturação de Bases (70\%), de acordo com PALHANO et alii (1984). Nota-se, também, que houve boa resposta da aplicação de calcário para estes dados experimen tais (Figuras 7 a 3.2 ).

Para o modelo raiz quadrada, obtiveram-se os valores das doses econômicas mais altos do que para os modelos quadrático e 2 à aproximação de Mitscherlich, discordando dos resultados de PESEK e HEADY (1956) e concordantes com os resultados de COSTA (1977). 
93.

6. CONCIUSOEES

Através dos resultados obtidos com as metodo logias empregadas, nas condições de condução desses exrerimentos, pode-se tirar as seguintes conclusões:

6.1 - Com os trēs modelos, nos dois locais, para todos os anos agricolas, obtiveram-se valores altamente sig nificativos para a regressão. Para os modelos quadrático e raiz quadrada, nos experimentos de Guara puava, ocorreram em dois anos valores de $F$ signifi cativos para o desvio de regressão.

6.2 - Os critérios empregados para a comparação dos mode los matemáticos foram consistentes quando comparados com os critérios mais utilizados, havendo con-. cordāncia entre os mesmos. 
6.3 - Para os experimentos de Campo Mourão, o modelo que melhor se ajustou aos dados foi o quadrático e, em seguida, a 2ạ aproximação de Mitscherlich.

6.4 - Para os experimentos de Guarapuava, o modelo que melhor se ajustou aos dados foi a 2ạ aproximação de Mitscherlich e, em seguida, o modelo raiz guadrada.

6.5 - Na obtenção das estimativas dos parâmetros nara a 2ạ aproximação de Mitscherlich, utilizando-se os dados experimentais de Guarapuava, obteve-se um nú mero de iterações bem menor do que nos exnerimentos de Campo Mourão.

6.6 - o modelo raiz quadrada não é aconselhável devido ao fato de seu ponto de máximo acontecer, alfumas vezes, acima das doses de calcário estudadas.

6.7 - Em geral, as doses econōmicas determinadas para os modelos quadráticos e 2 ạ aproximação de MitscherIich, estão próximas das doses de calcário recomen dadas para elevar a saturação de bases a 70\%, méto do esse recomendado nos Estados de São Paulo e Paraná. 
AKAIKE, H., 1971. Information theory and an extension of the maximum likelihood principle. Proceedings 2nd International Symposia on Information Theory, September 2 nd to 8 th.

ARRUDA, E.V., 1969. Determinação da dose econômica de um dạ do nutriente em experimentos de adubação. Ara. Biol. São Paulo, $30(1): 41-45$.

BIANCHINI SOBRINHO, E., 1984. Estudo da curva de lactação de vacas da raça Gir. Faculdade de Medicina de Ribeirão Pre to, USP, Ribeirão Preto, 87 p. [Tese de Doutorado].

BORKERT, C.M. . 1973. Efeito do calcário e do cloreto de potássio sobre as concentrações de manganēs e alumínio nos oxissolos Santo Ânqelo e Passo Fundo e suas relações com a nodulação e rendimento de duas cultivares de soja. Por.. to Alegre. UFRGS. 
BORKERT, C.M., 1975. Avaliação do efeito da calagem e da adubação fosfatada sobre as propriedades do solo e o rendi mento da soja, em sistema do cultivo de trigo e soja. Reu-

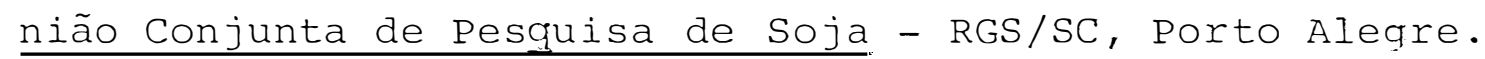

BOX, G.E.P. E K.B. WILSON, 1951. On the experimental attainment of optimum conditions. Journal of the Royal statistical Society. Londres, B13: 1-45. Manchester.

DRAPER, N. e H. SMITH, 1966. Applied regression analysis. New York, John Wiley \& Sons, Inc. 407 p.

FREITAS, A.R. de, 1978. A distribuição do ponto de máximo ou de minimo de uma função usada em experimento de adubação. Piracicaba, ESALQ/USP, 81 p. [Dissertação de Mestrado].

FRENCH, B.L., 1956. Functional relationships for irrigated corn response to nitrogen. Agricultural Research Service Journal of Farm Economics, 38(3): 736-747.

HARTLEY, H.O., 1958. The estimation of non linear parameters by "Internal Least Squares". Biometrika. Londres, 35: 32-45 .

HARTLEY, H.O., 1961. The modified Gauss-Newton method for the fitting on non-linear regression functions by Least Squares. Technometrics, 3: 269-280.

HASTINGS, N.A.J. e J.B. PEACOCK, 1974. Statistical distributions. Great Britain. 130 p. 
HEADY, E.O. e J.T. PESEK, 1954. A fertilizer production sur face with specification of Economic optima for corn grown on calcareous ida silt loam. Journal of Farm Economics. Philadelphia, Penn, 36(3): 466-482.

HEADY, E.O.; J.T. PESEK e W.G. BROWN, 1955. Crop response surfaces and economic optima in fertilizer use. Yowa sta te College, Research Bulletin, no 424: 293-332.

HEADY, E.O., 1956. Methodological Problems use. In: Methodological Procedures in the Economic Analysis of Fertilizer Innovations and Resourch Use. Ames, Iowa State University Press. $218 \mathrm{p}$.

HEADY, E.O. e J.L. DILLON, 1964. Agricultural Production Functions. 2ạ edição. Iowa. Iowa state University Press. $667 \mathrm{p}$.

HOFFMANN, R. e S. VIEIRA, 1976. Determinação do...interyalo de confiança para a dose econômica de nutriente com base em experimentação de adubação. Piracicaba, ESALO/USP, 43 p. [Mimeografado] .

HOFFMANN, R. e S.VIEIRA, 1977. Análise de regressão._Uma introdução à Econometria. 2å edição. São Paulo HUCITEC. Editora da USP. 379 p.

LANZER, E.A., 1970. Análise econômica de um grupo de experi mentos de fertilização do solo na cultura do trigo. UFRGS. Imprensa Universitária. Porto Alegre, 117 p. [Dissertação de Mestrado]. 
LANZER, E.A., 1976. Um modelo de quantificação do efeito re sidual da calagem para análise econômica. Reunião conjunta de Pesquisa de Soja. Santa Maria, RGS.

LIMA, A.R.C., 1980. Superficies de resposta em experimentos fatoriais $3^{3}$ incompletos de adubação NPK em mandioca no Estado do Ceará. Piracicaba, ESAL@/USP, 100 p. [Disserta ção de Mestrado].

MAGNANI, R., 1985. Alguns aspectos da aplicação da segunda lei de Mitscherlich e da equação de regressão quadrática à maturação da cana-de-açúcar. Piracicaba, ESALQ/USP. 73 p. [Dissertação de Mestrado].

MARQUARDT, D.W., 1963. An algorithm for least-square estima tion of non-linear parameters. J. Soc. Indust. Appl. Math. $11: 431-441 \mathrm{p}$.

MEMÓRIA, J.M.P., 1972. Curso de Estatistica aplicada à pesquisa científica. UFMG. Escola de Veterinária. 215 p.

MENEGHELLI, C.A., 1976. Avaliação do efeito de forma alquébrica inadequada para a função resposta à adubação. Brasilia, UB, Dep. Estatística. 41 p. [Dissertação de Mestra do].

MENEGHETTI, M.L., 1983. Modelos polinomial e Mitscherlich aplicados a ensaios de adubação no delineamento fAO de se te pontos. Piracicaba, ESALQ/USP, 77 p. [Dissertação de Mestrado. 
MITSCHERLICH, E.A., 1909. Das gesetz das minimuns und das gesetz des Abnehmenden Bodenertrages. Landwirtschaftliche Jahrbücher. Berlim, 38: 537-552.

MITSCHERLICH, E.A., 1928. Die zweite Annäherung des wirkungs herung. Düngung und Bodenkunde. Berlim, 12: 273-282.

MITSCHERLICH, E.A., 1954. Das wirkungsgesetz der wachstums faktoren. Bodenkunde fur Landwirte: Forstwirte und Gärtner. Paul Parey, Berlim, 7: 167-174.

MORAES, R.S., 1969. Superficie polinomial de resposta num en saio de adubação com niveis equidistantes. Piracicaba, ESALQ/USP, 58 p. [Tese de Doutorado].

MORRISON, J.; M.V. JACKSON E P.E. SPARROW, 1980. The respon se of perenial ryegrass to fertilizer nitrogen in relation to climate and soil. Grassland Research Institute Technical Report no 27. $14 \mathrm{p}$.

NELDER, J.A., 1966. Inverse polynomials, a useful group of multi-factor responses. Biometrics. England, 22: 128-141.

NELDER, J.A., 2968. Weighted regression, quantal response da ta, and inverse polynomials. Biometrics, 24: 979-985.

NETER, J.; W. WASSERMAN, 1974. Applied linear statistical models. Richard D. Irwin Inc. Homewood. Illinois. $842 \mathrm{p}$.

NICOLLELA, G., 1981. O uso de superficie de resposta na interpretação de ensaios de adubação NPK em plantações de cacau (Theobroma cacao, L.). Piracicaba, ESALৎ/USP, 91 p. [Dissertação de Mestrado]. 
PALHANO, J.B.; R.J. CAMPO; G.J. SFREDO; C.M. BORKERT;e D.S. CORDEIRO, 1981. Efeito de níveis de calcário sobre o ren dimento da soja. In: Seminário Nacional de Pesquisa de Soja. 2, 1984. Anais, Brasilia, EMBRAPA. CNPSo. V. 2. p. $617-624$.

PESEK, J.e E.O. HEADY, 1956. A two nutrient response function with determination of economic optima for the rate and grade of fertilizer for alfafa. Soil Science Society of America Proceedings. $V \cdot 20, n ? 2$. Iowa state Universi ty Press. p. 240-246.

PIMENTEL GOMES, F. e E. MALAVOLTA, 1949a. Considerações mate máticas sobre a Lei de Mitscherlich. 'Boletim no 3 da E. S.A. "Luiz de Queiroz", Piracicaba, 24 p.

PIMENTEL GOMES, F. e E. MALAVOLTA, 1949b. Aspectos matemáticos e estatisticos da Lei de Mitscherlich. Anais E.S.A. "Luiz de Queiroz". Piracicaba, 6: 198-229.

PIMENTEL GOMES, F. e C.P. ABREU, 1963. Sobre uma fórmula pa ra o cálculo da dose mais econômica de adubo. Anais E.S. A. "Luiz de Queiroz". Piracicaba, 9: 192-198.

PIMENTEL GOMES, F。 e H. CAMPOS, 1966. Resultados de ensaios de adubação. In: Cultura e Adubação do Milho. São Pau10. Instituto Brasileiro de Potassa. p. 429-449.

PIMENTEL GOMES, F., 1973, Curso de Estatistica Experimental. 5ạ edição. Piracicaba, São Paulo, Livraria Nobel. 427 p. 
RAMIREZ DÁVILA, L.E. e J. BENITEZ, 1975. Vantajas e desvantajas del modelo polinomial cuadrático a los fertilizantes. Trabalho apresentado à Reunião Comemorativa do 28 ? Aniversário da Região Brasileira da Sociedade Internacional de Biometria. Piracicaba.

RIBOLDI, J., 1978. Ajustamento de duas superficies de resposta usadas em ensaios de adubação. Piracicaba, ESALQ/ USP, 81 p. [Dissertação de Mestrado].

SALVIANO, A., 1973. Aspectos metodológicos de la construction de modelos estadísticos en las ciēncias sociales. Chapingo, México, 264 p. [Dissertação de Mestrado].

SEREDO, G.J., 1976. Efeito das relações entre Ca e Mg sobre o pH, Al, Ca no solo e sobre a produção de matéria seca do sorgo (Sorghum bicolor (I.) Moench). Viçosa, Escola de Agronomia, 61 p. [Dissertação de Mestrado].

SILVA, M.A.P. da, 1978. Segunda aproximação de Mitscherlich $Y=A\left[1-10^{-C(X+b)}\right] 10^{-\mathrm{k}(X+b)^{2}}$ aplicada à adubação mineral. Piracicaba, ESALo/USP, 96 p. [Dissertação de Mestra do].

SILVA, M.A.P. da, 1980. Métodos de estimação de parâmetros do modelo $\underline{Y}=A\left[1-10^{-\mathrm{CX}}\right] \quad 10^{-\mathrm{k}^{2} \mathrm{X}}$ aplicados a da-. dos de maturação da cana-de-açücar. Piracicaba, ESALQ/ USP, 85 p. [Tese de Doutorado].

SILVA, P.R., 1967. Análise econômica do emprego de fertilizantes na cultura do feijoeiro, através de função de produção. Universidade Federal de Viçosa, 61 p. [Dissertação de Mestrado]. 
SPARROW, P.E., 1979. Nitrogen response curves of spring bar ley. Journal of Agricultural Science. Cambridge, 92: 307-317 .

SPARROW, P.E., 1979. The comparison of five response curves for representing the relationship between the annual dry-matter yield of grass herbage and fertilizer nitrogen. Journal of Agricultural Science. Cambridge, 93: 513-520.

STEFANELO, E.L., 1975. Análise econōmica e relação técnica entre o rendimento da soja e o emprego de fertilizantes e calcário em dez locais do Rio Grande do Sul. Porto Alegre, UFRS, 149 p. [Dissertação de Mestrado].

THEIL, H., 1971. Principles of Econometrics. New York, John Wiley \& Sons, Inc. $736 \mathrm{p}$.

UDO, M.C.T., 1983. Estudo de funções que se ajustam à maturação da cana-de-açúcar. Piracicaba, ESALQ/USP, 74 p. [Dissertação de Mestrado] .

VIDOR, C.; J.R.J.FREIRE; J. KOLLIN; H.M. GONÇALVES; V. ZANO TELLI e G.N. MENDES, 1971. Efeito da calagem e da adubação fosfatada sobre a fixação simbiótica do nitrogênio pe la soja (Glycine max (L.) Merril). Agron. Sulriog., Por to Alegre. $181 \mathrm{p}$.

VIDOR, C.; J.R.J. FREIRE; J. KOLLIN; H.M. GONÇALVES; V. ZANO TELLI e G.N. MENDES, 1974. Efeito da calagem e da aduba-ção fosfatada na nodulação e rendimento de grãos de soja (Glycine max (L.) Merril). VII Reunião Latinoamericana sobre Rhizobium. Chaco. 
VIEIRA, S., 1970. Aspectos das funções de produção ajustadas aos ensaios fatoriais $3^{3}$ de adubação. Piracicaba, ESALQ/ USP, 165 p. [Tese de Doutorado].

VIEIRA, S.; H.V. ARRUDA e R. HOFFMANN, 1971. Estudo compara tivo de três funções na análise econômica de experimentos de adubação. Piracicaba, ESALQ/USP, lll p. [Mimeografado].

WEISBERG, S., 1947. Applied linear regression. John Willey \& Sons, Inc. Univ. of Minnésota. 283 p.

WINKLER, H.S. e G.J.SFREDO, 1979. Efeito da calagem e da adubação fosfatada sobre a produção do trigo e a disponibilidade de fósforo em quatro unidades de solo do Estado de Santa Catarina. Agron. Sulriograndense, V. 15, Porto Alegre, no 1 .

ZAGATTO, A.G. e F.P. GOMES, 1960. O problema técnico-econômico da adubação. Anais E.S.A. "Luiz de Sueiroz". Piraci caba, 17: 149-164.

ZAGATTO, A.G. e F.P. GOMES, 1967. Aspectos econōmicos da adubação. In: Manual de Química Agrícola. Adubos e Adubação. 2ạ edição, Ed. Agronômica ceres. São Paulo. p. 560$-586$. 
104.

8. A P E $N$ D $C E$ 
Tabela 20 - Valores iniciais utilizados para o ajustamento da 2a aproximação da equação de Mitscherlich, aos dados experimentais de Campo Mourão.

\begin{tabular}{crrrr}
\hline \multirow{2}{*}{ ANO } & \multicolumn{5}{c}{ P A R A M E T R O S } \\
\cline { 2 - 5 } & $\mathrm{A}_{0}$ & $\mathrm{~b}_{0}$ & $\mathrm{C}_{0}$ & $\mathrm{k}_{0}$ \\
\hline $78 / 79$ & 5.200 & 15,03 & 0,020 & 0,000230 \\
$79 / 80$ & 4.000 & 7,50 & 0,042 & 0,005000 \\
$80 / 81$ & 4.000 & 11,00 & 0,500 & 0,050000 \\
$81 / 82$ & 4.000 & 7,50 & 0,042 & 0,000500 \\
$82 / 83$ & 4.100 & 3,80 & 0,110 & 0,000350 \\
$83 / 84$ & 4.000 & 5,40 & 0,060 & 0,000280 \\
\hline
\end{tabular}

Tabela 21 - Valores iniciais utilizados para o ajustamento da 2ạ aproximação da equação de Mitscherlich, aos dados experimentais de Guarapuava.

\begin{tabular}{ccccc}
\hline \multirow{4}{*}{ ANO } & \multicolumn{5}{c}{ P A R A M E T O S } \\
\cline { 2 - 5 } & $A_{0}$ & $b_{0}$ & $c_{0}$ & $k_{0}$ \\
\hline $78 / 79$ & 1.900 & 6,80 & 0,070 & 0,000090 \\
$79 / 80$ & 3.200 & 5,00 & 0,090 & 0,000060 \\
$80 / 81$ & 3.000 & 3,80 & 0,140 & 0,000020 \\
$81 / 82$ & 2.300 & 4,80 & 0,090 & 0,000039 \\
$82 / 83$ & 2.300 & 5,00 & 0,080 & 0,000040 \\
$83 / 84$ & 2.900 & 1,10 & 0,290 & 0,000086 \\
\hline
\end{tabular}


Tabela 22 - Resultados de produção de \$oja, em kg/ha, referentes ao expe rimento com calagem em Carmo Mourão. Ano 78/79.

\begin{tabular}{cccccc}
\hline $\begin{array}{c}\text { NIVEIS DE } \\
\text { CAICARIO } \\
\text { (ton/ha) }\end{array}$ & 1 & 2 & 3 & 4 & MÉDIAS \\
\cline { 2 - 5 } & 2.330 & 2.057 & 1.901 & 2.023 & $2.077,75$ \\
0 & 2.308 & 2.177 & 2.035 & 2.021 & $2.135,25$ \\
4 & 2.442 & 2.417 & 2.208 & 2.185 & $2.313,00$ \\
6 & 2.462 & 2.236 & 2.113 & 2.406 & $2.304,25$ \\
8 & 2.275 & 2.375 & 2.328 & 2.280 & $2.314,50$ \\
10 & 2.534 & 2.317 & 2.138 & 2.356 & $2.336,25$ \\
\hline
\end{tabular}

Tabela 23 - Resultados de produção de soja, em kg/ha, referentes ao expe rimento com calagem em Campo Mourão. Ano 79/80.

\begin{tabular}{cccccc}
\hline $\begin{array}{c}\text { NIEIS DE } \\
\text { CALCARIO } \\
\text { (ton/ha) }\end{array}$ & 1 & 2 & 3 & 4 & MEDIAS \\
\cline { 2 - 5 } 0 & 1.969 & 2.197 & 1.363 & 1.419 & $1.737,00$ \\
2 & 2.937 & 3.126 & 1.978 & 2.326 & $2.591,75$ \\
4 & 2.589 & 2.773 & 3.001 & 2.206 & $2.642,25$ \\
6 & 2.597 & 2.933 & 2.262 & 2.524 & $2.579,00$ \\
8 & 2.842 & 2.558 & 2.614 & 2.692 & $2.676,50$ \\
10 & 2.743 & 2.524 & 2.709 & 2.756 & $2.683,00$ \\
\hline
\end{tabular}


Tabela 24 - Resultados de produção de soja, em kg/ha, referentes ao exoe rimento com calagem em Campo Mourão. Ano 80/81.

\begin{tabular}{cccccc}
\hline $\begin{array}{c}\text { NIVEIS DE } \\
\text { CAICARIO } \\
\text { (ton/ha) }\end{array}$ & 1 & 2 & 3 & 4 & MFDIAS \\
\cline { 2 - 5 } & 2.817 & 2.877 & 2.237 & 2.383 & $2.578,50$ \\
2 & 3.503 & 3.257 & 3.173 & 3.307 & $3.310,00$ \\
4 & 3.500 & 3.560 & 3.343 & 3.280 & $3.420,75$ \\
6 & 3.643 & 3.643 & 3.423 & 3.583 & $3.573,00$ \\
8 & 3.997 & 3.393 & 3.657 & 3.720 & $3.691,75$ \\
10 & 3.496 & 3.590 & 3.490 & 3.693 & $3.567,25$ \\
\hline
\end{tabular}

Tabela 25 - Resultados de produção de soja, em kg/ha, referentes ao expe rimento com calagem em Carmo Mourão. Ano 81/82.

\begin{tabular}{cccccc}
\hline $\begin{array}{c}\text { NIVEIS DE } \\
\text { CALARIO } \\
\text { (ton/ha) }\end{array}$ & 1 & 2 & 3 & 4 & MEDIAS \\
\cline { 2 - 5 } & 1.833 & 2.000 & 1.116 & 1.709 & $1.664,50$ \\
2 & 2.000 & 1.976 & 1.383 & 1.643 & $1.750,50$ \\
4 & 2.600 & 1.909 & 2.126 & 1.949 & $2.146,00$ \\
6 & 2.276 & 2.256 & 1.689 & 2.100 & $2.080,25$ \\
8 & 2.486 & 2.533 & 2.300 & 2.130 & $2.362,25$ \\
10 & 2.823 & 2.466 & 2.429 & 2.243 & $2.490,25$ \\
\hline
\end{tabular}


Tabela 26 - Resultados de produção de soja, em kg/ha, referentes ao expe rimento com calagem em Campo Mourão. Ano 82/83.

\begin{tabular}{|c|c|c|c|c|c|}
\hline \multirow{2}{*}{$\begin{array}{l}\text { NIVEIS DE } \\
\text { CAICÁRIO } \\
\text { (ton/ha) }\end{array}$} & \multicolumn{4}{|c|}{$\mathrm{B} I \mathrm{OCOS}$} & \multirow{2}{*}{ MÉDIAS } \\
\hline & $I$ & 2 & 3 & 4 & \\
\hline 0 & 2.440 & 2.431 & 2.397 & 2.496 & $2.441,00$ \\
\hline 2 & 3.382 & 3.226 & 2.600 & 2.885 & $3.023,25$ \\
\hline 4 & 3.500 & 3.117 & 3.223 & 3.426 & $3.316,50$ \\
\hline 6 & 3.163 & 3.543 & 3.334 & 3.394 & $3.358,50$ \\
\hline 8 & 3.526 & 3.595 & 3.454 & 3.394 & $3.492,25$ \\
\hline 10 & 3.455 & 2.533 & 3.844 & 3.477 & $3.327,25$ \\
\hline
\end{tabular}

Tabela 27 - Resultados de produção de soja, em ka/ha, referentes ao expe rimento com calagem em Campo Mourão. Ano 83/84.

\begin{tabular}{|c|c|c|c|c|c|}
\hline \multirow{2}{*}{$\begin{array}{l}\text { NIVEIS DE } \\
\text { CAICÁRIO } \\
\text { (ton/ha) }\end{array}$} & \multicolumn{4}{|c|}{$\mathrm{B} I \mathrm{OCOS}$} & \multirow{2}{*}{ MEEDIAS } \\
\hline & 1 & 2 & 3 & 4 & \\
\hline 0 & 2.323 & 2.237 & 2.403 & 2.340 & $2.325,75$ \\
\hline 2 & 2.803 & 3.063 & 2.360 & 2.470 & $2.658,25$ \\
\hline 4 & 3.103 & 3.147 & 3.030 & 2.993 & $3.068,25$ \\
\hline 6 & 3.247 & 2.900 & 3.057 & 3.373 & $3.144,25$ \\
\hline 8 & 3.273 & 2.957 & 3.207 & 3.130 & $3.141,75$ \\
\hline 10 & 3.293 & 3.350 & 3.240 & 3.017 & $3.225,00$ \\
\hline
\end{tabular}


Tabela 28 - Resultados de produção de soja, em kg/ha, referentes ao exoe rimento com calagem em Guarapuava. Ano 78/79.

\begin{tabular}{cccccc}
\hline $\begin{array}{c}\text { NIVEIS DE } \\
\text { CAICARIO } \\
\text { (ton/ha) }\end{array}$ & 1 & 2 & 3 & 4 & MFDIAS \\
\cline { 2 - 5 } & 1.111 & 1.287 & 1.139 & 1.167 & $1.176,00$ \\
3 & 1.481 & 1.509 & 1.528 & 1.306 & $1.456,00$ \\
6 & 1.639 & 1.444 & 1.528 & 1.315 & $1.481,50$ \\
9 & 1.676 & 1.509 & 1.620 & 1.713 & $1.629,50$ \\
12 & 1.778 & 1.759 & 1.398 & 1.667 & $1.650,50$ \\
18 & 1.620 & 1.694 & 1.583 & 1.537 & $1.608,50$ \\
\hline
\end{tabular}

Tabela 29 - Resultados de produção de soja, em kg/ha, referentes ao expe rimento com calagem em Guarapuava. Ano 79/80.

\begin{tabular}{|c|c|c|c|c|c|}
\hline \multirow{2}{*}{$\begin{array}{l}\text { NIVEIS DE } \\
\text { CAICÁRIO } \\
\text { (ton/ha) }\end{array}$} & \multicolumn{4}{|c|}{$\mathrm{B} I O \mathrm{COS}$} & \multirow{2}{*}{ MFDIAS } \\
\hline & 1 & 2 & 3 & 4 & \\
\hline 0 & 2.074 & 2.158 & 2.186 & 1.953 & $2.092,75$ \\
\hline 3 & 2.719 & 2.644 & 2.542 & 2.523 & $2.607,00$ \\
\hline 6 & 3.074 & 2.831 & 2.859 & 2.598 & $2.840,50$ \\
\hline 9 & 2.878 & 2.999 & 2.981 & 2.841 & $2.924,75$ \\
\hline 12 & 3.252 & 3.037 & 2.925 & 2.915 & $3.032,25$ \\
\hline 18 & 3.084 & 2.738 & 3.084 & 2.915 & $2.955,25$ \\
\hline
\end{tabular}


Tabela 30 - Resultados de produção de soja, em kg/ha, referentes ao expe rimento com calagem em Guarapuava. Ano 80/81.

\begin{tabular}{cccccc}
\hline $\begin{array}{c}\text { NIVEIS DE } \\
\text { CAICÁRIO } \\
\text { (ton/ha) }\end{array}$ & 1 & 2 & 3 & 4 & MEIDIAS \\
\cline { 2 - 5 } & 2.489 & 2.322 & 2.411 & 1.967 & $2.297,25$ \\
0 & 3.489 & 2.800 & 2.511 & 2.533 & $2.833,25$ \\
6 & 3.178 & 3.878 & 3.133 & 2.411 & $3.150,00$ \\
9 & 3.122 & 2.989 & 3.300 & 2.933 & $3.086,00$ \\
12 & 3.311 & 3.344 & 3.011 & 3.011 & $3.169,25$ \\
18 & 3.433 & 2.944 & 3.089 & 3.178 & $3.161,00$ \\
\hline
\end{tabular}

Tabela 31. - Resultados de produção de soja, em k $\boldsymbol{\bullet} / \mathrm{ha}$, referentes ao expe rimento com calagem em Guarapuava. Ano 81/82.

\begin{tabular}{cccccc}
\hline $\begin{array}{c}\text { NIVEIS DE } \\
\text { CAICARIO } \\
\text { (ton/ha) }\end{array}$ & 1 & 2 & 3 & 4 & MÉDIAS \\
\cline { 2 - 5 } & 1.525 & 1.244 & 1.666 & 1.666 & $1.525,25$ \\
0 & 1.799 & 2.055 & 1.811 & 1.977 & $1.910,50$ \\
3 & 2.033 & 1.955 & 1.999 & 2.066 & $2.013,25$ \\
9 & 2.199 & 2.166 & 2.688 & 2.255 & $2.327,00$ \\
12 & 1.822 & 2.055 & 2.644 & 1.811 & $2.083,00$ \\
18 & 2.277 & 1.888 & 2.333 & 2.322 & $2.205,00$ \\
\hline
\end{tabular}


Tabela 32 - Resultados de produção de soja, em kg/ha, referentes ao expe rimento com calagem em Grarapuava. Ano 82/83.

\begin{tabular}{cccccc}
\hline $\begin{array}{c}\text { NIVEIS DE } \\
\text { CALCÁRIO } \\
\text { (ton/ha) }\end{array}$ & 1 & 2 & 3 & 4 & MEDIAS \\
\cline { 2 - 5 } 0 & 1.550 & 1.600 & 1.787 & 1.362 & $1.574,75$ \\
3 & 2.287 & 2.375 & 2.350 & 2.055 & $2.266,75$ \\
6 & 2.312 & 2.725 & 2.425 & 2.300 & $2.440,50$ \\
9 & 2.325 & 2.725 & 2.650 & 2.262 & $2.490,50$ \\
12 & 2.675 & 2.437 & 2.475 & 2.662 & $2.562,25$ \\
18 & 1.675 & 2.425 & 1.875 & 1.225 & $1.800,00$ \\
\hline
\end{tabular}

Tabela 33 - Resultados de produção de soja, em kq/ha, referentes ao expe rimento com calagem em Guarapuava. Ano 83/84.

\begin{tabular}{cccccc}
\hline $\begin{array}{c}\text { NIVEIS DE } \\
\text { CAICARIO } \\
\text { (ton/ha) }\end{array}$ & 1 & 2 & 3 & 4 & MEDIAS \\
\cline { 2 - 5 } & 1.770 & 1.120 & 1.685 & 1.527 & $1.525,50$ \\
\hline 0 & 2.600 & 2.925 & 3.333 & 2.194 & $2.763,00$ \\
6 & 2.985 & 2.766 & 3.018 & 2.732 & $2.875,25$ \\
9 & 3.085 & 2.796 & 3.064 & 2.537 & $2.870,50$ \\
12 & 2.660 & 3.212 & 2.907 & 2.916 & $2.923,75$ \\
18 & 2.660 & 2.962 & 2.962 & 2.342 & $2.731,50$ \\
\hline
\end{tabular}


Tabela 34 - Quadro da análise de variância para os dados experimentais de Campo Mourão. Ano 78/79.

\begin{tabular}{lcccc}
\hline C. Variação & G.L. & S.O. & O.M. & $F$ \\
\hline Tratamentos & 5 & $245.155,33$ & $49.031,06$ & $5,28 * *$ \\
Blocos & 3 & $230.861,33$ & & \\
Resíduo & 15 & $139.226,66$ & $9.281,77$ \\
\hline Total & 23 & $615.243,32$ & \\
\hline
\end{tabular}

Tabela 35 - Quadro da análise de variāncia para os dados experimentais de Carnpo Mourão. Ano 79/80 .

\begin{tabular}{lcccc}
\hline C. Variação & G.L. & S. . & Q.M. & F \\
\hline Tratamentos & 5 & $2.721 .357,33$ & $544.271,46$ & $6,06 * \star$ \\
Blocos & 3 & $661.857,83$ & & \\
Resíduo & 15 & $1.345 .064,66$ & $89.670,97$ & \\
\hline Total & 23 & $4.728 .279,82$ & & \\
\hline
\end{tabular}


Tabela 36 - Quadro da análise de variāncia para os dados experimentais de Campo Mourão. Ano 80/81.

\begin{tabular}{lcccc}
\hline C. Variação & G.L. & S.Q. & Q.M. & F \\
\hline Tratamentos & 5 & $3.261 .015,37$ & $652.203,07$ & $23,14^{* *}$ \\
Blocos & 3 & $232.669,12$ & & \\
Resíduo & 15 & $422.730,12$ & $28.182,00$ & \\
\hline Total & 23 & $3.916 .414,61$ & & \\
\hline
\end{tabular}

Tabela 37 - Quadro da análise de variāncia para os dados experimentais de Campo Mourão. Ano 81/82.

\begin{tabular}{lcccc}
\hline C. Variação & G.L. & S.Q. & Q.M. & F \\
\hline Tratamentos & 5 & $2.134 .020,70$ & $426.804,14$ & $10,45^{\star *}$ \\
Blocos & 3 & $893.948,79$ & & \\
Resíduo & 15 & $612.195,45$ & $40.813,03$ & \\
\hline Total & 23 & $3.640 .164,94$ & & \\
\hline
\end{tabular}


Tabela 38 - suadro da análise de variância para os dados experimentais de Campo Mourão. Ano 82/83.

\begin{tabular}{lcccc}
\hline C. Variação & G.L. & S.Q. & O.M. & F \\
\hline Tratamentos & 5 & $2.951 .673,70$ & $590.334,74$ & $6,28 * *$ \\
Blocos & 3 & $90.910,45$ & & \\
Residuo & 15 & $1.409 .961,79$ & $93.997,45$ & \\
\hline Total & 23 & $4.452 .545,94$ & & \\
\hline
\end{tabular}

Tabela 39 - guadro da análise de variāncia para os dados experimentais de Campo Mourão. Ano 83/84.

\begin{tabular}{|c|c|c|c|c|}
\hline C. Variação & G.L. & $S . Q$. & Q.M. & $F$ \\
\hline Tratamentos & 5 & $2.543 .194,20$ & $508.638,84$ & $13,91 * *$ \\
\hline Blocos & 3 & $66.714,45$ & & \\
\hline Residuo & 15 & $548.377,29$ & $36.558,48$ & \\
\hline Total & 23 & $3.158 .285,94$ & & \\
\hline
\end{tabular}


Tabela 40 - Quadro da análise de variāncia para os dados experimentais de Guarapuava. Ano 78/79.

\begin{tabular}{lcccc}
\hline C. Variação & G.L. & S... & Q.M. & F \\
\hline Tratamentos & 5 & $633.785,33$ & $126.757,06$ & $9,98 * \star$ \\
Blocos & 3 & $43.742,33$ & & \\
Residuo & 15 & $190.475,66$ & $12.698,37$ \\
\hline Total & 23 & $868.003,32$ & & \\
\hline
\end{tabular}

Tabela 41 - Quadro da análise de variância para os dados experimentais de Guarapuava. Ano 79/80.

\begin{tabular}{lcccc}
\hline C. Variação & G.L. & S.. & Q.M. & F \\
\hline Tratamentos & 5 & $2.450 .283,83$ & $490.056,76$ & $38,08 * *$ \\
Blocos & 3 & $152.189,83$ & & \\
Residuo & 15 & $193.010,16$ & $12.867,34$ \\
\hline Total & 23 & $2.795 .483,82$ & & \\
\hline
\end{tabular}


Tabela 42 - Quadro da análise de variāncia para os dados experimentais de Guarapuava. Ano 80/81.

\begin{tabular}{|c|c|c|c|c|}
\hline c. Variação & G.L. & $S . \Omega$. & Q.M. & $\mathrm{F}$ \\
\hline Tratamentos & 5 & $2.363 .195,70$ & $472.639,14$ & $5,25 * *$ \\
\hline Blocos & 3 & $819.914,12$ & & \\
\hline Resíduo & 15 & $1.348 .930,12$ & $89.928,67$ & \\
\hline Total & 23 & $4.532 .039,94$ & & \\
\hline
\end{tabular}

Tabela 43 - Quadro da análise de variāncia para os dados experimentais de Guarapuava. Ano 81/82.

\begin{tabular}{lcccc}
\hline C. Variação & G.L. & S. . & Q.M. & F \\
\hline Tratamentos & 5 & $1.554 .934,83$ & $310.986,96$ & $7,27 * \star$ \\
Blocos & 3 & $303.283,33$ & & \\
Residuo & 15 & $641.009,16$ & $42.733,94$ \\
\hline Total & 23 & $2.499 .227,32$ & \\
\hline
\end{tabular}


Tabela 44 - Quadro da análise de variāncia para os dados experimentais de Guarapuava. Ano 82/83.

\begin{tabular}{lcccc}
\hline C. Variação & G.L. & S.Q. & Q.M. & F \\
\hline Tratamentos & 5 & $3.312 .556,37$ & $662.511,27$ & $14,50 * \star$ \\
Blocos & 3 & $536.085,79$ & & \\
Residuo & 15 & $685.302,45$ & $45.686,83$ & \\
\hline Total & 23 & $4.533 .944,61$ & & \\
\hline
\end{tabular}

Tabela 45 - Quadro da análise de variāncia para os dados experimentais de Guarapuava. Ano 83/84.

\begin{tabular}{lcccc}
\hline C. Variação & G.L. & S.Q. & Q.M. & $F$ \\
\hline Tratamentos & 5 & $5.803 .293,33$ & $1.160 .658,66$ & $17,22^{* *}$ \\
Blocos & 3 & $621.397,50$ & & \\
Residuo & 15 & $1.010 .909,00$ & $67.393,93$ & \\
\hline Total & 23 & $7.435 .599,83$ & & \\
\hline
\end{tabular}


Tabela 46 - Valores do teste F para calcário, e C.V. (으) dos experimentos de Carmpo Mourão e Guarapuava, no período de 78/79 e 83/84.

\begin{tabular}{ccccc}
\hline ANO & \multicolumn{2}{c}{ CAMPO MOURÃO } \\
C.V. (\%) & $F$ & $\begin{array}{c}\text { GUARAPUAVA } \\
\text { C.V. (\%) }\end{array}$ \\
\hline $78 / 79$ & $5,28 * *$ & 4,29 & $9,98 * *$ & 7,51 \\
$79 / 80$ & $6,07 * *$ & 12,05 & $38,08 * *$ & 4,14 \\
$80 / 81$ & $23,14 * *$ & 5,00 & $5,25 * *$ & 10,17 \\
$81 / 82$ & $10,46 * *$ & 9,70 & $7,28 * *$ & 10,28 \\
$82 / 83$ & $6,28 * *$ & 9,70 & $14,50 * *$ & 9,76 \\
$83 / 84$ & $13,91 * *$ & 6,43 & $17,22 * *$ & 9,93 \\
\hline
\end{tabular}


Tabela 47 - Análise de regressão para os dados experimentais de Campo Mourão, utilizando o modelo quadrático. Ano 78/79.

\begin{tabular}{|c|c|c|c|c|}
\hline C. Variação & G.L. & S.Q. & $Q . M$. & $E$ \\
\hline Regressão & 2 & $223.895,77$ & $111.947,88$ & $12,06 * *$ \\
\hline Desv.Regressão & 3 & $21,259,55$ & $7.086,52$ & $0,76 \mathrm{NS}$ \\
\hline (Calcário) & (5) & $245.155,32$ & $49.031,06$ & $5,28 * *$ \\
\hline Blocos & 3 & $230.861,33$ & & \\
\hline Resíduo & 15 & $139.226,66$ & $9.281,77$ & \\
\hline Total & 23 & $615.243,31$ & & \\
\hline
\end{tabular}

Tabela 48 - Análise de regressão para os dados experimentais de Cambo Mourão, utilizando o modelo quadrático. Ano 79/80.

\begin{tabular}{lcrrr}
\hline C. Variação & G.L. & S.Q. & O.M. & F \\
\hline Regressão & 2 & $2.166 .110,68$ & $1.083 .055,34$ & $12,08 * \star$ \\
Desv.Regressão & 3 & $555.246,64$ & $185.082,21$ & $2,06 \mathrm{NS}$ \\
\hline (Calcário) & $(5)$ & $2.721 .357,33$ & $544.271,46$ & $6,07 * \star$ \\
Blocos & 3 & $661.857,83$ & & \\
Resĩduo & 15, & $1.345 .064,66$ & $89.670,97$ & \\
\hline Total & 23 & $4.728 .279,81$ & & \\
\hline
\end{tabular}


Tabela 49 - Análise de regressão para os dados experimentais de Campo Mourão, utilizando o modelo quadrático. Ano 80/81.

\begin{tabular}{lcrrr}
\hline C. Variação & G.L. & \multicolumn{1}{c}{ S.0. } & \multicolumn{1}{c}{ Q.M. } & \multicolumn{1}{c}{ F } \\
\hline Regressão & 2 & $3.085 .206,92$ & $1.542 .603,46$ & $54,74^{* *}$ \\
Desv. Regressão & 3 & $175.808,44$ & $58.602,81$ & $2,08 \mathrm{NS}$ \\
\hline (Calcário) & $(5)$ & $3.261 .015,36$ & $652.203,07$ & $23,14^{* *}$ \\
Blocos & 3 & $232.669,12$ & & \\
Resíduo & 15 & $422.730,12$ & $28.182,00$ & \\
\hline Total & 23 & $3.916 .414,60$ & & \\
\hline
\end{tabular}

Tabela 50 - Análise de regressão para os dados experimentais de Campo Mourão, utilizando o modelo quadrático. Ano 81/82.

\begin{tabular}{lcrrr}
\hline C. Variação & G.L. & \multicolumn{1}{c}{ S.Q. } & \multicolumn{1}{c}{ Q.M. } & \multicolumn{1}{c}{ F } \\
\hline Regressão & 2 & $1.990 .798,08$ & $995.399,04$ & $24,30 * \star$ \\
Desv.Regressão & 3 & $143.222,62$ & $47.740,87$ & $1,17 \mathrm{NS}$ \\
\hline (Calcário) & $(5)$ & $2.134 .020,70$ & $426.804,14$ & $10,46^{* *}$ \\
Blocos & 3 & $893.948,79$ & & \\
Resíduo & 15 & $612.195,45$ & $40.813,03$ & \\
\hline Total & 23 & $3.640 .164,94$ & & \\
\hline
\end{tabular}


Tabela 51 - Análise de regressão para os dados experimentais de Carmo Mourão, utilizando o modelo quadrático. Ano 82/83.

\begin{tabular}{lcrrr}
\hline C. Variação & G.L. & \multicolumn{1}{c}{ S.Q. } & Q.M. & \multicolumn{1}{c}{ F } \\
\hline Regressão & 2 & $2.886 .993,85$ & $1.443 .496,92$ & $15,35 * *$ \\
Desv.Regressão & 3 & $64.679,85$ & $21.559,95$ & $0,22 \mathrm{NS}$ \\
\hline (Calcário) & $(5)$ & $2.951 .673,70$ & $590.334,74$ & $6,28 * *$ \\
Blocos & 3 & $90.910,45$ & & \\
Resíduo & 15 & $1.409 .961,79$ & $93.997,45$ & \\
\hline Total & 23 & $4.452 .545,94$ & & \\
\hline
\end{tabular}

Tabela 52 - Análise de regressão para os dados experimentais de Campo Mourão, utilizando o modelo quadrático. Ano 83/84.

\begin{tabular}{lcrrr}
\hline C. Variação & G.L. & \multicolumn{1}{c}{ S.Q. } & Q.M. & \multicolumn{1}{c}{ F } \\
\hline Regressão & 2 & $2.472 .213,58$ & $1.236 .106,79$ & $33,81^{* *}$ \\
Desv. Regressão & 3 & $70.980,62$ & $23.660,20$ & $0,64 \mathrm{NS}$ \\
\hline (Calcário) & $(5)$ & $2.543 .194,20$ & $508.638,84$ & $13,91^{* *}$ \\
Blocos & 3 & $66.714,45$ & & \\
Resíduo & 15 & $548.377,29$ & $36.558,48$ & \\
\hline Total & 23 & $3.158 .285,94$ & & \\
\hline
\end{tabular}


Tabela 53 - Análise de regressão para os dados experimentais de Campo Mourão, utilizando o modelo raiz quadrada. Ano 78/79.

\begin{tabular}{lccrr}
\hline C. Variação & G.L. & S.Q. & Q.M. & \multicolumn{1}{c}{ F } \\
\hline Regressão & 1 & $211.163,56$ & $211.163,56$ & $22,75 * *$ \\
Desv.Regressão & 4 & $33.991,76$ & $8.497,94$ & $0,91 \mathrm{NS}$ \\
\hline (Calcário) & $(5)$ & $245.155,32$ & $49.031,06$ & $5,28 * *$ \\
Blocos & 3 & $230.861,33$ & & \\
Resíduo & 15 & $139.226,66$ & $9.281,77$ & \\
\hline Total & 23 & $615.243,31$ & & \\
\hline
\end{tabular}

Tabela 54 - Análise de regressão para os dados experimentais de Carmoo Mourão, utilizando o modelo raiz quadrada. Ano 79/80.

\begin{tabular}{|c|c|c|c|c|}
\hline C. Variação & G.L. & $S . Q$. & Q.M. & $F$ \\
\hline Regressão & 2 & $2.632 .916,92$ & $1.316 .458,46$ & $14,68 * *$ \\
\hline Desv.Regressão & 3 & $88.440,41$ & $29.480,13$ & $0,32 \mathrm{NS}$ \\
\hline (Calcário) & (5) & $2.721 .357,33$ & $544.271,46$ & $6,07 * *$ \\
\hline Blocos & 3 & $661.857,83$ & & \\
\hline Resíduo & $15^{\circ}$ & $1.345 .064,66$ & $89.670,97$ & \\
\hline Total & 23 & $4.728 .279,82$ & & \\
\hline
\end{tabular}


Tabela 55 - Análise de regressão para os dados experimentais de Campo Mourão, utilizando o modelo raiz quadrada. Ano 80/81.

\begin{tabular}{lcrrr}
\hline C. Variação & G.L. & \multicolumn{1}{c}{ S.Q. } & \multicolumn{1}{c}{ Q.M. } & \multicolumn{1}{c}{ F } \\
\hline Regressão & 2 & $3.208 .166,11$ & $1.604 .083,05$ & $56,91^{* *}$ \\
Desv.Regressão & 3 & $52.849,25$ & $17.616,41$ & $0,62 \mathrm{NS}$ \\
\hline (Calcário) & $(5)$ & $3.261 .015,36$ & $652.203,07$ & $23,14 * *$ \\
Blocos & 3 & $232.669,12$ & & \\
Resíduo & 15 & $422.730,12$ & $28.182,00$ & \\
\hline Total & 23 & $3.916 .414,60$ & & \\
\hline
\end{tabular}

Tabela 56 - Análise de regressão para os dados experimentais de Camழo Mourão, utilizando o modelo raiz quadrada. Ano 81/82.

\begin{tabular}{|c|c|c|c|c|}
\hline c. Variação & G.L. & $S . \Omega$ & Q.M. & $F$ \\
\hline Regressão & 2 & $1.988 .380,84$ & $994.190,42$ & $24,36 * *$ \\
\hline Desv.Regressão & 3 & $145.639,86$ & $48.546,62$ & $1,19 \mathrm{NS}$ \\
\hline (Calcário) & $(5)$ & $2.134 .020,70$ & $426.804,14$ & $10,46 * *$ \\
\hline Blocos & 3 & $893.948,79$ & & \\
\hline Resíduo & 15 & $612.195,45$ & $40.813,03$ & \\
\hline Total & 23 & $3.640 .164,94$ & & \\
\hline
\end{tabular}


Tabela 57 - Análise de regressão para os dados experimentais de Caño Mourão, utilizando o modelo raiz quadrada. Ano 82/83.

\begin{tabular}{lcrrr}
\hline C. Variação & G.I. & \multicolumn{1}{c}{ S.Q. } & \multicolumn{1}{c}{ Q.M. } & \multicolumn{1}{c}{$F$} \\
\hline Regressão & 2 & $2.853 .149,39$ & $1.426 .574,69$ & $15,17^{* *}$ \\
Desv. Regressão & 3 & $98.524,31$ & $32.841,43$ & 0,35NS \\
\hline (Calcário) & $(5)$ & $2.951 .673,70$ & $590.334,74$ & $6,28^{* *}$ \\
Blocos & 3 & $90.910,45$ & & \\
Resíduo & 15 & $1.409 .961,79$ & $93.997,45$ & \\
\hline Total & 23 & $4.452 .545,94$ & & \\
\hline
\end{tabular}

Tabela 58 - Análise de regressão para os dados experimentais de Campo Mourão, utilizando o modelo raiz quadrada. Ano 83/84.

\begin{tabular}{lcrrr}
\hline C. Variação & G.L. & \multicolumn{1}{c}{ S.ก. } & \multicolumn{1}{c}{ Q.M. } & \multicolumn{1}{c}{ F } \\
\hline Regressão & 1 & $2.388 .163,08$ & $2.388 .163,08$ & $65,32^{* *}$ \\
Desv.Regressão & 4 & $155.031,12$ & $38.757,77$ & $1,06 \mathrm{NS}$ \\
\hline (Calcário) & $15)$ & $2.543 .194,20$ & $.508 .638,84$ & $13,91^{* *}$ \\
Blocos & 3 & $66.714,45$ & & \\
Resíduo & 15 & $548.377,29$ & $36.558,48$ & \\
\hline Total & 23 & $3.158 .285,94$ & & \\
\hline
\end{tabular}


Tabela 59 - Equações de regressão para o modelo quadrático com os dados de Campo Mourão.

\begin{tabular}{ll}
\hline ANO & EQUAÇÕES ESTIMADAS \\
\hline $78 / 79$ & $\widehat{Y}=2.066,00+63,9120 X-3,7890 \mathrm{X}^{2}$ \\
$79 / 80$ & $\hat{\mathrm{Y}}=1.892,00+251,2486 \mathrm{X}-18,0948 \mathrm{X}^{2}$ \\
$80 / 81$ & $\widehat{Y}=2.658,00+278,8035 \mathrm{X}-18,9642 \mathrm{X}^{2}$ \\
$81 / 82$ & $\widehat{Y}=1.646,00+95,1535 \mathrm{X}-1,0892 \mathrm{X}^{2}$ \\
$82 / 83$ & $\widehat{Y}=2.479,00+279,2826 \mathrm{X}-19,5279 \mathrm{X}^{2}$ \\
$83 / 84$ & $\hat{\mathrm{Y}}=2.325,00+215,3361 \mathrm{X}-12,9296 \mathrm{X}^{2}$ \\
\hline
\end{tabular}


Tabela 60 - Valores dos Y observados, $\widehat{Y}$ estimados e Desvios, com os dados experimentais de Campo Mourão. Ano 78/79.

\begin{tabular}{ccc}
\hline & $\begin{array}{c}\text { MODELO QUADRATICO } \\
\text { Y Observado }\end{array}$ & Desvios \\
\hline $2.078,00$ & $2.066,00$ & 12,00 \\
$2.135,00$ & $2.179,00$ & $-44,00$ \\
$2.313,00$ & $2.261,00$ & 52,00 \\
$2.304,00$ & $2.313,00$ & $-9,00$ \\
$2.314,00$ & $2.335,00$ & $-21,00$ \\
$2.336,00$ & $2.326,00$ & 10,00 \\
\hline
\end{tabular}

Tabela 61 - Valores dos Y observados, $\bar{Y}$ estimados e desvios, com os dados experimentais de Campo Mourão. Ano 79/80.

\begin{tabular}{ccc}
\hline & $\begin{array}{c}\text { MODELO QUADRÁTICO } \\
\bar{Y} \text { Estimado }\end{array}$ & Desvios \\
\hline $1.737,00$ & $1.892,00$ & $-155,00$ \\
$2.592,00$ & $2.322,00$ & 270,00 \\
$2.642,00$ & $2.608,00$ & 34,00 \\
$2.579,00$ & $2.748,00$ & $-169,00$ \\
$2.676,00$ & $2.744,00$ & $-68,00$ \\
$2.683,00$ & $2.595,00$ & 88,00 \\
\hline
\end{tabular}


Tabela 62 - Valores dos Y observados, $Y$ estimados e Desvios, com os dados experimentais de Campo Mourão. Ano 80/81.

\begin{tabular}{ccc}
\hline & $\begin{array}{c}\text { MODELO QUADRÁtICO } \\
\hat{Y} \text { Fstimado }\end{array}$ & Desvios \\
\hline $2.578,00$ & $2.658,00$ & $-80,00$ \\
$3.310,00$ & $3.140,00$ & 170,00 \\
$3.421,00$ & $3.470,00$ & $-49,00$ \\
$3.573,00$ & $3.648,00$ & $-75,00$ \\
$3.692,00$ & $3.675,00$ & 17,00 \\
$3.567,00$ & $3.550,00$ & 17,00 \\
\hline
\end{tabular}

Tabela 63 - Valores dos Y observados, Y estimados e Desvios, com os dados experimentais de Campo Mourão. Ano 81/83.

\begin{tabular}{ccr}
\hline & $\begin{array}{c}\text { MODELO QUADRÁTICO } \\
\text { Y Observado }\end{array}$ & Desvios \\
\hline $1.664,00$ & $1.646,00$ & 18,00 \\
$1.751,00$ & $1.832,00$ & $-81,00$ \\
$2.146,00$ & $2.010,00$ & 136,00 \\
$2.080,00$ & $2.178,00$ & $-98,00$ \\
$2.362,00$ & $2.338,00$ & 24,00 \\
$2.490,00$ & $2.489,00$ & 1,00 \\
\hline
\end{tabular}


Tabela 64 - Valores dos Y observados, $\widehat{Y}$ estimados e Desvios, com os dados experimentais de Cammo Mourão. Ano 82/83.

\begin{tabular}{ccr}
\hline & $\begin{array}{c}\text { MODELO QUADRÁTICO } \\
\text { Y Observado }\end{array}$ & Estimado \\
\hline $2.441,00$ & $2.479,00$ & $-38,00$ \\
$3.023,00$ & $2.960,00$ & 63,00 \\
$3.317,00$ & $3.284,00$ & 33,00 \\
$3.358,00$ & $3.452,00$ & $-94,00$ \\
$3.492,00$ & $3.464,00$ & 28,00 \\
$3.327,00$ & $3.31 .9,00$ & 8,00 \\
\hline
\end{tabular}

Tabela 65 - Valores dos Y abservados, $\bar{Y}$ estimados e Desvios, com os dados experimentais de Carmo Mourão. Ano 83/84.

\begin{tabular}{ccr}
\hline & $\begin{array}{c}\text { MODELO QUADRÁtICO } \\
\text { Y Observado }\end{array}$ & Estimado \\
\hline $2.326,00$ & $2.325,00$ & 1,00 \\
$2.658,00$ & $2.703,00$ & $-45,00$ \\
$3.068,00$ & $2.979,00$ & 89,00 \\
$3.144,00$ & $3.151,00$ & $-7,00$ \\
$3.142,00$ & $3.220,00$ & $-78,00$ \\
$3.225,00$ & $3.185,00$ & 40,00 \\
\hline
\end{tabular}


Tabela 66 - Equações de regressão para o modelo raiz quadrada, com os dados experimentais de Cambo Mourão, no período de 78/79 a 83/ 84 .

\begin{tabular}{ll}
\hline ANO & \multicolumn{1}{c}{ EQUAÇÕES ESTIMADAS } \\
\hline $78 / 79$ & $\hat{\mathrm{Y}}=2.069,00+89,5807 \sqrt{\mathrm{X}}$ \\
$79 / 80$ & $\hat{\mathrm{Y}}=1.756,00+738,7154 \sqrt{\mathrm{X}}-145,9005 \mathrm{X}$ \\
$80 / 81$ & $\hat{\mathrm{Y}}=2.577,00+654,5372 \sqrt{\mathrm{X}}-102,5578 \mathrm{X}$ \\
$81 / 82$ & $\hat{\mathrm{Y}}=1.654,00+13,0182 \sqrt{\mathrm{X}}+80,4520 \mathrm{X}$ \\
$82 / 83$ & $\hat{\mathrm{Y}}=2.423,00+618,5724 \sqrt{\mathrm{X}}-97,1804 \mathrm{X}$ \\
$83 / 84$ & $\hat{\mathrm{Y}}=2.332,00+301,2572 \sqrt{\mathrm{X}}$ \\
\hline
\end{tabular}


Tabela 67 - Valores dos Y observados, $\widehat{Y}$ estimados e Desvios, com os dados experinentais de Campo Mourão. Ano 78/79.

\begin{tabular}{ccc}
\hline & $\begin{array}{r}\text { MODELO RAIZ QUADRADA } \\
\text { Y Observado }\end{array}$ & Estimado \\
\hline $2.078,00$ & $2.059,00$ & 9,00 \\
$2.135,00$ & $2.196,00$ & $-61,00$ \\
$2.313,00$ & $2.249,00$ & 64,00 \\
$2.304,00$ & $2.289,00$ & 15,00 \\
$2.314,00$ & $2.323,00$ & $-9,00$ \\
$2.335,00$ & $2.353,00$ & $-18,00$ \\
\hline
\end{tabular}

Tabela 68 - Valores dos Y observados, $\bar{Y}$ estimados e Desvios, com os dados experimentais de Campo Mourão. Ano 79/80.

\begin{tabular}{ccr}
\hline & $\begin{array}{r}\text { MODEIO RAIZ QUADRADA } \\
\text { Y Observado }\end{array}$ & Estimado \\
\hline $1.737,00$ & $1.756,00$ & $-19,00$ \\
$2.592,00$ & $2.508,00$ & 84,00 \\
$2.642,00$ & $2.649,00$ & $-7,00$ \\
$2.579,00$ & $2.689,00$ & $-110,00$ \\
$2.677,00$ & $2.677,00$ & 0,00 \\
$2.683,00$ & $2.631,00$ & 52,00 \\
\hline
\end{tabular}


Tabela 69 - Valores dos Y observados, $\hat{Y}$ estimados e Desvios, com os dados experimentais de Campo Mourão. Ano 80/8I.

\begin{tabular}{ccr}
\hline & $\begin{array}{r}\text { MODEI.O RAIZ OUADRADA } \\
\hat{Y} \text { Estimado }\end{array}$ & Desvios \\
\hline $2.578,00$ & $2.577,00$ & 1,00 \\
$3.310,00$ & $3.297,00$ & 13,00 \\
$3.421,00$ & $3.475,00$ & $-54,00$ \\
$3.573,00$ & $3.564,00$ & 9,00 \\
$3.692,00$ & $3.607,00$ & 85,00 \\
$3.567,00$ & $3.621,00$ & $-54,00$ \\
\hline
\end{tabular}

Tabela 70 - Valores dos Y observados, $\bar{Y}$ estimados e Desvios, com os dados experimentais de Campo Mourão. Ano 81/82.

\begin{tabular}{ccc}
\hline & $\begin{array}{r}\text { MODELO RAIZ @UADRADA } \\
\text { Y Observado }\end{array}$ & Desvios \\
\hline $1.665,00$ & $1.654,00$ & 11,00 \\
$1.750,00$ & $1.833,00$ & $-83,00$ \\
$2.146,00$ & $2.002,00$ & 144,00 \\
$2.080,00$ & $2.169,00$ & $-89,00$ \\
$2.362,00$ & $2.335,00$ & 27,00 \\
$2.490,00$ & $2.500,00$ & $-10,00$ \\
\hline
\end{tabular}


Tabela 71 - Valores dos Y observados, $\hat{Y}$ estimados e Desvios, com os dados experimentais de Campo Mourão. Ano 82/83.

\begin{tabular}{ccr}
\hline & $\begin{array}{r}\text { MODEL R RAIZ QUADRADA } \\
\hat{Y} \text { Estimado }\end{array}$ & Desvios \\
\hline $2.441,00$ & $2.423,00$ & 18,00 \\
$3.023,00$ & $3.104,00$ & $-81,00$ \\
$3.317,00$ & $3.272,00$ & 45,00 \\
$3.359,00$ & $3.356,00$ & 3,00 \\
$3.492,00$ & $3.396,00$ & 96,00 \\
$3.327,00$ & $3.408,00$ & $-81,00$ \\
\hline
\end{tabular}

Tabela 72 - Valores dos Y observados, $\widehat{Y}$ estimados e Desvios, com os dados experimentais de Carmpo Mourão. Ano 83/84.

\begin{tabular}{ccr}
\hline & $\begin{array}{r}\text { MODELO RAIZ SUADRADA } \\
\text { Y Observado }\end{array}$ & Estimado \\
\hline $2.326,00$ & $2.332,00$ & $-6,00$ \\
$2.658,00$ & $2.758,00$ & $-100,00$ \\
$3.068,00$ & $2.934,01$ & 134,00 \\
$3.144,00$ & $3.070,00$ & 74,00 \\
$3.142,00$ & $3.184,00$ & $-42,00$ \\
$3.225,00$ & $3.285,00$ & $-60,00$ \\
\hline
\end{tabular}


Tabela 73 - Análise de regressão para os dados experimentais de ruarapua va, utilizando o modelo quadrático. Ano 78/79.

\begin{tabular}{lcccc}
\hline C. Variação & G.L. & S.O. & $0 . M$. & F \\
\hline Regressão & 2 & $603.468,01$ & $301.734,00$ & $23,76^{\star *}$ \\
Desv. Regressão & 3 & $30.317,31$ & $10.105,77$ & $0,79 \mathrm{NS}$ \\
\hline (Calcário) & $(5)$ & $633.785,32$ & $126.757,07$ & $9,98 * *$ \\
Blocos & 3 & $43.742,33$ & & \\
Resíduo & 15 & $190.475,66$ & $12.698,38$ & \\
\hline Total & 23 & $868.003,31$ & & \\
\hline
\end{tabular}

Tabela 74 - Análise de regressão para os dados experimentais de Guarapua va, utilizando o modelo quadrático. Ano 79/80.

\begin{tabular}{lcrrr}
\hline C. Variação & G.I. & \multicolumn{1}{c}{ S. } & Q.M. & \multicolumn{1}{c}{$F$} \\
\hline Regressão & 2 & $2.385 .721,85$ & $1.192 .860,92$ & $92,70 * *$ \\
Desv. Regressão & 3 & $64.561,97$ & $21.520,65$ & $1,65 \mathrm{NS}$ \\
\hline (Calcário) & $(5)$ & $2.450 .283,82$ & $490.056,77$ & $38,08 * \star$ \\
Blocos & 3 & $152.189,83$ & & \\
Residuo & 15 & $193.010,16$ & $12.867,34$ & \\
\hline Total & 23 & $2.795 .483,81$ & & \\
\hline
\end{tabular}


Tabela 75 - Análise de regressão para os dados experinentais de Guarapua va, utilizando o modelo quadrático. Ano 80/81.

\begin{tabular}{lcrrr}
\hline c. Variação & G.L. & \multicolumn{1}{c}{ S..} & Q.M. & \multicolumn{1}{c}{ F } \\
\hline Regressão & 2 & $2.151 .425,78$ & $1.075 .712,89$ & $11,96 * *$ \\
Desv .Regressão & 3 & $211.769,92$ & $70.589,97$ & $0,78 \mathrm{NS}$ \\
\hline (Calcário) & $(5)$ & $2.363 .195,70$ & $472.639,14$ & $5,25 * *$ \\
Blocos & 3 & $819.914,12$ & & \\
Resíduo & 15 & $1.348 .930,12$ & $89.928,67$ & \\
\hline Total & 23 & $4.532 .039,94$ & & \\
\hline
\end{tabular}

Tabela 76 - Análise de regressão para os dados experimentais de Guarapua va, utilizando o modelo quadrático. Ano 81/82.

\begin{tabular}{|c|c|c|c|c|}
\hline C. Variação & G.L. & S. $\Omega$. & Q.M. & $F$ \\
\hline Regressão & 2 & $1.327 .373,53$ & $663.686,76$ & $15,53 * *$ \\
\hline Desv. Regressão & 3 & $227.561,30$ & $75.853,76$ & $1,77 \mathrm{NS}$ \\
\hline (Calcārio) & (5) & $1.554 .934,83$ & $310.986,96$ & $7,28 * *$ \\
\hline Blocos & 3 & $303.283,33$ & - & \\
\hline Resíduo & 15 & $641.009,16$ & $42.733,94$ & \\
\hline Total & 23 & $2.499 .227,32$ & & \\
\hline
\end{tabular}


Tabela 77 - Análise de regressão para os dados experimentais de Guarapua va, utilizando o modelo quadrático. Ano 82/83.

\begin{tabular}{lcrrr}
\hline C. Variação & G.L. & \multicolumn{1}{c}{ S.Q. } & \multicolumn{1}{c}{ Q.M. } & \multicolumn{1}{c}{ F } \\
\hline Regressão & 2 & $3.192 .298,01$ & $1.596 .149,00$ & 34,94 ** \\
Desv. Regressão & 3 & $120.258,35$ & $40.086,11$ & $0,87 \mathrm{NS}$ \\
\hline (Calcário) & $15)$ & $3.312 .556,36$ & $662.511,27$ & $14,50 * *$ \\
Blocos & 3 & $536.085,79$ & & \\
Resíduo & 15 & $685.302,46$ & $45.686,83$ & \\
\hline Total & 23 & $4.533 .944,61$ & & \\
\hline
\end{tabular}

Tabela 78 - Análise de regressão para os dados experimentais de Guarapua va, utilizando o modelo quadrático. Ano 83/84.

\begin{tabular}{lcrrr}
\hline C. Variação & G.L. & \multicolumn{1}{c}{ S.Q. } & \multicolumn{1}{c}{ Q.M. } & \multicolumn{1}{c}{ F } \\
\hline Regressão & 2 & $4.693 .417,41$ & $2.346 .708,70$ & $34,82^{* *}$ \\
Desv. Regressão & 3 & $1.109 .875,92$ & $369.958,64$ & $5,48^{* *}$ \\
\hline (Calcário) & $(5)$ & $5.803 .293,33$ & $1.160 .658,66$ & $17,22^{* *}$ \\
Blocos & 3 & $621.397,50$ & & \\
Resĩduo & 15 & $1.010 .909,00$ & $67.393,93$ & \\
\hline Total & 23 & $7.435 .599,83$ & & \\
\hline
\end{tabular}


Tabela 79 - Análise de regressão para os dados experimentais de Guarapua va, utilizando o modelo raiz quadrada. Ano 78/79.

\begin{tabular}{lcrrr}
\hline C. Variação & G.I. & S.Q. & Q.M. & \multicolumn{1}{c}{ F } \\
\hline Regressão & 2 & $603.231,85$ & $301.615,92$ & $23,75^{* *}$ \\
Desv.Regressão & 3 & $30.553,47$ & $10.184,49$ & $0,80 \mathrm{NS}$ \\
\hline (Calcário) & $(5)$ & $633.785,32$ & $126.757,07$ & $9,98 * *$ \\
Blocos & 3 & $43.742,33$ & & \\
Resíduo & 15 & $190.475,66$ & $12.698,38$ & \\
\hline Total & 23 & $868.004,31$ & & \\
\hline
\end{tabular}

Tabela 80 - Análise de regressão para os dados experimentais de Guarapua va, utilizando o modelo raiz quadrada. Ano 79/80.

\begin{tabular}{lcrrr}
\hline C. Variação & G.L. & \multicolumn{1}{c}{ S.Q. } & Q.M. & \multicolumn{1}{c}{ F } \\
\hline Regressão & 2 & $2.406 .189,82$ & $1.203 .094,91$ & $93,49 * *$ \\
Desv. Reqressão & 3 & $44.094,00$ & $14.698,00$ & $1,14 \mathrm{NS}$ \\
\hline (Calcário) & $(5)$ & $2.450 .283,82$ & $490.056,77$ & $38,08 * *$ \\
Blocos & 3 & $152.189,83$ & & \\
Resíduo & 15 & $193.010,16$ & $12.867,34$ & \\
\hline Total & 23 & $2.795 .483,81$ & & \\
\hline
\end{tabular}


Tabela 81 - Análise de regressão para os dados experimentais de Guarapua va, utilizando o modelo raiz quadrada. Ano 80/81.

\begin{tabular}{lcrrr}
\hline C. Variação & G.I. & \multicolumn{1}{c}{ S...} & Q.M. & \multicolumn{1}{c}{ F } \\
\hline Regressão & 2 & $2.299 .086,36$ & $1.149 .543,18$ & $12,78 * \star$ \\
Desv.Regressão & 3 & $64.109,34$ & $21.369,78$ & $0,23 \mathrm{NS}$ \\
\hline (Calcário) & $(5)$ & $2.363 .195,70$ & $472.639,14$ & $5,25 * \star$ \\
Blocos & 3 & $819.914,12$ & & \\
Resíduo & 15 & $1.348 .930,12$ & $89.928,67$ & \\
\hline Total & 23 & $4.532 .039,94$ & & \\
\hline
\end{tabular}

Tabela 82 - Análise de regressão para os dados experimentais de Guarapua va, utilizando o modelo raiz quadrada. Ano 81/82.

\begin{tabular}{lcrrr}
\hline C. Variação & G.L. & \multicolumn{1}{c}{ S...} & O.M. & \multicolumn{1}{c}{ F } \\
\hline Regressão & 2 & $1.355 .333,19$ & $677.666,59$ & $15,86 * *$ \\
Desv.Regressão & 3 & $199.601,63$ & $66.533,87$ & $1,56 \mathrm{NS}$ \\
\hline (Calcário) & $(5)$ & $1.554 .934,82$ & $311.043,14$ & $7,27 * *$ \\
Blocos & 3 & $303.283,33$ & & \\
Resíduo & 15 & $641.211,03$ & $42.747,40$ & \\
\hline Total & 23 & $2.499 .429,18$ & & \\
\hline
\end{tabular}


Tabela 83 - Análise de regressão para os dados experimentais de Guarapua va, utilizando o modelo raiz quadrada. Ano 82/83.

\begin{tabular}{lcrrr}
\hline C. Variação & G.L. & \multicolumn{1}{c}{ S.Q. } & \multicolumn{1}{c}{ Q.M. } & \multicolumn{1}{c}{ F } \\
\hline Regressão & 2 & $2.861 .216,18$ & $1.430 .608,09$ & $31,31^{* *}$ \\
Desv. Regressão & 3 & $451.340,18$ & $150.446,72$ & $3,29 * *$ \\
\hline (Calcário) & $(5)$ & $3.312 .556,36$ & $662.511,27$ & $14,50 * *$ \\
Blocos & 3 & $536.085,79$ & & \\
Resíduo & 15 & $685.302,46$ & $45.686,83$ & \\
\hline Total & 23 & $4.533 .944,61$ & & \\
\hline
\end{tabular}

Tabela 84 - Análise de regressão para os dados experimentais de Guarapua va, utilizando o modelo raiz quadrada. Ano 83/84.

\begin{tabular}{lcrrr}
\hline C. Variação & G.L. & \multicolumn{1}{c}{ S.Q. } & \multicolumn{1}{c}{ Q.M. } & \multicolumn{1}{c}{ F } \\
\hline Regressão & 2 & $5.755 .836,44$ & $2.877 .918,22$ & $42,70^{* *}$ \\
Desv.Regressão & 3 & $47.456,88$ & $15.818,96$ & 0,23 NS \\
\hline (Calcário) & $(5)$ & $5.803 .293,32$ & $1.160 .658,66$ & $17,22^{\star *}$ \\
Blocos & 3 & $621.397,50$ & & \\
Resĩduo & 15 & $1.010 .909,00$ & $67.393,93$ & \\
\hline Total & 23 & $7.435 .599,82$ & & \\
\hline
\end{tabular}


Tabela 85 - Equações de regressão para o modelo quadrático, para os dados de Guarapuava.

\begin{tabular}{ll}
\hline ANO & EQUAÇÕES ESTIMADAS \\
\hline $78 / 79$ & $\hat{Y}=1.204,00+69,6333 X-2,6342 X^{2}$ \\
$79 / 80$ & $\hat{Y}=2.151,00+140,6404 X-5,3931 X^{2}$ \\
$80 / 81$ & $\hat{Y}=2.386,00+136,1011 X-5,3048 X^{2}$ \\
$81 / 82$ & $\hat{Y}=1.571,00+103,1214 X-3,8961 X^{2}$ \\
$82 / 83$ & $\hat{Y}=1.634,00+201,9488 X-10,7096 X^{2}$ \\
$83 / 84$ & $\hat{Y}=1.778,00+228,9571 X-10,0449 X^{2}$ \\
\hline
\end{tabular}


Tabela 86 - Valores dos Y observados, $\bar{Y}$ estimados e Desvios, com os dados experimentais de Guarapuava. Ano 78/79.

\begin{tabular}{ccr}
\hline & $\begin{array}{c}\text { MODELO QUADRATICO } \\
\text { Y Observado }\end{array}$ & \multicolumn{1}{c}{ Desvios } \\
\hline $1.176,00$ & $1.204,00$ & $-28,00$ \\
$1.456,00$ & $1.389,00$ & 67,00 \\
$1.482,00$ & $1.527,00$ & $-45,00$ \\
$1.629,00$ & $1.617,00$ & 12,00 \\
$1.650,00$ & $1.660,00$ & $-10,00$ \\
$1.608,00$ & $1.604,00$ & 4,00 \\
\hline
\end{tabular}

Tabela 87 - Valores dos Y observados, y estimados e Desvios, com os dados experimentais de Guarapuava. Ano 79/80.

\begin{tabular}{ccr}
\hline & $\begin{array}{c}\text { MODELO OUADRÁTICO } \\
\text { Y Observado }\end{array}$ & Desvios \\
\hline $2.093,00$ & $2.151,00$ & $-58,00$ \\
$2.607,00$ & $2.524,00$ & 83,00 \\
$2.840,00$ & $2.800,00$ & 40,00 \\
$2.925,00$ & $2.980,00$ & $-55,00$ \\
$3.032,00$ & $3.062,00$ & $-30,00$ \\
$2.955,00$ & $2.935,00$ & 20,00 \\
\hline
\end{tabular}


Tabela 88 - Valores dos Y observados, $\widehat{Y}$ estimados e Desvios, com os dados experimentais de Guarapuava. Ano 80/81.

\begin{tabular}{ccc}
\hline & $\begin{array}{c}\text { MODELO QUADRÁTICO } \\
\text { Y Observado }\end{array}$ & Destimado \\
\hline $2.297,00$ & $2.386,00$ & $-89,00$ \\
$2.833,00$ & $2.746,00$ & 87,00 \\
$3.150,00$ & $3.011,00$ & 139,00 \\
$3.086,00$ & $3.181,00$ & $-95,00$ \\
$3.169,00$ & $3.255,00$ & $-86,00$ \\
$3.161,00$ & $3.117,00$ & 44,00 \\
\hline
\end{tabular}

Tabela 89 - Valores dos Y observados, 9 estimados e Desvios, com os dados experimentais de Guarapuava. Ano 81/82.

\begin{tabular}{ccc}
\hline \multicolumn{3}{c}{ MODEIO OUADRÁTICO } \\
Y Observado & $\hat{Y}$ Estimado & Desvios \\
\hline $1.525,00$ & $1.571,00$ & $-46,00$ \\
$1.911,00$ & $1.846,00$ & 65,00 \\
$2.013,00$ & $2.050,00$ & $-37,00$ \\
$2.327,00$ & $2.184,00$ & 147,00 \\
$2.083,00$ & $2.248,00$ & $-165,00$ \\
$2.205,00$ & $2.165,00$ & 40,00 \\
\hline
\end{tabular}


Tabela 90 - Valores dos Y observados, $\widehat{Y}$ estimados e Desvios, com os dados experimentais de Guarapuava. Ano 82/83.

\begin{tabular}{ccc}
\hline & $\begin{array}{c}\text { MODELO OUADRATICO } \\
\hat{Y} \text { Estimado }\end{array}$ & Desvios \\
\hline $1.575,00$ & $1.634,00$ & $-59,00$ \\
$2.267,00$ & $2.143,00$ & 123,00 \\
$2.441,00$ & $2.460,00$ & $-19,00$ \\
$2.490,00$ & $2.584,00$ & $-94,00$ \\
$2.562,00$ & $2.515,00$ & 47,00 \\
$1.800,00$ & $1.798,00$ & 1,00 \\
\hline
\end{tabular}

Tabela 91 - Valores dos Y observados, $\bar{Y}$ estimados e Desvios, com os dados experimentais de Guarapuava. Ano 83/84.

\begin{tabular}{ccr}
\hline & $\begin{array}{r}\text { MODELO OUADRATICO } \\
\hat{Y} \text { Estimado }\end{array}$ & Desvios \\
\hline $1.526,00$ & $1.778,00$ & $-252,00$ \\
$2.763,00$ & $2.374,00$ & 389,00 \\
$2.875,00$ & $2.790,00$ & 85,00 \\
$2.871,00$ & $3.025,00$ & $-154,00$ \\
$2.924,00$ & $3.079,00$ & $-155,00$ \\
$2.731,00$ & $2.644,00$ & 87,00 \\
\hline
\end{tabular}


143.

Tabela 92 - Equações de regressão para o modelo raiz quadrada, com os da dos experimentais de Guarapuava.

\begin{tabular}{ll}
\hline ANO & EQUACÕES ESTIMADAS \\
\hline $78 / 79$ & $\hat{Y}=1.167,00+206,9515 \sqrt{\mathrm{X}}-22,8432 \mathrm{X}$ \\
$79 / 80$ & $\widehat{Y}=2.076,00+429,4135 \sqrt{\mathrm{X}}-49,9340 \mathrm{X}$ \\
$80 / 81$ & $\widehat{Y}=2.287,00+455.4593 \sqrt{\mathrm{X}}-58,5553 \mathrm{X}$ \\
$81 / 82$ & $\hat{Y}=1.513,00+316,4763 \sqrt{\mathrm{X}}-35,9164 \mathrm{X}$ \\
$82 / 83$ & $\widehat{Y}=1.527,00+796,0020 \sqrt{\mathrm{X}}-164,1405 \mathrm{X}$ \\
$83 / 84$ & $\widehat{Y}=1.542,00+929,9405 \sqrt{\mathrm{X}}-154,3310 \mathrm{X}$ \\
\hline
\end{tabular}


Tabela 93 - Valores dos Y observados, $\widehat{Y}$ estimados e Desvios, com os dados experimentais de Guarapuava. Ano 78/79.

\begin{tabular}{ccc}
\hline & $\begin{array}{r}\text { MODEIO RAIZ OUADRADA } \\
\text { Y Observado }\end{array}$ & Desvios \\
\hline $1.176,00$ & $1.170,00$ & 6,00 \\
$1.456,00$ & $1.459,00$ & $-3,00$ \\
$1.481,00$ & $1.539,00$ & $-58,00$ \\
$1.629,00$ & $1.585,00$ & 44,00 \\
$1.651,00$ & $1.612,00$ & 39,00 \\
$1.608,00$ & $1.636,00$ & $-28,00$ \\
\hline
\end{tabular}

Tabela 94 - Valores dos Y observados, $\widehat{Y}$ estimados e Desvios, com os dados experimentais de Guarapuava. Ano 79/80.

\begin{tabular}{ccc}
\hline & $\begin{array}{r}\text { MODELO RAIZ QUADRADA } \\
\hat{Y} \text { Estinado }\end{array}$ & Desvios \\
\hline $2.093,00$ & $2.076,00$ & 17,00 \\
$2.607,00$ & $2.670,00$ & $-63,00$ \\
$2.840,00$ & $2.828,00$ & 12,00 \\
$2.925,00$ & $2.915,00$ & 10,00 \\
$3.032,00$ & $2.964,00$ & 68,00 \\
$2.955,00$ & $2.999,00$ & $-44,00$ \\
\hline
\end{tabular}


Tabela 95 - Valores dos Y observados, Y estimados e Desvios, com os dados experimentais de Guarapuava. Ano 80/81.

\begin{tabular}{ccr}
\hline & $\begin{array}{r}\text { MODELO RAIZ DUADRADA } \\
\text { Y Observado }\end{array}$ & Estimado \\
\hline $2.297,00$ & $2.287,00$ & 19,00 \\
$2.833,00$ & $2.901,00$ & $-68,00$ \\
$3.150,00$ & $3.052,00$ & 98,00 \\
$3.086,00$ & $3.127,00$ & $-41,00$ \\
$3.169,00$ & $3.163,00$ & 6,00 \\
$3.161,00$ & $3.166,00$ & $-5,00$ \\
\hline
\end{tabular}

Tabela 96 - Valores dos Y observados, $\widehat{Y}$ estimados e Desvios, com os dados experimentais de Guarapuava. Ano 81/82.

\begin{tabular}{ccc}
\hline & $\begin{array}{r}\text { MODEIO RAIZ QUADRADA } \\
\text { Y Observado }\end{array}$ & Estimado \\
\hline $1.525,00$ & $1.513,00$ & 12,00 \\
$1.910,00$ & $1.953,00$ & $-43,00$ \\
$2.013,00$ & $2.072,00$ & $-59,00$ \\
$2.328,00$ & $2.139,00$ & 189,00 \\
$2.083,00$ & $2.178,00$ & $-95,00$ \\
$2.205,00$ & $2.209,00$ & $-4,00$ \\
\hline
\end{tabular}


Tabela 97 - Valores dos Y observados, $\bar{Y}$ estimados e Desvios, com os dados experimentais de Guarapuava. Ano 82/83.

\begin{tabular}{ccr}
\hline & $\begin{array}{r}\text { MODELO RAIZ QUADRADA } \\
\hat{Y} \text { Estimado }\end{array}$ & \multicolumn{1}{c}{ Desvios } \\
\hline $1.575,00$ & $1.527,00$ & 48,00 \\
$2.267,00$ & $2.413,00$ & $-146,00$ \\
$2.440,00$ & $2.492,00$ & $-52,00$ \\
$2.491,00$ & $2.438,00$ & 53,00 \\
$2.562,00$ & $2.315,00$ & 247,00 \\
$1.800,00$ & $1.949,00$ & $-150,00$ \\
\hline
\end{tabular}

Tabela 98 - Valores dos Y observados, $\bar{Y}$ estimados e Desvios, com os dados experimentais de Guarapuava. Ano 83/84.

\begin{tabular}{ccc}
\hline & $\begin{array}{r}\text { MODELO RAIZ QUADRADA } \\
\text { Y Observado }\end{array}$ & Desvios \\
\hline $1.525,00$ & $1.542,00$ & $-17,00$ \\
$2.763,00$ & $2.690,00$ & 73,00 \\
$2.875,00$ & $2.894,00$ & $-19,00$ \\
$2.870,00$ & $2.943,00$ & $-73,00$ \\
$2.294,00$ & $2.911,00$ & 13,00 \\
$2.732,00$ & $2.709,00$ & 23,00 \\
\hline
\end{tabular}


Tæabela 99 - Análise de regressão para os dados experimentais de Camtoo Mou rão, utilizando a 2ạ abroximação de Mitscherlich. Ano 78/79.

\begin{tabular}{lcccc}
\hline C. Variação & G.L. & S.Q. & Q.M. & F \\
\hline Regressão & 3 & $224.041,89$ & $74.680,63$ & $8,04 * \star$ \\
Desv.Regressão & 2 & $21.113,44$ & $10.556,72$ & $1,13 N S$ \\
\hline (Calcärio) & $(5)$ & $245.155,33$ & $49.031,06$ & $5,28 * \star$ \\
Blocos & 3 & $230.861,33$ & & \\
Resíduo & 15 & $139.226,66$ & $9.281,77$ & \\
\hline Total & 23 & $615.243,32$ & & \\
\hline
\end{tabular}

Tabela 100 - Análise de regressão para os dados experimentais de Carmo Mou rão, utilizando a 2ạ aproximação de Mitscherlich. Ano 79/80.

\begin{tabular}{lcrrr}
\hline C. Variação & G.L. & \multicolumn{1}{c}{ S.Q. } & Q.M. & \multicolumn{1}{c}{ F } \\
\hline Regressão & 3 & $2.705 .366,45$ & $901.788,81$ & $10,05^{* *}$ \\
Desv.Regressão & 2 & $15.990,88$ & $7.995,44$ & $0,09 \mathrm{NS}$ \\
\hline (Calcário) & $(5)$ & $2.721 .357,33$ & $544.271,46$ & $6,06 * *$ \\
Blocos & 3 & $661.857,83$ & & \\
Resĩduo & 15 & $1.345 .064,66$ & $89.670,97$ & \\
\hline Total & 23 & $4.728 .279,82$ & & \\
\hline
\end{tabular}


Tabela 101 - Análise de regressão para os dados experimentais de Campo Mou rão, utilizando a 2à aprozimação de Mitscherlich. Ano 80/81.

\begin{tabular}{lcrrr}
\hline C. Variação & G.L. & \multicolumn{1}{c}{ S.Q. } & Q.M. & \multicolumn{1}{c}{ F } \\
\hline Regressão & 3 & $3.190 .013,77$ & $1.063 .337,92$ & $37,73 * *$ \\
Desv.Regressão & 2 & $71.001,60$ & $35.500,80$ & $1,26 \mathrm{NS}$ \\
\hline (Calcário) & $15)$ & $3.261 .015,37$ & $652.203,07$ & $23,14 * *$ \\
Blocos & 3 & $232.669,12$ & & \\
Resíduo & 15 & $422.730,12$ & $28.182,00$ & \\
\hline Total & 23 & $3.916 .414,61$ & & \\
\hline
\end{tabular}

Tabela 102 - Anāli ise de regressão para os dados experimentais de Campo Mou rão, utilizando a 2a aproximação de Mitscherlich. Ano 81/82.

\begin{tabular}{lcrrr}
\hline C. Variação & G.L. & \multicolumn{1}{c}{ S.Q. } & Q.M. & F \\
\hline Regressão & 3 & $1.990 .929,10$ & $663.643,03$ & $16,26 * *$ \\
Desv.Regressão & 2 & $143.091,60$ & $71.545,80$ & $1,75 \mathrm{NS}$ \\
\hline (Calcärio) & $(5)$ & $2.134 .020,70$ & $462.804,14$ & $11,34 * *$ \\
Blocos & 3 & $893.948,79$ & & \\
Resíduo & 15 & $612.195,45$ & $40.813,03$ & \\
\hline Total & 23 & $3.640 .164,94$ & & \\
\hline
\end{tabular}


Tabela 103 - Análise de regressão para os dados experimentais de Campo Mou rão, utilizando a 2ạ aproxinação de Mitscherlich. Ano 82/83.

\begin{tabular}{lcrrr}
\hline C. variação & G.L. & \multicolumn{1}{c}{ S.Q. } & Q.M. & \multicolumn{1}{c}{ F } \\
\hline Regressão & 3 & $2.913 .700,82$ & $971.233,60$ & $10,33 * *$ \\
Desv. Regressão & 2 & $37.972,88$ & $18.986,44$ & $0,20 \mathrm{NS}$ \\
\hline (Calcário) & $(5)$ & $2.951 .673,70$ & $590.334,74$ & $6,28 * *$ \\
Blocos & 3 & $90.910,45$ & & \\
Residuo & 15 & $1.409 .961,79$ & $93.997,45$ & \\
Total & 23 & $4.452 .545,94$ & & \\
\hline
\end{tabular}

Tabela 104 - Análise de regressão para os dados experimentais de Campo Mou rão, utilizando a 2ạ aproximação de Mitscherlich. Ano 83/84.

\begin{tabular}{lcrrr}
\hline C. Variação & G.L. & \multicolumn{1}{c}{ S..} & \multicolumn{1}{c}{ Q.M. } & \multicolumn{1}{c}{ F } \\
\hline Regressão & 3 & $2.482 .143,00$ & $827.381,00$ & $22,63 * *$ \\
Desv .Regressão & 2 & $61.051,20$ & $30.525,60$ & $0,83 \mathrm{NS}$ \\
\hline (Calcário) & $(5)$ & $2.543 .194,20$ & $508.638,84$ & $13,91 * *$ \\
Blocos & 3 & $66.714,45$ & & \\
Resíduo & 15 & $548.377,29$ & $36.558,48$ & \\
\hline Total & 23 & $3.158 .285,94$ & & \\
\hline
\end{tabular}


Tabela 105 - Equaçães de regressão para a 2ạ aproximação de Mi.tscherlich, com os dados experimentais de Campo Mourão.

\begin{tabular}{|c|c|c|}
\hline ANOS & I' & EЯֵUAÇ̃̃ES ESTIMADAS \\
\hline $78 / 79$ & 34 & $\widehat{Y}=5.331,85\left[1-10^{-0,0166(X+15,1134)}\right] 10^{-0,000237(X+15,1134)^{2}}$ \\
\hline $79 / 80$ & 30 & $\widehat{Y}=2.596,78\left[1-10^{-0,9909(X+0,4843)}\right] \quad 10^{0,000130(X+0,4843)^{2}}$ \\
\hline $80 / 81$ & 28 & $\widehat{Y}=3.603,01\left[1-10^{-0,2415(X+2,2707)}\right] \quad 10^{0,000012(X+2,2707)^{2}}$ \\
\hline $81 / 82$ & 33 & $\widehat{Y}=2.662,90\left[1-10^{-0,0337(X+11,5725)}\right] \quad 10^{0,000130(X+11,5725)^{2}}$ \\
\hline $82 / 83$ & 12 & $\widehat{Y}=4.038,23\left[1-10^{-0,1.103(X+3,7270)}\right] 10^{-0,000357(X+3,7270)^{2}}$ \\
\hline $83 / 84$ & 15 & $\bar{Y}=4.078,00\left[1-10^{-0,0692(X+5,3984)}\right] 10^{-0,000280(X+5,3984)^{2}}$ \\
\hline
\end{tabular}


Tabela 106 - Valores dos Y observados, $\widehat{Y}$ estimados e Desvios, com os dados experimentais de Carmo Mourão. Ano 78/79.

\begin{tabular}{ccc}
\multicolumn{3}{c}{ 2a APROXIMAÇÃO DE MITSCHERLICH } \\
Y Observado & $\bar{Y}$ Estimado & Desvios \\
\hline $2.078,00$ & $2.065,00$ & 13,00 \\
$2.135,00$ & $2.181,00$ & $-46,00$ \\
$2.313,00$ & $2.262,00$ & 51,00 \\
$2.304,00$ & $2.312,00$ & $-8,00$ \\
$2.314,00$ & $2.333,00$ & $-19,00$ \\
$2.336,00$ & $2.327,00$ & 9,00 \\
\hline
\end{tabular}

Tabela 107 - Valores dos Y observados, $\widehat{Y}$ estimados e Desvios, com os dados experimentais de Carmo Mourão. Ano 79/80.

\begin{tabular}{ccc}
\hline \multicolumn{3}{c}{ 2a APROXIMACÃo DE MITSCHERIICH } \\
Y Observado & $\hat{Y}$ Estimado & Desvios \\
\hline $1.737,00$ & $1.737,00$ & 0,00 \\
$2.592,00$ & $2.593,00$ & $-1,00$ \\
$2.642,00$ & $2.612,00$ & 30,00 \\
$2.579,00$ & $2.630,00$ & $-51,00$ \\
$2.677,00$ & $2.654,00$ & 23,00 \\
$2.683,00$ & $2.684,00$ & $-1,00$ \\
\hline
\end{tabular}


Tabela 108 - Valores dos Y observados, Ŷ estimados e Desvios, com os dados experimentais de Canpo Mourão. Ano 80/81.

\begin{tabular}{ccc}
\hline \multicolumn{3}{c}{ 2a APROXIMAÇÃO DE MITSCHERLICH } \\
Y Observado & $\tilde{Y}$ Estimado & Desvios \\
\hline $2.578,00$ & $2.584,00$ & $-6,00$ \\
$3.311,00$ & $3.270,00$ & 41,00 \\
$3.421,00$ & $3.497,00$ & $-76,00$ \\
$3.573,00$ & $3.574,00$ & $-1,00$ \\
$3.692,00$ & $3.602,00$ & 90,00 \\
$3.567,00$ & $3.615,00$ & $-48,00$ \\
\hline
\end{tabular}

Tabela 109 - Valores dos Y observados, $\widehat{Y}$ estimados e Desvios, com os dados experimentais de Camno Mourão. Ano 81/82.

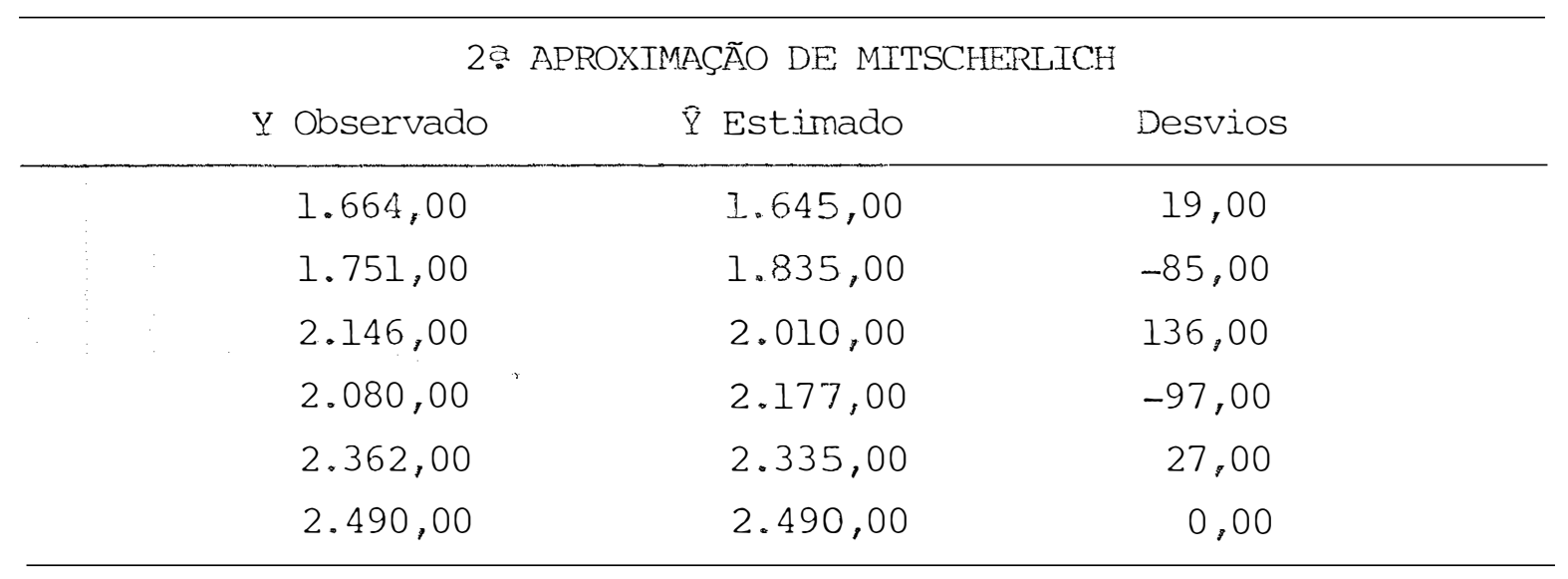


Tabela 110 - Valores dos Y observados, $\widehat{Y}$ estimados e Desvios, com os dados experimentais de Campo Mourão. Ano 82/83.

\begin{tabular}{ccc}
\hline \multicolumn{2}{c}{ 2a APROXIMACÃO DE MITSCHERLICH } \\
$Y$ Observado & $\widehat{\underline{Y}}$ Estimado & Desvios \\
\hline $2.441,00$ & $2.443,00$ & $-2,00$ \\
$3.023,00$ & $3.014,00$ & 9,00 \\
$3.316,00$ & $3.305,00$ & 11,00 \\
$3.358,00$ & $3.420,00$ & $-62,00$ \\
$3.492,00$ & $3.423,00$ & 69,00 \\
$3.327,00$ & $3.352,00$ & $-25,00$ \\
\hline
\end{tabular}

Tabela 111 - Valores dos Y observados, $\widehat{Y}$ estimados e Desvios, com os dados experimentais de Campo Mourão. Ano 83/84.

\begin{tabular}{|c|c|c|c|}
\hline \multicolumn{4}{|c|}{ 2ạ APROXIMAÇÃO DE MITSCHERLICH } \\
\hline $\mathrm{Y}$ & Observado & $\widehat{Y}$ Estjmado & Desvios \\
\hline & $2.326,00$ & $2.309,00$ & 17,00 \\
\hline & $2.658,00$ & $2.725,00$ & $-67,00$ \\
\hline & $3.068,00$ & $2.990,00$ & 78,00 \\
\hline & $3.144,00$ & $3.140,00$ & 4,00 \\
\hline & $3.142,00$ & $3.202,00$ & $-60,00$ \\
\hline & $3.225,00$ & $3.197,00$ & 28,00 \\
\hline
\end{tabular}


Tabela 112 - Análise de regressão para os dados experimentais de Guarapua va, utilizando a 2a aproxinação de Mitscherlich. Ano 78/79.

\begin{tabular}{|c|c|c|c|c|}
\hline C. Variação & G.L. & $S \cdot \Omega \cdot$ & Q.M. & $F$ \\
\hline Regressão & 3 & $608.434,15$ & $202.811,38$ & $15,97 * *$ \\
\hline Desv •Regressão & 2 & $25.404,72$ & $12.702,36$ & $1,00 \mathrm{NS}$ \\
\hline (Calcário) & (5) & $633.838,87$ & $126.757,06$ & $9,98 * *$ \\
\hline Blocos & 3 & $43.742,33$ & & \\
\hline Resíduo & 15 & $190.475,66$ & $12.698,37$ & \\
\hline Total & 23 & $868.056,86$ & & \\
\hline
\end{tabular}

Tabela 113 - Análise de regressão para os dados experimentais de Guarapua va, utilizando a 2ạ aproximação de Mitscherlich. Ano 79/80.

\begin{tabular}{lcrrr}
\hline C. Variação & G.L. & \multicolumn{1}{c}{ S.Q. } & Q.M. & \multicolumn{1}{c}{$F$} \\
\hline Regressão & 3 & $2.439 .852,67$ & $813.284,22$ & $63,20 * *$ \\
Desv.Regressão & 2 & $10.431,16$ & $5.215,58$ & $0,40 \mathrm{NS}$ \\
\hline (Calcário) & $(5)$ & $2.450 .283,83$ & $490.056,76$ & $38,08 * *$ \\
Blocos & 3 & $152.189,83$ & & \\
Resíduo & 15 & $193.010,16$ & $12.867,34$ & \\
\hline Total & 23 & $2.795 .483,82$ & & \\
\hline
\end{tabular}


Tabela 114 - Análise de regressão para os dados experimentais de Guarapua va, utilizando a 2ạ aproximação de Mitscherlich. Ano 80/81.

\begin{tabular}{lcrrr}
\hline C. Variação & G.L. & \multicolumn{1}{c}{ S.Q. } & Q.M. & F \\
\hline Regressão & 3 & $2.321 .404,50$ & $773.801,50$ & $8,60 * *$ \\
Desv.Regressão & 2 & $41.791,20$ & $20.895,60$ & $0,23 \mathrm{NS}$ \\
\hline (Calcário) & $(5)$ & $2.363 .195,70$ & $472.639,14$ & $5,25 * *$ \\
Blocos & 3 & $819.914,12$ & & \\
Resíduo & 15 & $1.348 .930,12$ & $89.928,67$ & \\
\hline Total & 23 & $4.532 .039,94$ & & \\
\hline
\end{tabular}

Tabela 115 - Análise de regressão para os dados experimentais de Guarapua va, utilizando a 2ạ aproximação de Mitscherlich. Ano 81/82.

\begin{tabular}{lcrrr}
\hline C. Variação & G.I. & \multicolumn{1}{c}{ S.@. } & Q.M. & \multicolumn{1}{c}{ F } \\
\hline Regressão & 3 & $1.378 .304,03$ & $459.434,67$ & $10,75^{* *}$ \\
Desv. Regressão & 2 & $176.630,80$ & $87.815,40$ & $2,05 \mathrm{NS}$ \\
\hline (Calcário) & $(5)$ & $1.554 .934,83$ & $310.986,96$ & $7,27 * *$ \\
Blocos & 3 & $303.283,33$ & & \\
Resíduo & 15 & $641.211,03$ & $42.747,40$ & \\
\hline Total & 23 & $2.499 .429,19$ & & \\
\hline
\end{tabular}


Tabela 116 - Análise de regressão para os dados experinentais de Guarapua va, utilizando a 2ạ aproximação de Mitscherlich. Ano 82/83.

\begin{tabular}{lcrrr}
\hline C. Variação & G.L. & \multicolumn{1}{c}{ S.९. } & Q.M. & \multicolumn{1}{c}{$F$} \\
\hline Regressão & 3 & $3.181 .149,17$ & $1.060 .383,05$ & $23,20 * *$ \\
Desv.Regressão & 2 & $131.407,20$ & $65.703,60$ & $1,44 \mathrm{NS}$ \\
\hline (Calcário) & $15)$ & $3.312 .556,37$ & $662.511,27$ & $14,50 * *$ \\
Blocos & 3 & $536.085,79$ & & \\
Resíduo & 15 & $685.302,46$ & $45.686,83$ & \\
\hline Total & 23 & $4.533 .944,62$ & & \\
\hline
\end{tabular}

Tabela 117 - Análise de regressão para os dados experimentais de Guarapua va, utilizando a 2ạ aproximação de Mitscherlich. Ano 83/84.

\begin{tabular}{lcrrr}
\hline C. Variação & G.L. & \multicolumn{1}{c}{ S.O. } & \multicolumn{1}{c}{ Q.M. } & \multicolumn{1}{c}{$F$} \\
\hline Regressão & 3 & $5.778 .992,21$ & $1.926 .330,73$ & $28,58 * *$ \\
Desv. Regressão & 2 & $24.301,12$ & $12.150,56$ & $0,18 \mathrm{NS}$ \\
\hline (Calcário) & $(5)$ & $5.803 .293,33$ & $1.160 .658,66$ & $17,22 * *$ \\
Blocos & 3 & $621.397,50$ & & \\
Resíduo & 15 & $1.010 .909,00$ & $67.393,93$ & \\
\hline Total & 23 & $7.435 .599,83$ & & \\
\hline
\end{tabular}


Tabela 118 - Equações de regressão para a 2a aproxiração de Mitscherlich, com os dados experimentais de Guarapuava.

\begin{tabular}{cccc}
\hline ANO & IT & EQUACOÕES ESTIMADAS \\
\hline $78 / 79$ & 5 & $\hat{Y}=1.861,27\left[1-10^{-0,0654(X+6,8356)}\right] 10^{-0,000083(X+6,8356)^{2}}$ \\
$79 / 89$ & 3 & $\hat{Y}=3.205,98\left[1-10^{-0,0906(X+5,1127)}\right] 10^{-0,000057(X+5,1127)^{2}}$ \\
$80 / 81$ & 4 & $\hat{Y}=3.203,22\left[1-10^{-0,1459(X+3,7446)}\right] 10^{-0,000012(X+3,7446)^{2}}$ \\
$81 / 82$ & 5 & $\hat{Y}=2.304,31\left[1-10^{-0,0997(X+4,7318)}\right] 10^{-0,000039(X+4,7318)^{2}}$ \\
$82 / 83$ & 91 & $\hat{Y}=11.252,60\left[1-10^{-0,0130(X+5,4711)}\right] 10^{-0,000893(X+5,4711)^{2}}$ \\
$83 / 84$ & 4 & $\hat{Y}=2.956,88\left[1-10^{-0,2903(X+1,0861)}\right] 10^{-0,000085(X+1,0861)^{2}}$ \\
\hline
\end{tabular}


Tabela 119 - Valores dos Y observados, $\widehat{Y}$ estimados e Desvios, com os dados experimentais de Guarapuava. Ano 78/79.

\begin{tabular}{ccc}
\hline \multicolumn{3}{c}{ 2a APROXIMACÃO DE MITSCHERLICH } \\
Y Observado & P Estimado & Desvios \\
\hline $1.176,00$ & $1.186,00$ & $-10,00$ \\
$1.456,00$ & $1.412,00$ & 44,00 \\
$1.481,00$ & $1.542,00$ & $-61,00$ \\
$1.629,00$ & $1.610,00$ & 19,00 \\
$1.651,00$ & $1.637,00$ & 14,00 \\
$1.608,00$ & $1.614,00$ & $-6,00$ \\
\hline
\end{tabular}

Tabela 120 - Valores dos Y observados, $\hat{Y}$ estimados e Desvios, com os dados experimentais de Guarapuava. Ano 79/80.

\begin{tabular}{ccc}
\hline \multicolumn{3}{c}{ 2a. APROXIMASÃO DE MITSCHERLICH } \\
Y Observado & $\bar{Y}$ Estimado & Desvios \\
\hline $2.093,00$ & $2.096,00$ & $-3,00$ \\
$2.607,00$ & $2.594,00$ & 13,00 \\
$2.840,00$ & $2.844,00$ & $-4,00$ \\
$2.925,00$ & $2.958,00$ & $-33,00$ \\
$3.032,00$ & $2.997,00$ & 35,00 \\
$2.955,00$ & $2.963,00$ & $-8,00$ \\
\hline
\end{tabular}


Tabela 121 - Valores dos Y observados, Ŷ. estimados e Desvios, com os dados experimentais de Guarapuava. Ano 80/81.

\begin{tabular}{ccr}
\hline \multicolumn{3}{c}{ 2a APROXIMACÃO DE MITSCHERLICH } \\
Observado & $\widehat{Y}$ Estimado & Desvios \\
\hline $2.297,00$ & $2.292,00$ & 5,00 \\
$2.833,00$ & $2.867,00$ & $-34,00$ \\
$3.150,00$ & $3.073,00$ & 77,00 \\
$3.086,00$ & $3.144,00$ & $-58,00$ \\
$3.169,00$ & $3.164,00$ & 5,00 \\
$3.161,00$ & $3.156,00$ & 5,00 \\
\hline
\end{tabular}

Tabela 122 - Valores dos Y observados, $\widehat{Y}$ estimados e Desvios, com os dados experimentais de Guarapuava. Ano 81/82.

\begin{tabular}{cccc}
\hline \multicolumn{2}{c}{ 2a APROXIMACÃO DE MITSCHERIICH } \\
Y Observado & Y Estimado & Desvios \\
\hline $1.525,00$ & $1.524,00$ & 1,00 \\
$1.910,00$ & $1.903,00$ & 7,00 \\
$2.013,00$ & $2.086,00$ & $-73,00$ \\
$2.327,00$ & $2.168,00$ & 159,00 \\
$2.083,00$ & $2.197,00$ & $-114,00$ \\
$2.205,00$ & $2.185,00$ & 20,00 \\
\hline
\end{tabular}


Tabela 123 - Valores dos Y observados, $\bar{Y}$ estimados e Desvios, com os dados experimentais de Guarapuava. Ano 82/83.

\begin{tabular}{ccc}
\hline \multicolumn{2}{c}{ 2ạ APROXIMAÇÃO DE MITSCHERJ_ICH } & \\
$Y$ Observado & $\hat{Y}$ Estimado & Desvios \\
\hline $1.575,00$ & $1.602,00$ & $-27,00$ \\
$2.267,00$ & $2.179,00$ & 88,00 \\
$2.440,00$ & $2.499,00$ & $-58,00$ \\
$2.490,00$ & $2.576,00$ & $-36,00$ \\
$2.563,00$ & $2.449,00$ & 114,00 \\
$1.800,00$ & $1.831,00$ & $-31,00$ \\
\hline
\end{tabular}

Tabela 124 - Valores dos Y observados, Y estimados e Desvios, com os dados experimentais de Guarapuava. Ano 83/84.

\begin{tabular}{ccc}
\hline \multicolumn{2}{c}{ 2ạ APROXIMAÇAO DE MITSCHERLICH } \\
Y Observado & $\hat{Y}$ Estimado & Desvios \\
\hline $1.525,00$ & $1.526,00$ & $-1,00$ \\
$2.763,00$ & $2.755,00$ & 8,00 \\
$2.875,00$ & $2.902,00$ & $-27,00$ \\
$2.870,00$ & $2.895,00$ & $-25,00$ \\
$2.924,00$ & $2.858,00$ & 66,00 \\
$2.731,00$ & $2.752,00$ & $-21,00$ \\
\hline
\end{tabular}




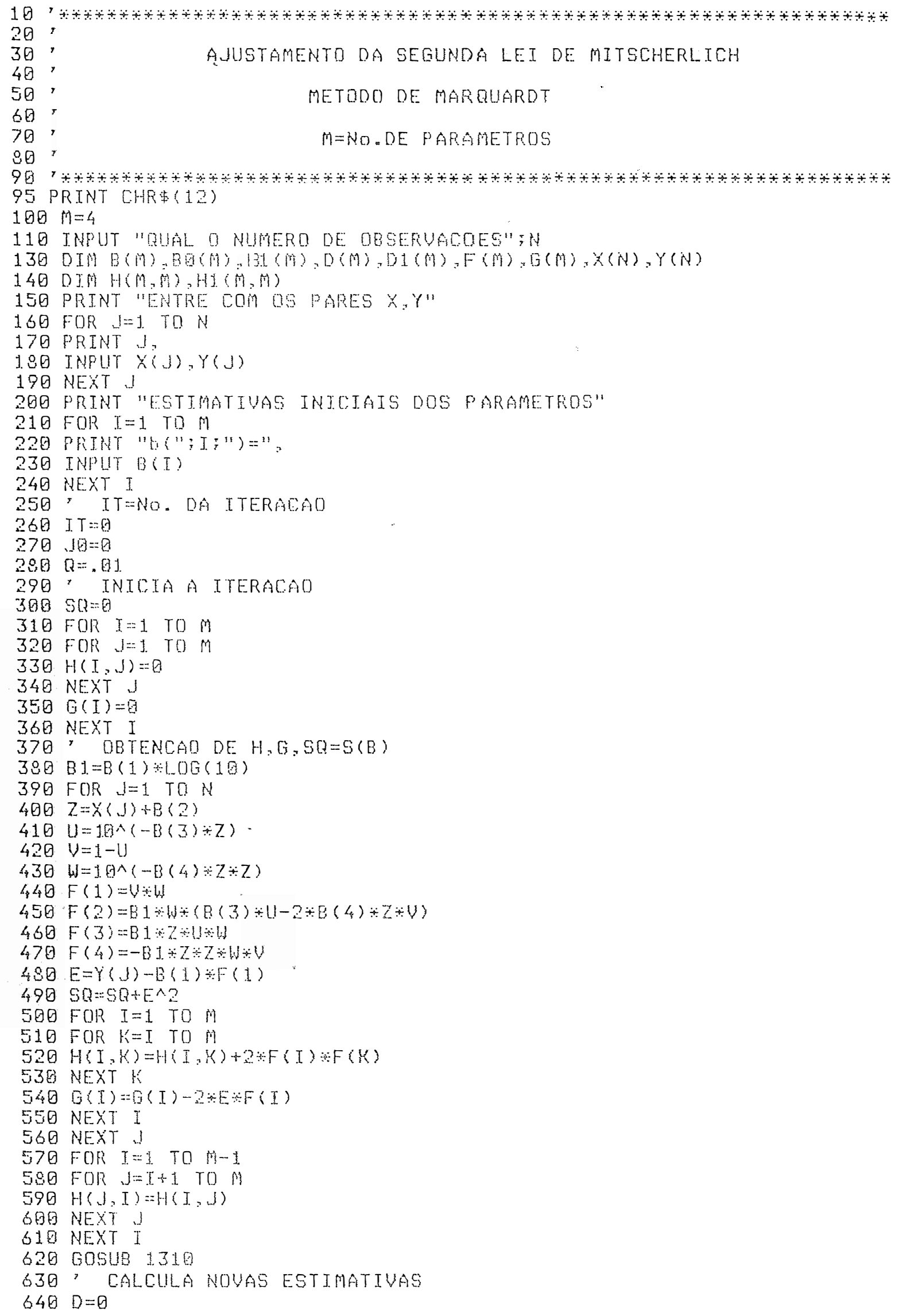




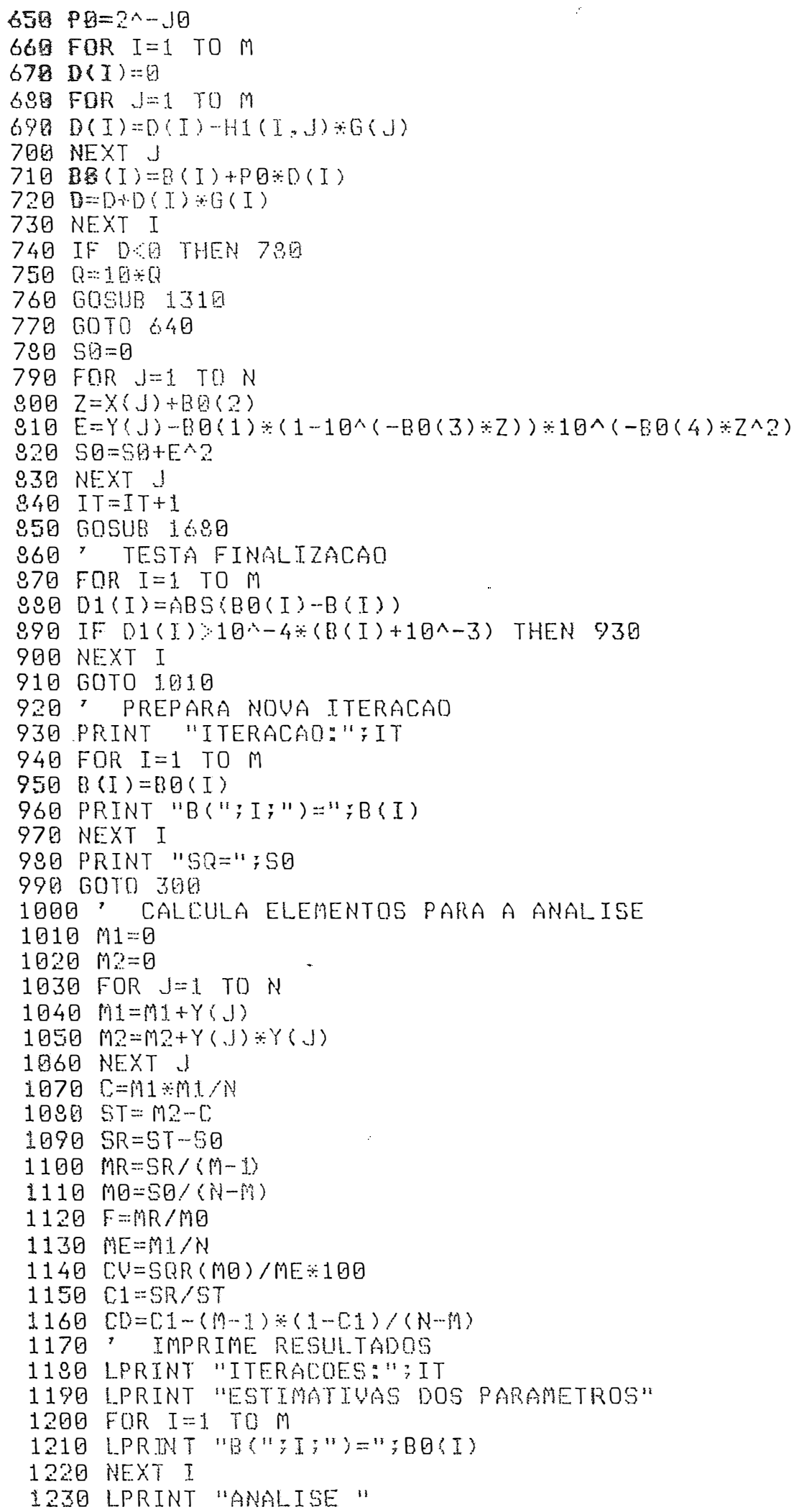




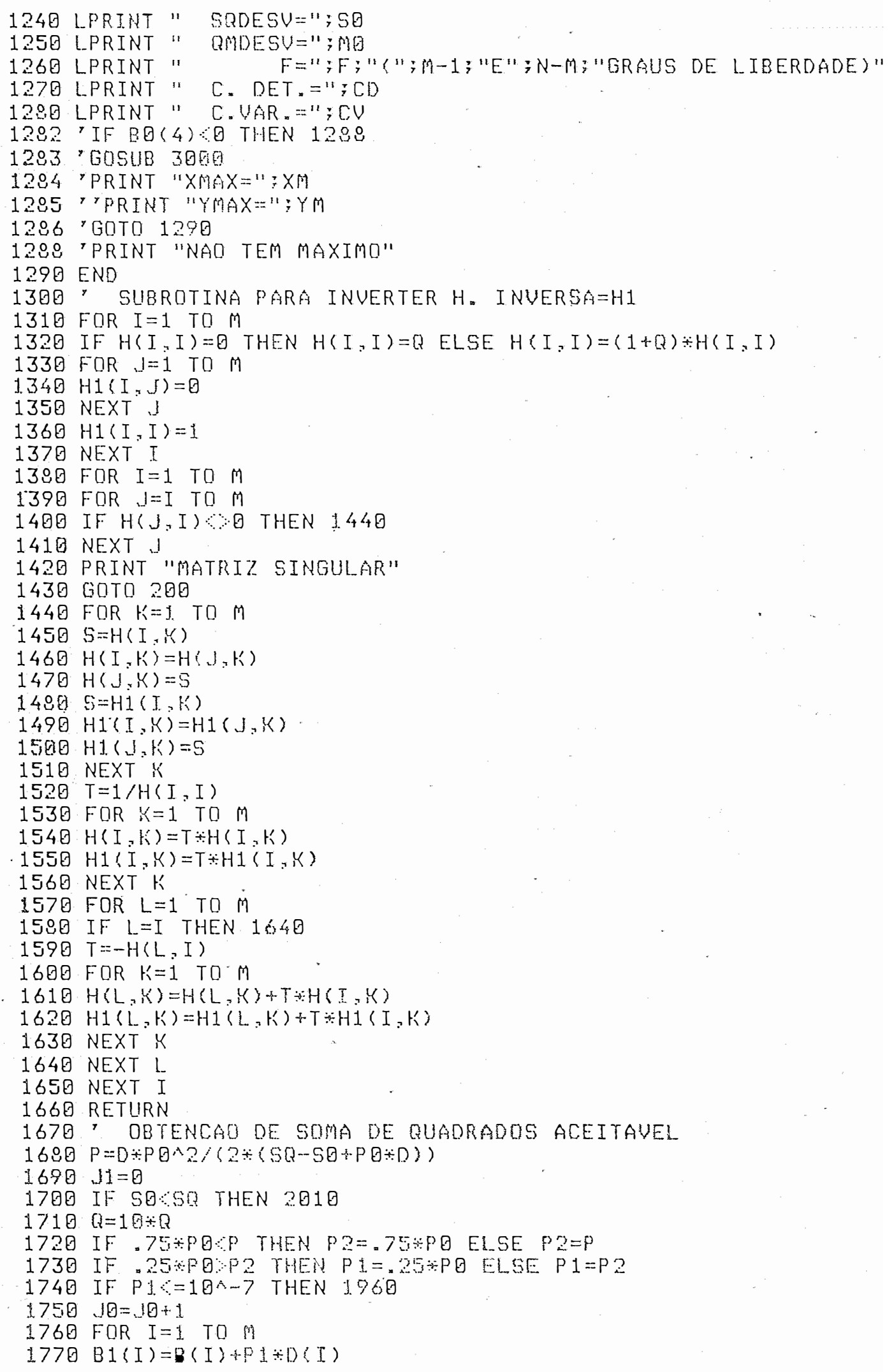




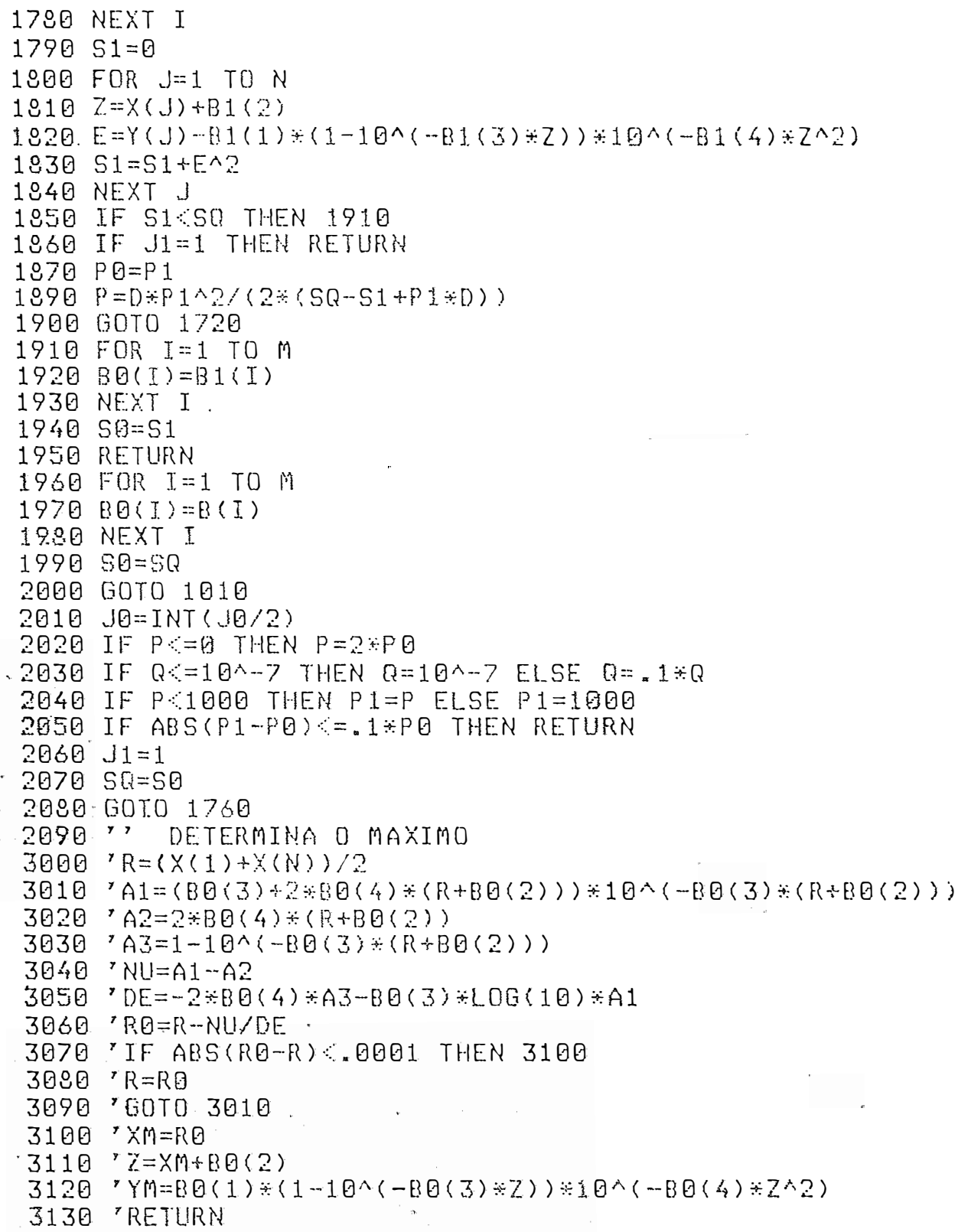


C CALCULO DO MAXIMO DA FUACAO

C $\quad Y=A^{*}\left(1-10 * *(-C+(X+B)) * 10 * *\left(-K^{*}(X+B) * * 2\right)\right.$

C

DINENSION Z (20), Y(20)

C ENTRADA DOS VALORES ALEATORIOS A,B,C,K, DELTA DA FUNCAO ACIMA

$10 \operatorname{READ}(5,1) \mathrm{N}, \mathrm{AO}, \mathrm{BO}, \mathrm{CO}, \mathrm{PKO}, \mathrm{DELTA}$

1 FORMAT (I1, 4F15.10, F4 , 2)

C ENTRADA IOS VALORES DE X

$\operatorname{READ}(5,2)(Z(I), I=1, N)$

2 FORMAT $(F 2,0)$

WRITE $(7,3)(Z(I), I=1, N), D E L T A$

3 FORMAT $\left(/ /, 6 \mathrm{~F} 3.0,{ }^{\prime} \mathrm{DELTA}=1, \mathrm{~F} 4.2\right)$

WRITE $(7,5) \mathrm{N}, \mathrm{AO}, \mathrm{BO}, \mathrm{CO}, \mathrm{PK}=$

5 FORMAT ('N=',I1,' $A={ }^{\prime}, F 15.10, ' B=, F 15.10$, ' $C=$ ' , F15.10, ' $K=$ ' , F15.

110)

$\mathrm{l}: \mathrm{I}=\mathrm{N}+1$

DO $42 \quad I=1, M$

$\mathrm{Y}(\mathrm{I})=\mathrm{AO}^{*}(1-10 * *(-\mathrm{CO} *(\mathrm{Z}(\mathrm{I})+\mathrm{BO}))) * 10 * *\left(-\mathrm{PKO}^{*}(\mathrm{Z}(\mathrm{I})+\mathrm{BO}) * * 2\right)$

$\mathrm{J}=\mathrm{I}+1$

$\mathrm{Y}(\mathrm{J})=\mathrm{AO}^{*}(1-10 * *(-\mathrm{CO} *(\mathrm{Z}(\mathrm{J})+\mathrm{BO}))) * 10 * *(-\mathrm{PK}=*(\mathrm{Z}(\mathrm{J})+\mathrm{BO}) * * 2)$

IF $(Y(J)-Y(I) 20,20,42$

20 WRITE $(7,8)$ I , J

8 FORMAT(IX, 'TROCA DE SINAL PARA $\left.I={ }^{\prime}, I 2, ' E J=', I 2\right)$

$X=Z(I)$

$32 \mathrm{Y} 1=\mathrm{AO}^{*}(1-10 * *(-\mathrm{CO} *(\mathrm{X} * \mathrm{BO}))) * 10 * *\left(-\mathrm{PKO}^{*}(\mathrm{X}+\mathrm{BO}) * * 2\right)$

$\mathrm{X}=\mathrm{X}+\mathrm{DELTA}$

$\mathrm{Y} 2=\mathrm{AO}^{*}(1-10 * *(-\mathrm{C}=*(\mathrm{X}+\mathrm{BO}))) * 10 * *\left(-\mathrm{PKO}^{*}(\mathrm{X}+\mathrm{BO}) * * 2\right)$

$\mathrm{DIF}=\mathrm{Y2}-\mathrm{Y1}$

IF(DIF) $35,33,35$

$33 \operatorname{WRITE}(7,9) \quad Y 1, Y 2, X, D I F$

9 FORMAT (' $Y 1=$ ',F15.8,' $Y 2={ }^{\prime}, F 15.8, ' X={ }^{\prime} F 15.8, ' \mathrm{DIF}=$ ' , F15.8)

35 TEST $=A B S(D I F)$

IF (TEST-0.0000001) 43,43,30

30 IF (DIF) 41,41,32

$41 \mathrm{X}=\mathrm{X}$-DELTA

DELTA $=$ DELTA $/ 2$

GO TO 32

42 CONTINUE

43 STOP

END 